\title{
Spectra Over Complex Terrain in the Surface Layer
}

H. A. Panofsky

J. A. Dutton

David Larko

Robert Lipschutz

Gregory Stone

Pennsylvania State University

September 1982

Prepared for the U.S. Department of Energy under Contract DE-AC06-76RLO 1830

Agreement B-9-2870-AH

Pacific Northwest Laboratory

Operated for the U.S. Department of Energy

by Battelle Memorial Institute 


\title{
DISCLAIMER
}

This report was prepared as an account of work sponsored by an agency of the United States Government. Neither the United States Government nor any agency thereof, nor any of their employees, makes any warranty, express or implied. or assumes any legal liability or responsibility for the accuracy, completeness, or usefulness of any information, apparatus, product, or process disclosed, or represents that its use would not infringe privately owned rights. Reference herein to any specific commercial product, process, or service by trade name, trademark, manufacturer, or otherwise, does not necessarily constitute or imply its endorsement, recommendation, or favoring by the United States Government or any agency thereof. The views and opinions of authors expressed herein do not necessarily state cr reflect those of the United States Government or any agency thereof.

\author{
PACIFIC NORTHWEST I.ABORATORY \\ operated by \\ BATTELLE \\ for the \\ UNITED STATES DEPARTMENT OF ENERGY \\ under Contract DE-AC06-76RLO 1830
}

\begin{tabular}{|c|c|}
\hline \multicolumn{2}{|c|}{ Printed in the United States of America } \\
\hline \multicolumn{2}{|c|}{ Available from } \\
\hline \multirow{4}{*}{\multicolumn{2}{|c|}{$\begin{array}{c}\text { National Technical Information Service } \\
\text { United States Department of Commerce } \\
5285 \text { Port Roval Road } \\
\text { Springfield, Virginia } 22151\end{array}$}} \\
\hline & \\
\hline & \\
\hline & \\
\hline \\
\hline \multicolumn{2}{|c|}{ Microfiche A01 } \\
\hline \multicolumn{2}{|c|}{ Printed Copy } \\
\hline & Price \\
\hline Pages & Codes \\
\hline 001-025 & $\mathrm{A} 02$ \\
\hline $026-050$ & $\mathrm{~A} 03$ \\
\hline $051-075$ & $\mathrm{~A} 04$ \\
\hline $076-100$ & $\mathrm{~A} 05$ \\
\hline $10 \div-125$ & $\mathrm{~A} 06$ \\
\hline $126-150$ & $\mathrm{~A} 07$ \\
\hline $151-175$ & $\mathrm{~A} 08$ \\
\hline $176-200$ & A09 \\
\hline $201-225$ & A010 \\
\hline $226-250$ & $\mathrm{~A} 011$ \\
\hline $251-275$ & $\mathrm{~A} 012$ \\
\hline $276-300$ & $\mathrm{~A} 013$ \\
\hline
\end{tabular}


SPECTRA OVER COMPLEX TERRAIN IN THE SURFACE LAYER

H. A. Panofsky

J. A. Dutton

David Larko

Robert Lipschutz

Gregory Stone

Pennsylvania State University 503 Walker Building

University Park, Pennsylavnia 16802

August 1982

Prepared for the U.S. Department of Energy Under Contract DE-AC06-76RLO 1830 Agreement B-9-2870-AH

Pacific Northwest Laboratory Richland, Washington 99352 

CONTENTS

Page

I. INTRODUCTION

II. SUMMARY OF SPECTRAL CHARACTERISTICS OVER UNIFORM TERRAIN • • 3

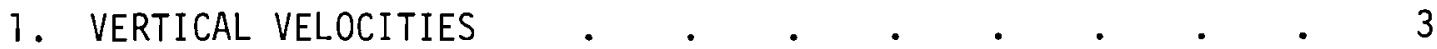

2. HORIZONTAL VELOCITY SPECTRA, STABLE AIR . . . $\quad . \quad$ • 3

3. SPECTRA OF THE HORIZONTAL COMPONENTS IN UNSTABLE AIR • • 5

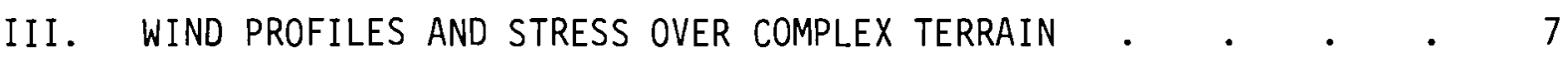

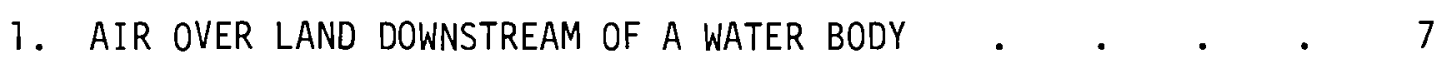

2. CHARACTERISTICS ON TOPS OF HILLS AND ESCARPMENTS ..$\quad$ • 8

3. CHARACTERISTICS OVER ROLLING FARMLAND $\quad \cdot \quad \cdot \quad \cdot \quad \cdot \quad \cdot \quad \cdot \quad 9$

IV. SPECTRA OVER COMPLEX TERRAIN: GENERAL CONSIDERATIONS $\quad$ • $\quad 11$

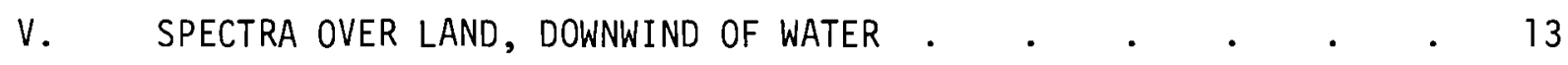

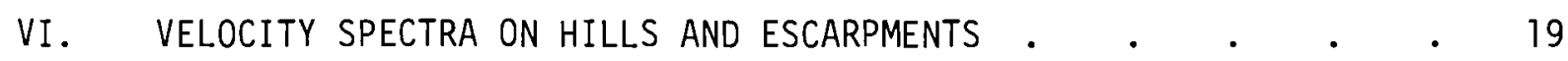

VII. SPECTRAL CHARACTERISTICS OVER ROLLING TERRAIN • • • • • • $\quad 25$

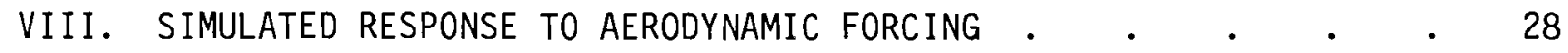

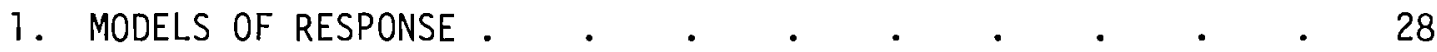

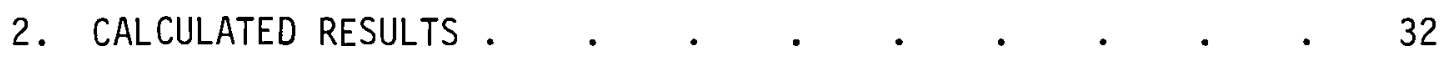

3. CONCLUSIONS AND IMPLICATIONS • • . . . . . . . . 34

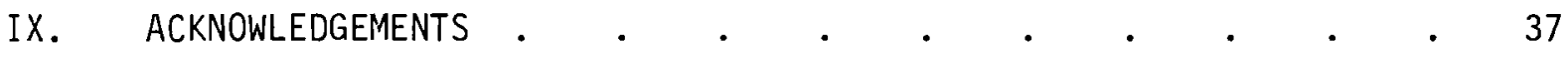

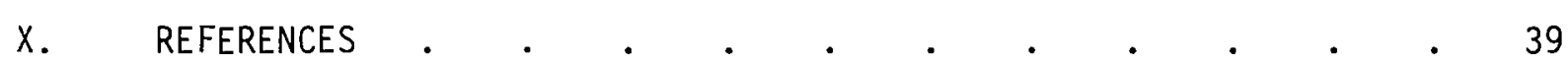


,

.

,

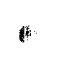




\section{LIST OF FIGURES}

Page

2.1 Spectra of the Lateral Velocity Component in Stable Air in Kansas (Computed by Søren Larsen) . . . . . . . .

3.1 Wind Profiles Downstream of a Roughness Change in Slightly Sloping Terrain

4.1 Spectra of the Longitudinal Component at $2 \mathrm{~m}$ at Ris $\phi$, Off-Shore and On Inland Mast.

5.1 Plan of Ris $\varnothing$ Experiments . . . . . . . . . . . . . 44

5.2 Relation Between Response Time and Wave Number . . . . . 45

5.3 Spectra of the u-Component at Ris $\phi$, Near-Neutral Conditions. . 46

5.4 Spectra of the v-Component at Ris $\phi$, Near-Neutral Conditions. . 47

5.5 Spectra of the $w$-Component at Ris $\phi$, Near-Neutral Conditions. . 48

5.6 Spectra of the u-Component at Ris $\phi$, Unstable Air . . . . . 49

5.7 Spectra of the v-Component at Ris $\phi$, Unstable Air . . . . . 50

5.8 Spectra of the w-Component at Ris $\phi$, Unstable Air . . . . . 51

6.1 Normalized Spectra of the u-Component, Black Mountain,

6.2 Normalized Spectra of the w-Component, Black Mountain, Canberra (Computed by Bradley) . . . . . . . . 53

6.3 Spectra of the u-Component Influenced by Sloping Escarpment
(After Bowen). $. . \quad . \quad . \quad . \quad . \quad . \quad . \quad . \quad . \quad 54$

6.4 Spectra of u-Components Influenced by Steep Cliff $\quad . \quad$. 55

6.5 Terrain Cross Sections at White Sands . . . . . . . . . 56

6.6 Envelopes for Normalized u-Spectra (a) and v-Spectra (b) for

6.7 Terrain Cross Sections at White Sands, East Winds. . . . . 58

6.8 Terrain Cross Section at Boone, NC, West Winds . . . . 59 


\section{LIST OF FIGURES (Continued)}

Page

6.9 Spectrum of u-Component at Boone, West Winds, at $18 \mathrm{~m} . .60$

6.10 Spectrum of u-Component at Boone, West Winds, at $46 \mathrm{~m}$. . 61

6.11 Spectrum of u-Component at Boone, West Winds, at $76 \mathrm{~m}$. . 62

6.12 Terrain Cross Section at Boone, NC, SSW Winds . . . . 63

6.13 Spectrum of u-Component at Boone, SSW Winds, at $18 \mathrm{~m} . \quad . \quad$. 64

6.14 Spectrum of u-Component at Boone, SSW Winds, at $76 \mathrm{~m} . \quad$. 65

7.1 Average u-Spectrum at Rock Springs, Stable Air . . . . 66

7.2 Average v-Spectrum at Rock Springs, Stable Air . . . . 67

7.3 Average u-Spectrum at Rock Springs, $-0.1<z / L<0$. . . 68

7.4 Average $v$-Spectrum at Rock Springs, $-0.1<z / L<0$. . . 69

7.5 Average $u$-Spectrum at Rock Springs, $z / L<-0.1$. . . . 70

7.6 Average $v$-Spectrum at Rock Springs, $z / L<-0.1$. . . . 71

7.7 Average w-Spectrum at Rock Springs, Stable Air . . . . 72

7.8 Average w-Spectrum at Rock Springs, Unstable Air. . . . 73

7.9 Average u-Spectrum at Rock Springs, Stable Air, Mountain 74

7.10 Average $v$-Spectrum at Rock Springs, Stable Air, Mountain

8.1 Spectral Density Functions for the Longitudinal Component
of the Rock Springs Data . . . . . . . . 76

8.2 Spectral Density Functions for the Longitudinal Component of the Ris $\varnothing$ Data . . . . . . . . . . . 77

8.3 Spectra of the Linearized Aerodynamic Forcing and the Responses
for Three Natural Frequencies for the Rock Springs Data . . 78

8.4 Exceedance Statistics for the Longitudinal Component $u^{\prime}$ of the Rock Springs Data . . . . . . . . . 79 
8.5 Exceedance Statistics for the Linear (L) and Nonlinear (N) Forms of the Aerodynamic Forcing for the Rock Springs Data . . . 80

8.6 Responses to Linear ( $L$ ) and Nonlinear (N) Aerodynamic Forcing for $\mathrm{R}=0.1$ and $\mathrm{c}=35.5$

8.7 Responses to Linear $(L)$ and Nonlinear $(N)$ Aerodynamic Forcing for $\mathrm{R}=0.01$ and $\mathrm{C}=355$. . . . . . . .

8.8 Responses to Linear ( $L$ ) and Nonlinear (N) Aerodynamic Forcing for $\mathrm{R}=0.01$ and $\mathrm{c}=35.5$..$\quad$. . . . . .

8.9 Responses to Linear (L) and Nonlinear (N) Aerodynamic Forcing for

8.10 Responses to Linear (L) and Nonlinear (N) Aerodynamic Forcing for $\mathrm{R}=0.001$ and $\mathrm{c}=35.5 . . \quad . \quad . \quad . \quad . \quad$.

8.11 Spectra of the Linearized Aerodynamic Forcing and the Responses for Three Neutral Frequencies for the Ris $\phi$ Data . . . .

8.12 Exceedance Statistics for the Longitudinal Component $u^{\prime}$ of the Ris $\varnothing$ Data

8.13 Exceedance Statistics for the Linear (L) and Nonlinear (N) Forms of the Aerodynamic Forcing for the Ris $\varnothing$ Data . . . .

8.14 Responses to Linear ( $L$ ) and Nonlinear (N) Aerodynamic Forcing for $R=0.1$ and $c=35$.

8.15 Responses to Linear ( $L$ ) and Nonlinear (N) Aerodynamic Forcing for $R=0.01$ and $c=355 . . \quad . \quad . \quad . \quad . \quad . \quad . \quad 90$

8.16 Responses to Linear ( $L$ ) and Nonlinear (N) Aerodynamic Forcing for $R=0.01$ and $c=35.5$

8.17 Responses to Linear ( $L$ ) and Nonlinear (N) Aerodynamic Forcing for $\mathrm{R}=0.01$ and $\mathrm{C}=3.55$

8.18 Responses to Linear ( $L$ ) and Nonlinear (N) Aerodynamic Forcing 


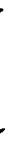




\section{LIST OF TABLES}

$\underline{\text { Page }}$

8.1 Characteristics of the Turbulence Data Records . . . . . 95

8.2 Responses Calculated for the Rock Springs Data . . . . . . 96

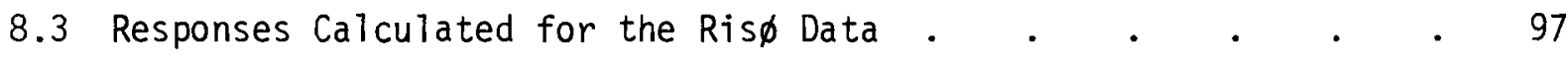




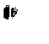

If

. 
H. A. Panofsky

J. A. Dutton

David Larko

Robert Lipschutz

Gregory Stone

\section{INTRODUCTION}

For design and control of Wind Energy Conversion Systems (WECS), considerable information about wind characteristics is needed. Wind engineers are most interested in wind profiles and turbulence intensities, that is, ratios of standard deviations of velocity components to mean wind speed, over various types of complex terrains where wind characteristics are favorable.

Without additional information, however, estimates of standard deviations are not particularly useful. The averaging procedure and sampling procedure are not uniform, so many different standard deviations can be derived in the same situation. Further, standard deviations are made up of fluctuations of different frequencies, and different frequency ranges have different effects on WECS control and stability. Two situations may have the same turbulence intensity, but have completely different effects on WECS. In addition to a knowledge of velocity variances, the spectral distribution over frequencies needs to be known. Therefore, we concentrate in this report on estimating velocity spectra over complex terrain, and the consequences of such spectra on response of mechanical systems.

In a previous report by Dutton et a1. (1979), techniques were described for estimation of profiles, variance spectra, and frequency distributions of wind components, primarily over uniform terrain. Such estimates are possible, given the wind speed at one level, the roughness length, and a measure of atmospheric stability. For very strong winds, of primary interest to WECS engineers, stability is relatively unimportant close to the ground. But at heights above 100 feet or so, stability effects on wind statistics may be 
important even in strong winds. Dutton et al. (1979) discussed practical methods for estimating the stability parameters needed: the Monin-Obukhov length, $L$, and the height of the lowest inversion (mixing depth), $z_{i}$.

The report also contained some measurements of variances of velocity components over rolling farmland, and downstream of a low mountain ridge. Here, the variances of the horizontal wind components (but not of the vertical) exceed those expected over uniform terrain under the same conditions.

In this report, we will concentrate on spectra and other velocity statistics over three types of complex terrain: on tops of hills or escarpments; on land, a short distance downwind from a water body; and over rolling farmland. of these, the first two terrain types are of special interest to WECS engineers.

In order to put the complex terrain information in perspective, we briefly summarize in Section II the most important characteristics of turbulence models over uniform terrain; Section III discusses theoretical aspects of spectral characteristics over complex terrain, and the following sections discuss in detail observations over complex terrain and procedures suggested for their estimation. Finally, a theory is presented for calculation of response of engineering systems to wind fluctuations. 


\section{SUMMARY OF SPECTRAL CHARACTERISTICS OVER UNIFORM TERRAIN}

Over uniform terrain, profiles, variances, and spectral densities in the surface layer (the 1 ower $10 \%$ of the planetary boundary layer) depend on surface roughness, Monin-Obukhov L, friction velocity, $u_{\star}$, and height of the lowest inversion, $z_{i}$. The relationships between variances, profiles, and these predictors were discussed by Dutton et al. (1979). In this report, also, new spectral models were proposed. However, these have now been modified by project personnel, and others, so that we will give here a brief summary of the most promising models.

\section{VERTICAL VELOCITIES}

There has been relatively little change in our interpretation of spectra of vertical velocities, and previously published models (Kaimal et al. 1972) will be used for comparison with spectra over complex terrain. However, there is some indication that the low-frequency behavior of such spectra may have to be modified in the presence of organized "large" eddies. It is not yet possible to infer the existence of such eddies from usually available information. Thus, current models of vertical velocity spectra are based on Monin-0bukhov theory, with $z_{0}, u_{\star}$, and $L$ as predictors.

\section{HORIZONTAL VELOCITY SPECTRA, STABLE AIR}

In stable air, spectra of the horizontal wind component are also usually described in terms of Monin-Obukhov theory. However, it is also clear that this theory cannot account for the behavior of these spectra at very low frequencies. At such frequencies, secondary peaks develop in logarithmic spectra, $n S(n)$ (where $n$ is frequency and $S$ is spectral density) as shown, for example, in Figure 2.1, based on Larsen's observations in the Kansas experiments. The same phenomenon has also been described recently by Caughey (1977), and has actually been known for some time (see, e.g., Lumley and Panofsky 1964). Thus, horizontal fluctuations include slow meanders, which may be gravity waves, as suggested by Caughey (1977), or just meanders around obstacles. In 
any case, these large, quasi-horizontal "eddies" cannot be estimated in terms of the conventional surface-layer predictors.

Models for stable spectra of the horizontal velocity components were first described (in terms of Monin-Obukhov theory) by Kaimal et al. (1972), and Kaimal (1973). We will use these models (particularly their neutral limit) later for comparison with spectra over complex terrain. In addition, however, we have developed new models that have been particularly designed to fit observations in New Zealand (see Flay 1978), and in Minnesota (kindly supplied by J. C. Kaimal). The main difference in the new models is that the slopes of $n S(n)$ as function of $\ln n$, on a $\log -\log$ plot, are $1 / 4$ at frequencies less than the peak frequency, as opposed to the slope of one appearing in Kaimal's model.

We propose the following general expression:

$$
\frac{n S(n)}{u_{\star}}=\left[\frac{11}{8+3\left(f / f_{m}\right)^{6.5}}\right]^{0.14}\left(\frac{f}{f_{m}}\right)^{0.25} \frac{p}{u_{\star}^{2}}
$$

where $f=n z / U$ ( $n$ frequency, $U$ mean wind speed), $f_{m}$ is the value of $f$ at a point where $n S(n) / u_{*}{ }^{2}$ reaches its maximum value, given by $P / u_{*}{ }^{2}$. The quantities, $f_{m}$ and $P / u_{*}^{2}$, are given by the following expressions:

$$
u-\text { spectrum } \begin{cases}\frac{p}{u_{*}{ }^{2}}=0.29 f_{m}^{+0.25} \phi_{E} & 0.67 /\left[11 /\left(8+3 f_{m}^{-6.5}\right)\right]^{0.14} \\ f_{m}= \begin{cases}0.09+0.6(z / L) & \text { for } 0 \leq z / L \leq 0.7 \\ 0.5 & 0.7 \leq z / L \leq 1\end{cases} \end{cases}
$$




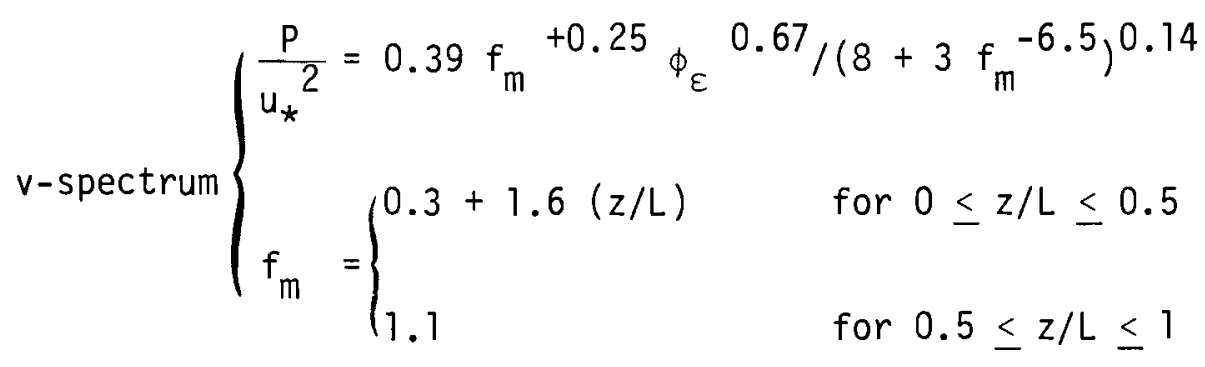

In these expressions, $\phi_{\varepsilon}=\left(1+2.5(z / L)^{3 / 5}\right)^{3 / 2}$.

Equation (2.1) provides an excellent fit to the observations which, however, are limited to the range $0 \leq z / L \leq 1$. However, these observations have poor resolution at low frequencies; thus the small power of $f$ at low frequencies may be due to the separate peaks at very low frequencies. At higher frequencies, there is very little difference between these formulae and Kaimal's.

\section{SPECTRA OF THE HORIZONTAL COMPONENTS IN UNSTABLE AIR}

Kaimal et al. (1972) al ready noted that spectra of the horizontal wind component in unstable stratification did not change monotonically with $z / L$, so that Monin-Obukhov theory was called into question.

Later (1978), Kaimal proposed a model, according to which the highfrequency components obeyed Kolmogorov and Monin-Obokhov scaling, but the low frequencies depended on height of the lowest inversion (approximately mixedlayer depth), $z_{i}$, rather than height above the surface, $z$. Between the lowfrequency and high-frequency portions, Kaimal interpolated linearly, on log-log paper. Kaimal also suggested that there was a discontinuity between neutral limits of the spectra, when approached from the stable and unstable sides.

Since the interpolation scheme is somewhat unsatisfactory physically, Højstrup (1981) described the horizontal spectra as sums of a low-frequency and $a$ high-frequency function: the low frequency function depends on $\frac{z_{i}}{L}$ and $\frac{n z_{j}}{U}$, and the high-frequency function on $z / L$ and $z n / U$. Højstrup further avoids the dependence on $z / L$, thus producing simpler formulae. 
In our formulation, there is a discontinuity between the neutral limits from the two sides; in Højstrup's model, there is no discontinuity, just a rapid variation of spectral densities. There is some unpublished evidence (Larsen, personal communication) that spectra do occur in the "gap", thus contradicting the existence of a discontinuity.

The two sets of spectral models are, in practice, quite similar provided $z / L<-0.1$. For near-neutral conditions, the differences can be substantial, with $H \varnothing j$ jstrup's spectral densities smaller at low frequencies than Shirer and Rossi's.

We will give here only Hळjstrup's model, because of its greater simplicity, and because of its presumably more realistic behavior under very slightly unstable conditions. His equations are:

For the u-component: $\frac{n S_{u}(n)}{u_{*}^{2}}=\frac{0.5 f_{i}}{1+2.2 f_{i}^{5 / 3}}\left(\frac{z_{i}}{-L}\right)^{2 / 3}+\frac{105 f}{(1+33 f)^{5 / 3}}$

and,

$$
\text { for the } v \text {-component: } \frac{\mathrm{nS}_{v}(n)}{u_{*}{ }^{2}}=\frac{0.32 f_{i}}{1+1.1 f_{i}^{5 / 3}}+\frac{17 f}{(1+9.5 f)^{5 / 3}}
$$

where $f_{i}=\frac{n z i}{U}$. 


\section{WIND PROFILES AND STRESS OVER COMPLEX TERRAIN}

1. AIR OVER LAND DOWNSTREAM OF A WATER BODY

As air moves over land after a previous over-water trajectory, its properties will be changed for several reasons: change of surface roughness, change of surface slope, change of heat flux, and change of moisture flux. Of these, effects of change of slope and roughness have received most attention and are best understood (for a summary, see, e.g., Jensen and Peterson 1979).

The effect of the increasing roughness change is to increase the shear up to a level $\mathrm{h}$, the height of the "interface". Over land, $h$ increases with fetch. Under neutral conditions, the slope of the interface height is well described, according to Elliott (1958) by the approximate formula:

$$
\frac{h}{z_{0}}=a\left(\frac{x}{z_{0}}\right)^{0.8}
$$

where $z_{0}$ is the roughness length over the land and $a$ is given by $0.75-0.03$ In $\frac{z_{0}}{z_{0}}$, where $z_{0}{ }^{\prime}$ is the roughness length over the water. Højstrup (1981) has generalized this expression for unstable stratification. For small $x$, the effect of instability on $h$ is not important. Later, $h$ increases more rapidly than in neutral air.

Below $z=h$, the profile is, to a very crude approximation, logarithmic with a slope of $k / u_{*_{0}}$, where $k$ is the von Karman constant $(0.35-0.40)$ and $u_{*_{0}}$ is the friction velocity at the surface. The friction velocity decreases with height, reaching its upstream value at the interface height, $z=h$. However, both rigorous theory and observations suggest that some significant systematic deviations from this behavior occur.

Even a small terrain slope has a pronounced effect on wind profile (see, e.g., Jackson and Hunt 1975). In an inner layer of height b, the wind shear is increased approximately by a factor $1+2 \mathrm{~s}$, where $\mathrm{s}$ is the slope of the hill. This factor is nearly independent of height, so that the profile, in neutral air, remains approximately logarithmic. The surface friction velocity 
also increases by the factor $1+2 s$, so that the slope of the modified wind

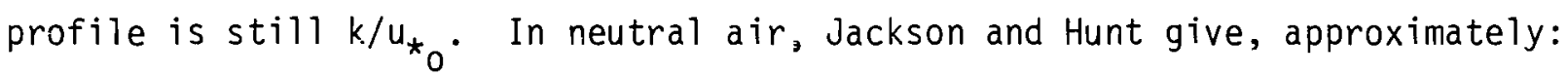

$$
\frac{b}{z_{0}}=0.3\left(\frac{L}{z_{0}}\right)^{0.9}
$$

for wind on top of a hill. In this notation, $L$ is the horizontal distance from the hilltop to the point where the height of the hillside is half that of the hilltop. For our purpose, $L$ is about $x / 2$.

The combined effects of roughness change and slight slope on wind profiles observed at Ris $\varnothing$ are shown in Figure 3.1 (taken from Peterson et al. 1980).

To the author's knowledge, effects of changes of surface fluxes of heat and moisture on the wind profiles have not been analyzed quantitatively. Presumably, the effects are least pronounced in strong winds.

In application to WECS, these results suggest that rotor blades should remain above $z=h$ and $z=b$ to avoid regions of weak winds, strong shear, and strong turbulence.

\section{CHARACTERISTICS ON TOPS OF HILLS AND ESCARPMENTS}

Although most theories of upslope flow apply to gentle slopes (e.g., Jackson and Hunt 1975), Bradley (1980) has shown from his observations on Black Mountain, Canberra, Australia, that the theory gives an excellent indication of conditions on a steep hill.

In particular, there is an inner layer with strong wind shear, the thickness of which agrees with Equation (3.2); but the speed-up factor from the lowland upstream to the hilltop, calculated from the theory, also agrees well with observations; the fractional velocity increase is roughly twice the slope. Further, the speed-up factor is almost independent of height, and the surface friction velocity increases by the same factor as the wind. Hence, 
the wind profile for $z<b$ is essentially logarithmic under neutral conditions, so that the effective roughness and surface stress can be estimated from the wind profile. This stress agrees with directly measured Reynolds stress. On hilltops, theory and observations agree in that the stress decreases significantly with height. For $z>b$, wind shears are weak.

As was mentioned by Dutton et al. (1979), variances on hilltops tend to decrease upward in the inner layer, perhaps proportionally to the stress. For all these reasons, blades of WECS mounted on hilltops should avoid the region $z<b$.

\section{CHARACTERISTICS OVER ROLLING FARMLAND}

Wind profiles over rolling farmland (Dutton et al. 1979, also Schotz and Panofsky 1980) tend to remain logarithmic under near-neutral conditions. However, there is some indication that the "effective" roughness length is not just a measure of ground cover, but may be increased by larger-scale topography. For example, at the 300-m tower east of Boulder, Colorado, the roughness length varies from about $4 \mathrm{~cm}$ for west winds to about $25 \mathrm{~cm}$ for south winds, even though the ground cover is the same; but there is a slight rise just south of the tower, whereas the terrain up to $1 \mathrm{~km}$ to the west of the tower is essentially horizontal.

There is no significant variation of stress with height in the surface layer over rolling terrain, except in locally flat terrain downstream of rolling terrain, where the stress tends to increase slowly upwards.

As was suggested by Dutton et a1. (1979), turbulence over rolling terrain differs from that over flat terrain in that the variances of the horizontal wind components are increased relative to the Reynolds stress by up to $50 \%$. In contrast, vertical-velocity variances are not increased. 


\section{SPECTRA OVER COMPLEX TERRAIN: GENERAL CONSIDERATIONS}

When spectra over complex terrain are compared with corresponding spectra over uniform terrain, the following characteristics emerge:

1) Near the surface, the high frequencies (wavelength much less than fetch over the changed terrain) are in local equilibrium; methods used for estimating spectral characteristics over uniform terrain apply also to these frequencies. Higher up, this rapid modification begins after the "interface" has been reached.

2) Since vertical-velocity spectra, in contrast to those of the horizontal components, have most of their energy in relatively high frequencies, over these types of terrain they closely resemble those over uniform terrain.

3) The low frequencies of the spectra of the horizontal component are affected by the upstream terrain characteristics. In this respect, there are important differences among the three terrain types considered in this report. Qualitatively, these properties suggest that sma11 "eddies", in contrast, have longer memory.

When air travels from water to land, the low frequencies remain substantially unchanged. This is shown in Figure 4.1, which compares spectra at the u-component of wind $2 \mathrm{~m}$ over water, and with 70-m fetch over land. Clearly, the two spectra show no significant differences at low frequencies, but the high-frequency spectral densities have increased. In the next section, we will consider the over-water to over-land transition in more detail.

When air flows uphill, there is horizontal divergence. According to rapid distortion theory, this causes the 10w-frequency spectral densities of the longitudinal velocity component to decrease, but not those of the other components. Britter et a1. (1981) present some evidence of this phenomenon. Near the surface, high frequencies rapidly reach equilibrium with the increased surface stress, as before. Thus, compared to upstream, spectral densities of the longitudinal velocity on hilltops near the surface (in the inner layer) 
should show increased values at high frequencies and decreased values at low frequencies. Unfortunately, we have no observations to make such comparisons.

As before, spectra of vertical velocity should be in equilibrium with local terrain, at least in the range of frequency responsible for most of the energy. For the lateral spectra, the low frequencies should resemble upstream spectra, and the high frequencies in the "inner" layer should be in equilibrium with local terrain. In Chapter VI, we will consider spectra on hills and escarpments in more detail.

Over rolling terrain, we would again expect high-frequency horizontal spectra near the surface, and therefore most of the vertical spectra to be in local equilibrium. In contrast, low-frequency horizontal spectral densities could be enhanced by the two-dimensional meandering produced by the terrain irregularities. This effect should be especially pronounced in stable air. Further magnification of the effect could occur when the terrain is relatively flat at the point of observation, and the low frequencies "remember" the rolling terrain upstream. Finally, we will discuss observations downstream of a low mountain ridge. Here, even larger low-frequency turbulence is possible because of the wake produced by the hill. More detail for spectra over rolling farmland is given in Section VII. 


\section{SPECTRA OVER LAND, DOWNWIND OF WATER}

When air moves from water to land, many surface properties change. We will deal here first with strong winds, that is, with small $|z / L|$, where $z$ is the height and $L$ the Monin-Obukhov length. In that case, the most important change, by far, is that of roughness length, $z_{0}$. Over water, $z_{0}$ is typically $0.01 \mathrm{~cm}$, and over land considered here, $z_{0}$ is about $3 \mathrm{~cm}$.

In June-July 1978, a surface-layer wind experiment was conducted at the Ris $\varnothing$ National Laboratory, Denmark, directed by E. W. Peterson, Oregon State University. Many members of the Ris $\varnothing$ staff and of the Department of Meteorology, The Pennsylvania State University, cooperated in this experiment. The general purpose was to study the properties of changes in air crossing from water to slightly sloping land.

Profiles of wind are being analyzed elsewhere. It is already clear that both roughness change and slope affect the development of the wind profile, as required by theory (see, e.g., Jackson and Hunt 1975; Peterson 1969; Taylor and Bent 1974; Jensen and Peterson 1978). However, the development of the spectra in the lowest $12 \mathrm{~m}$ can be explained entirely by the roughness change, provided $z /|L|$ is small.

Figure 5.1 shows the plan of the Ris $\varnothing$ experiments. Three masts were instrumented, mast 0 in the water, mast I at the beach, and mast II inland. The fetch over land to mast II varied from $50 \mathrm{~m}$ to $70 \mathrm{~m}$, depending on wind direction. According to Equation (3.1), the height of the interface was about $6 \mathrm{~m}$. This height agrees well with the height inferred from profile measurements.

The spectral measurements used here were based on wind fluctuation records produced by Norman thrust, three-dimensional drag anemometers (see Perry et al. 1978). High-frequency measurements were made on mast 0 at $2 \mathrm{~m}$, mast $\mathrm{I}$ at 2 and $4 \mathrm{~m}$, and mast II at $2,4,8$, and $12 \mathrm{~m}$ height. The runs lasted about 45 minutes, and data were recorded at $10 \mathrm{~Hz}$, later block-averaged over $3 / 10$ seconds.

In Figure 4.1, we saw a spectrum of the u-component with small $\mathrm{z} / \mathrm{L} \mid$ over water and $70 \mathrm{~m}$ downwind of the water, at $2 \mathrm{~m}$ height. The abscissa was the 
normalized frequency, $f=n z / V$, where $n$ is the natural frequency and $V$ the local wind speed. The ordinate was the spectral density multiplied by $n$. As was noted in Section IV, the figure shows that there is no significant difference between the two spectra at low frequencies. However, the increased roughness of the land has produced increased spectral densities at high frequencies, in accordance with the suggestion made above that low-frequency turbulence responds very slowly to changing conditions, whereas high-frequency turbulence adjusts rapidly.

We will now present a crude hypothesis to describe the modification of spectra by terrain change, under neutral conditions. Under these conditions, spectral densities at a given wave number and height are proportional to the surface stress, $u_{\star}^{2}$ (where $u_{\star}$ is the surface friction velocity). In a separate paper, Højstrup (1981) has extended the hypothesis to unstable conditions.

Now consider a sudden change of surface stress, which a parcel of air would encounter when it passes the line of changing roughness. Then its spectral density at a given wave number will change in the same sense, but adjust gradually to the new stress. We now postulate that the spectral density will respond in the same manner as a first-order mechanical system (assuming steady-state conditions):

$$
\frac{d S\left(k_{1}\right)}{d t}=\frac{S_{1}\left(k_{1}\right)-S\left(k_{1}\right)}{\tau} .
$$

Here, $S\left(k_{1}\right)$ is the spectral density at the one-dimensional wave number, $k_{1}$, and $s_{1}\left(k_{1}\right)$ is the spectral density that would be in equilibrium with its environment. The quantity " $\tau$ " is a response time. It would be small for small eddies (large $k_{1}$ ), and larger for the large eddies (small $k_{1}$ ). Thus, for example, as air moves from smooth to rough terrain, the surface stress suddenly increases. Therefore, the spectral densities at high wave numbers will increase rapidly, and low wave numbers very slowly. Hence, e.g., $70 \mathrm{~m}$ downwind of the roughness change and close to the ground, spectral densities will have increased at high frequencies but not at low frequencies. 
We now speculate further concerning the characteristics of the response time, $\tau$. This quantity is inversely proportional to eddy velocity and proportional to wave length, $1 / k_{1}$. The eddy velocity was assumed to be proportional to the standard deviation of the longitudinal velocity component, $\sigma$, for large eddies (smal1 $k_{1}$ ) only. For small eddies, we assume conditions of the inertial subrange, so that the eddy velocity is proportional to $\left(\varepsilon / k_{1}{ }^{1 / 3}\right)$, where $\varepsilon$ is the dissipation rate. Therefore, we have for large eddies:

$$
\tau=\alpha / k_{1} \sigma_{u}
$$

and, for small eddies:

$$
\tau=\beta \varepsilon^{-1 / 3} k_{1}-2 / 3
$$

where $\alpha$ and $\beta$ are constants.

In order to put Equations (5.1) to (5.3) on a quantitative basis, we have considered a roughness change at which the surface stress changes suddenly from $u_{\star_{0}}{ }^{2}$ to $u_{\star}{ }^{2}$, and integrated Equation (5.1) from the terrain change at $x=0$ to an arbitrary distance, $x=t / V$. It will be assumed that neither $s_{1}$ nor $V$ change significantly with $x$. This is only a crude approximation. Essentially the same result can be obtained by assuming that $S_{1} / V$ is independent at $x$, a somewhat less unrealistic assumption. The model by Højstrup (1981) is more realistic in this respect.

With these simple assumptions, the solution of Equation (5.1) is:

$$
\frac{S_{1}-S_{1}}{S_{1}-S_{0}}=e^{-x / V \tau} .
$$

Here, $S_{0}$ is the spectral density upwind of the terrain change.

This equation has been used to estimate $\tau$-values, separately at different wavelengths, from the data in Figure 4.1. $S_{0}$ was obtained from the over-water spectrum at $2 \mathrm{~m} ; \mathrm{S}_{1} / \mathrm{S}_{0}$ was assumed equal to the ratio of the downstream to 
upstream spectral densities at very high frequencies, which was about four, in quite good agreement with the ratio of land and water surface stresses measured directly. Figure 5.2 shows the variation of $\tau$ with $\left(\sigma_{u} k_{1}\right)^{-1}$, at $2 \mathrm{~m}$ height. According to Equations (5.2) and (5.3), $\tau$ should be proportional to $k_{1}^{-1}$ at low $k_{1}$, and be proportional to $k_{1}^{-2 / 3}$ for large $k_{1}$. The figure shows that the data are in surprisingly good agreement with these conclusions, agreement which, in view of the crude nature of some of the assumptions, may be partly fortuitous. Also, inertial-subrange scaling applies to lower wavenumbers than would have been expected from the hypothesis.

Højstrup (1981) has generalized this theory. First, he scales the "response time" somewhat differently:

$$
\tau=\frac{A}{k_{1} \sqrt{k_{1} S\left(k_{1}\right)}} .
$$

Here, $\sqrt{k_{1} S\left(k_{1}\right)}$ represents the "eddy velocity" in a band centered at $k_{1}$. When the logarithmic spectrum is flat, (5.5) reduces to (5.2); in the inertial range, it is equivalent to (5.3). Højstrup determines $S_{1}\left(k_{1}\right)$ in (5.1) from his spectral model, which is valid in unstable as well as neutral conditions. In order to use this model, the distribution of $u_{\star}$ and heat flux must be known. He assumes that these values are varying linearly between their known values at the surface and at the interface.

Figures $5.3,5.4$ and 5.5 show spectra of the three velocity components under near-neutral conditions. Each spectrum is the average of spectra in three separate periods.

In al1 cases, the spectra on the inland mast at heights of $8 \mathrm{~m}$ and $12 \mathrm{~m}$ are not significantly different from the upstream spectra at $2 \mathrm{~m}$. The highfrequency portions of the 2-m spectra have been strongly raised from their upstream values, and those at $4 \mathrm{~m}$ much less so. This is consistent with an interface height of about $6 \mathrm{~m}$, as expected from Equation (3.1). The modification at $2 \mathrm{~m}$ is much more apparent for longitudinal than for lateral spectra. This can be explained from Højstrup's theory (Eq. 5.5) above, for the spectral densities of the $v$-components are relatively low, leading to larger response times, $\tau$. In Figures 5.3 to 5.5 , spectra expected from Højstrup's mode 1 are 
also given. The fit is quite good, for the $v$ - and $w$-components. For the u-component, there are some deviations. But in another period, not shown here, the fit is much better.

Figures 5.6 to 5.8 show spectra under unstable conditions, again, compared to Højstrup's model. Once more, the fit is good.

The original data suggested that the effect of the changed terrain in unstable air had reached $12 \mathrm{~m}$, higher than expected from Højstrup's model. This result now appears doubtful, as it was based on comparison with data on the upstream mast. These observations have now been questioned for other reasons. However, this development still leaves the large differences between spectra at $2 \mathrm{~m}$ and $12 \mathrm{~m}$ on the inland mast much larger than in neutral air. This difference is probably due to the large heat flux over land.

In summary, spectral observations on land downstream of a water surface can be well estimated by Højstrup's model, which begins with estimation of the equilibrium spectra over water and then allows for gradual modification of the spectra over land. 


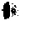

f:

(1) 


\section{VELOCITY SPECTRA ON HILLS AND ESCARPMENTS}

The properties of the turbulence on hilltops in neutral conditions are now quite well understood, with theoretical studies (Jackson and Hunt 1975; Mason and Sykes 1979), and observations (Bradley 1980; Mason and Sykes 1979) in good agreement. Generally, there is an "inner" layer of strong shear in which variances and stress decrease with height. This layer has a thickness essentially proportional to the fetch over the slope. Above this layer, there is an "outer" region with weak shear where the mean stream-lines follow potential flow theory, and the turbulence may be obtained by rapid-distortion theory (Jackson and Hunt 1975).

As Britter et a1. (1981) suggest, we would expect spectral densities of the longitudinal wind component to be depressed, due to horizontal stretching, provided that the response time, $\tau$, exceeds travel time, T. With Equation (5.2), this condition implies that the wavelength in the $x$ direction, $\lambda$, exceeds $x \sigma_{u} / V$. For shorter wavelengths, the turbulence is in equilibrium with the local surface, as it was over terrain downstream of a water surface.

We first consider spectra obtained in neutral air on Black Mountain, Canberra. This site has been described in detail by Bradley (1980). The hill is about $170 \mathrm{~m}$ above the surrounding plain, and the "inner layer", both theoretically and from observations, is about $28 \mathrm{~m}$ thick. There is a 100-m mast on the hill and a smaller mast on the plain upwind. Unfortunately, spectra are available only on the hilltop, and not on the plain upstream.

Figure 6.1 shows spectra of longitudinal wind components on Black Mountain at two levels, one within the inner layer, and the other above the inner layer. The spectra are normalized by their variances, and therefore have areas of unity. Both spectra are underestimated at very high frequencies (particulariy at the lower leve1) due to the low-pass filter used in the recording system.

The model spectrum proposed by Kaimal et a1. (1972) ${ }^{(a)}$, for the neutral limit approached from the unstable side, is also shown. It has been shifted parallel to the ordinate axis until it coincided with the observed spectra at high frequencies, but below frequencies affected by instrumental response.

(a) The model by Hфjstrup (1981) for neutral air is nearly the same. 
The basis of this fit is that, at high frequencies, both model and observations obey the conditions of the inertial range. Thus, at high frequencies, for all curves:

$$
n S(n)=\alpha_{1} \varepsilon^{2 / 3} k_{1}-2 / 3
$$

where $\alpha_{1}$ is the Kolmogorov constant, with a value around 0.5 .

We now assume that, in the inner layer, and of course, for the model, there is equilibrium between production and dissipation, so that:

$$
\varepsilon=u_{\star}^{2} \frac{\partial V}{\partial z}
$$

where $u_{\star_{\ell}}$ is the local friction velocity. Since the wind profile in the inner layer is logarithmic, $\frac{\partial V}{\partial z}=\frac{u_{\star}}{k z}$, so that:

$$
\frac{n S_{u}(n)}{\left(u_{*_{\ell}}{ }^{2} u_{\star}\right)^{2 / 3}}=0.30 f^{-2 / 3} .
$$

Since Bradley's spectra were originally normalized by $\sigma_{u}{ }^{2}$, the shift required to fit the model to the spectra at high frequencies should imply a multiplication of the model spectra by $\left(u_{*_{l}}{ }^{2} u_{*}\right)^{2 / 3} / \sigma_{u}{ }^{2}$. This ratio could be evaluated from direct measurements of variances and covariances, and the required shift agreed with this hypothesis within the inner layer.

In the outer layer, the dissipation cannot be in balance with production, since the wind shear is zero or very small, either positive or negative. Instead, Figure 6.1 shows that the spectral characteristics at the top of the inner layer continue without significant change into the outer layer.

The figure also shows a low-frequency deficit of spectral density, as expected from the theory by Britter et al. (1981) for $\lambda>\sigma_{u} x / V$. In contrast, Figure 6.2 shows spectra of vertical velocity, again compared to the model by Kaimal et al. (1972). The figures suggest no significant differences between spectra on the hill and over uniform terrain, except for the filter loss at very high frequencies. This result, again, agrees with the theory of Britter et al. (1981) and the discussion in the Introduction. 
Bowen (1979a) has made measurements of wind characteristics on two escarpments, about $10 \mathrm{~m}$ high: one has a vertical face, the other a slope of 1 (vertical) to 2 (horizontal). Experimental details are given in this paper, and in his Ph.D. thesis (Bowen 1979b). Suffice it to say here that measurements were made, up to $20 \mathrm{~m}$, on three masts: one upwind, the second $5 \mathrm{~m}$ past the upper edge of the escarpments, and the third $40 \mathrm{~m}$ past this edge. Because of the short fetch up the escarpments, the thickness of the "inner" layer is only about $1 \mathrm{~m}$ for the sloping escarpment and essentially zero (and rather meaningless) for the cliff. Hence, all observations were made in the "outer" layer.

Figure 6.3 compares un-normalized spectra of the longitudinal velocity components at the three positions for the gentle escarpment. No spectra of lateral velocity components were available. The figure shows the decrease in low-frequency energy from the upwind mast to the first mast on the escarpment. Again, rapid-distortion theory accounts for this change.

However, the high-frequency energy remains unchanged, even though the wind, and presumably also $u_{\star}$, increase by about $30 \%$. This result is caused by the fact that, even for the shorter wavelength, $\lambda>\sigma_{u} x / V$ (where $x$ is the short uphil1 fetch), so that these eddies are not in local equilibrium.

Figure 6.4 shows an analogous graph for the vertical cliff. This time, the decrease of low-frequency spectral density, $5 \mathrm{~m}$ beyond the edge, is more spectacular, and again, spectral densities are restored further along the top of the cliff. This time, however, the high-frequency energy is increased greatly. Theories quoted earlier do not apply to this situation. The increase is probably due to the fact that the instrument is submerged in the strong wake generated by the sharp cliff edge.

Next, we consider an escarpment on a much larger scale, within the white Sands Missile Range, New Mexico. Vertical cross-sections from the SSW and from the east are given in Figure 6.5. These directions were chosen because relatively reliable data were available when winds blew in these directions.

The data set for this study consisted of 95 days of observations made by the U.S. Army between January 15 and December 15, 1977. The wind was sampled every second and the data reduced to 10-second, nonoverlapping block averages. 
Thus, the data imposed rather severe restrictions on the possible analysis. Without temperature information, it is impossible to organize results according to atmospheric stability. Therefore, the study was limited to near-neutral conditions, which were assumed to exist whenever the wind at the 8-m height exceeded $4 \mathrm{~m} / \mathrm{s}$ between the hours of sunset and sunrise. And, because of the lack of high-frequency information, it was decided to limit the study to the horizontal velocity components.

To compile data sets for each flow direction, results of the initial scan were used to identify 4-hour periods that met the criteria for data quality, stability, and direction. Selected periods were then divided into runs approximately 43 minutes in length, consisting of 256 ten-second averages. For each run, the coordinate system at each height was rotated twice (once about the vertical axis and once about the $y$-axis), to align the $x$-axis with the 43-minute mean wind vector, $u$.

Forty-eight runs, clustered around an azimuth of $200^{\circ}$, were identified. In this group, six instances of positive uw-covariance were noted, and the wind always increased with height. Also, erratic and "flat" spectra were quite common; about $32 \%$ of the $u$ spectra and $37 \%$ of the $v$ spectra fell into this category.

These runs were eliminated. Finally, 16 runs were chosen to represent near-neutral flow up the escarpment surface. Selection was based primarily on general spectral shape. Runs in which one or more of the four horizontal velocity spectra ( $u$ and $v$ at 8 and $16 \mathrm{~m}$ ) displayed excessive scatter and a slope less than or equal to zero (on a log-log plot) were rejected. The wind directions represented ranged from $187^{\circ}$ to $221^{\circ}$, and as a group will be referred to as the south-southwest sector.

The search for observations during easterly winds was carried out in the same manner. Although some of the peculiarities found in the southwest and the south-southwest were also observed in easterly flow, they were comparatively rare (again, they occurred in February after midnight). Fourteen strong-wind runs form the data set for easterly flow.

Since only 10-second average velocity components were available, only the low-frequency portions of the spectra could be obtained. Because spectra were 
only computed in relatively strong winds, effects of $z /|L|$ were neglected. Values of "effective" $u_{\star}$ 's were computed from the logarithmic wind profile, fitted to the wind speeds at $8 \mathrm{~m}$ and $16 \mathrm{~m}$. Measurements at various nonequilibrium sites (Ris $\varnothing$, and Black Mountain, Australia) have shown that such measurements are in good agreement with those computed from the inertial subrange in spectra, and from directly measured Reynold's stresses, extrapolated downwind to the surface. At White Sands, only rough estimates of local Reynold's stresses could be made, because large fractions in the high frequencies had to be estimated from a co-spectral model (Panofsky and Mares 1968). Sti11, the agreement between surface stresses estimated in this way and from the wind profiles was quite good considering the crudeness of the approximations.

The spectra of the horizontal wind components normalized by $\left(u_{\star}{ }_{\ell} u_{\star}\right)^{2 / 3}$ stresses are shown in Figures 6.6 and 6.7. Kaimal et a1.'s neutral limit of stable-air spectra (1972) over uniform terrain is shown for comparison, since a11 observations were made at night.

Figure 6.6 shows spectra for winds from the south-southwest. As Figure 6.5 shows, the slope in this direction is steep, and the fetch about $200 \mathrm{~m}$. Thus, the wavelengths are long enough to be affected by distortion, and the spectral densities, properly normalized, should lie below the corresponding equilibrium spectra, for the longitudinal component, but not for the lateral component. The figure agrees with this hypothesis.

Figure 6.7 shows spectra with winds from the east. Here, the fetch is $2000 \mathrm{~m}$ and the slope gentle. In this case, the fetch is so long that the spectra should be in local equilibrium. The observations, again, are in good agreement with this hypothesis.

Finally, we have a very small sample of spectra of the longitudinal components on a hill near Boone, North Carolina. This hill is of special interest because a WECS is being tested on this hill.

First, there are a few spectra with generally westerly winds. Figure 6.8 shows the terrain cross-section in this direction. Apparently, the up-hill fetch is only about $600 \mathrm{~m}$. Preceding this fetch, the air is moving downhill. 
Therefore, one would not expect the spectral densities to exhibit the lowfrequency deficit characteristics of hilltops. In fact, the spectra are well described by uniform-terrain models (see Figures 6.9 through 6.11).

In addition, two spectra were available for winds from the south-southwest. The terrain cross-section in this direction is shown in Figure 6.12. In this case, there is a rather steep ascent without preceding downslope motion. Figure 6.13 , showing the spectrum at $18 \mathrm{~m}$ in this wind direction, does show the low-frequency deficit required by theory, which is also shown on other hills and escarpments studied so far. Unfortunately, the simultaneous spectrum at $76 \mathrm{~m}$ (Figure 6.14 ) does not show this deficit at low frequencies. The reason is not clear at present. 


\section{SPECTRAL CHARACTERISTICS OVER ROLLING TERRAIN}

Spectra of all velocity components were obtained at a rural site at Rock Springs, Pennsylvania, (near State College) by members of the Meteorology Department of The Pennsylvania State University, under the direction of John Norman (now at The University of Nebraska). The site has been described elsewhere (see, e.g., Perry et al. 1978).

Suffice it to say here that the observations were obtained in locally flat terrain, with roughness length of $1 \mathrm{~cm}$, surrounded by rolling farmland. To the south and southeast of the site, there was a nearly two-dimensional wooded ridge, extending about $200 \mathrm{~m}$ above the surrounding plain. The closest approach of the foot of the ridge to the measuring site was about $400 \mathrm{~m}$.

Spectra of all three velocity components were computed from measurements by Norman dragmeters at $2 \mathrm{~m}$, with data-handling very similar to that at Ris $\varnothing$.

However, in contrast to most of the measurements discussed so far, spectra were obtained also in non-neutral stability conditions. Therefore, the spectra were normalized by $u_{*}{ }^{2} \phi_{\varepsilon}{ }^{2 / 3}$, as is customary over uniform terrain (see, e.g., Kaimal et al. 1972). $\phi_{\varepsilon}$ is defined as:

$$
\phi_{\varepsilon}=\frac{\varepsilon k z}{u_{\star}^{3}}
$$

where $k$ is von Karman's constant. When spectra are normalized in this way, and expressed in terms of $f=n z / V$, they become independent of $z / L$ at high frequencies and are again described by $0.30 \mathrm{f}^{-2 / 3}$ for longitudinal components, and by $0.40 f^{-2 / 3}$ for the lateral components, at sufficiently low levels where $u_{*}$ does not differ significantly from $u_{*_{\ell}}$.

For these observations, $u_{*}{ }^{2}$ was estimated from the u-spectra under the assumption that $f S(f) / u_{\star}{ }^{2} \phi_{\varepsilon} 2 / 3^{*}=0.3$ at $f=1 . \phi_{\varepsilon}$ was prescribed by:

$$
\phi_{\varepsilon}=\left(1+2.5\left(\frac{z}{L}\right)^{3 / 5}\right)^{3 / 2}
$$


in stable air, and from:

$$
\phi_{\varepsilon}=\left(1-\frac{Z}{L}\right)
$$

in unstable air.

The formula for stable air comes from Kaimal et al. (1972), and the one for unstable air is a compromise derived from Kaimal et al. (1972), Kaimal et al. (1976), and unpublished observations at the Boulder Atmospheric Observatory, supplied by Kaimal.

Figures 7.1 to 7.6 show envelopes of spectra of the horizontal velocity components in stable and unstable air, which have not crossed the ridge. Models by Dutton et al. (1979) developed for uniform terrain, differing only slightly from Kaimal's model, are shown for comparison in the stable cases, Figures 7.1 and 7.2 .

The model curve is based on the average value of $z / L$ in each sample. Due to the procedure used, model and observations agree at high frequencies; essentially, we have assumed that the spectral densities have adjusted to local terrain there.

In contrast, the spectral densities in stable air exceed those over uniform terrain at low frequencies. This is consistent with the result by Panofsky et al. (1978) that the normalized variances at the same site are larger than expected over uniform terrain. The reason is, again, that low frequencies are "conservative" and remember the more rolling terrain upstream. The excess of low-frequency turbulence over that in uniform terrain appears to be 1 argest for the $v$-components.

Figures 7.3 through 7.6 show spectra of the horizontal velocity components for unstable conditions, for air which had not crossed the ridge. Corresponding spectra for air that had crossed the ridge were not available.

Also shown in the figures are two uniform terrain models. For large $-z / L$, the two theoretical models for the u-spectra agree well with each other, and with the observations. Apparently, rolling terrain has no significant effect 
on u-spectra when turbulence is primarily of convective origin. But, for slightly unstable conditions, the situation is not clear because the models disagree. For the v-spectra, rolling terrain appears to increase low-frequency energy, even in unstable air, but again, this effect is observed by the disagreement between the models.

Figures 7.7 and 7.8 show the spectra of vertical velocities under the same conditions. They also show a slight excess of low-frequency spectral densities. But this occurs with spectral densities low enough to have a negligible effect on the variances of vertical velocity (see, again, Panofsky et al. 1978).

Figures 7.9 and 7.10 show spectra of the two horizontal components in stable air after it has crossed the ridge. Clearly, the low-frequency excess of the spectral densities is much larger than for air, which has trajectories over the plain only.

In summary, low-frequency spectral densities of the horizontal components in neutral and stable air over rolling farmland exceed those over uniform terrain. This effect is opposite to the behavior in the other two categories discussed here. The reason for this increase may be a combination of three factors: memory of the layer roughness upstream, gravity waves, and horizontal meandering around terrain irregularities. In very unstable air, this effect is much less pronounced and may disappear entirely.

As in the other categories, however, high frequencies are in local equilibrium, and therefore vertical velocity spectra closely resemble spectra over uniform terrain. 


\section{SIMULATED RESPONSE TO AERODYNAMIC FORCING}

Systems built to stand or operate in the wind are subject to aerodynamic forces composed of both a quasi-steady and a fluctuating or turbulent component. Prediction of the response of the system, both in major structural modes and in fatigue modes, is necessary to optimize the design with respect to performance, reliability, and longevity.

The essential difficulty is that the response is a weighted integral of the loads imposed by aerodynamic forces--either lift or drag forces. In order to obtain the statistical characteristics of the anticipated response, a means must be found for translating knowledge about the statistical characteristics of the forcing into those of the response.

This endeavor poses formidable mathematical difficulties, as we shall see below. These difficulties have often been circumvented by assumptions that linearization and use of a Gaussian model provide adequate approximations. The results that are thus obtained have been tested only rarely, to our knowledge, against measurements or more realistic computations schemes of greater complexity that presumabiy would produce more accurate results.

The aim, then, of the the present study is to compare the results obtained with the aid of the usual approximations against more accurate computations, in order to assess whether these approximations are acceptable and whether the design of improved computational schemes might be beneficial, or even essential.

\section{MODELS OF RESPONSE}

The response of the system we consider here is described by a linear differential equation, with constant coefficients of the form:

$$
L Y(t)=v(t)
$$

where $L$ is a linear $n^{\text {th }}$ order differential operator, $Y(t)$ is a response variable such as displacement, and $v(t)$ is the aerodynamic forcing, usually given by: 


$$
v(t)=\frac{1}{2} C \rho A u^{2}
$$

with $C$ a lift or drag coefficient, $\rho$ the density, A the cross-sectional area, and $u(t)$ the fluctuating wind velocity.

The solution of the linear system may be represented as:

$$
Y(t)=\int_{0}^{\infty} W(\tau) v(t-\tau) d \tau
$$

and the statistics of $Y$ are obtained from this integral. For the covariance function, we have:

$$
\begin{aligned}
R_{Y}(t, t+\tau) & =E\{Y(t) Y(t+\tau)\} \\
& =\int_{0}^{\infty} \int_{0}^{\infty} W\left(\tau_{1}\right) W\left(\tau_{2}\right) E\left\{v\left(t-\tau_{1}\right) v\left(t-\tau_{2}+\tau\right)\right\} d \tau_{1} d \tau_{2} .
\end{aligned}
$$

If the forcing is second-order stationary, then:

$$
E\left\{v\left(t-\tau_{1}\right) v\left(t-\tau_{2}+\tau\right)\right\}=R_{v}\left(\tau_{1}-\tau_{2}+\tau\right) .
$$

Now, (8.4) implies that:

$$
\begin{aligned}
R_{Y}(t, t+\tau) & =R_{Y}(\tau) \\
& =\iint_{0}^{\infty} W\left(\tau_{1}\right) W\left(\tau_{2}\right) R_{V}\left(\tau_{1}-\tau_{2}+\tau\right) d \tau_{1} d \tau_{2}
\end{aligned}
$$

and so $Y$ is also second-order stationary. The Fourier transform of (8.6) gives the spectral density as: 


$$
S_{Y}(\omega)=|\hat{W}(\omega)|^{2} S_{V}(\omega)
$$

More generally, we may want statistics that depend on the probability density function. Then we might attempt to calculate the characteristic function:

$$
\begin{aligned}
\phi_{Y}(s) & =E\left\{e^{i s Y}\right\} \\
& =E\left\{\exp \left[i s \int_{0}^{\infty} W(\tau) v(t-\tau) d \tau\right]\right\} .
\end{aligned}
$$

There is no known way to evaluate this expectation in general, and we must resort to finite-dimensional approximations involving expansion of the exponential function to obtain moments or to use an N-point joint distribution of $v(t)$.

One of the major reasons for obtaining the probability density functions is to determine probabilities of large responses. A convenient statistic is $\mathrm{N}(\mathrm{Y})$, defined as the frequency with which the value $Y$ is exceeded by the time history $Y(t)$. It can be shown that:

$$
N(\dot{Y})=\int_{0}^{\infty} \dot{Y}_{p}(\dot{Y}, Y) d Y
$$

where $\dot{Y}=\mathrm{d} Y / \mathrm{dt}$. Thus to calculate $N(Y)$ from (8.9), we would have to obtain a characteristic function $\phi_{Y}, \dot{y}\left(s_{1}, s_{2}\right)$ in the form (8.8) and transform to find $p(y, \dot{y})$.

Two approximations have been in common use. The first is that the aerodynamic force can be linearized through use of $u(t)=U+u^{\prime}$ where $U$ is the average $U=\bar{u}$. With:

$$
v(t)=\frac{1}{2} \operatorname{C\rho A}\left(u^{2}+2 u u^{\prime}+u^{\prime 2}\right)
$$

we define: 


$$
\bar{y}+y=\Psi(t) /\left(\frac{1}{2} C D A\right) \approx U^{2}+2 U u^{\prime}
$$

where $\bar{y}$ is the steady response to the mean $u^{2}$ and $y(t)$ is the response to the linearized fluctuation $2 \mathrm{Uu}^{\prime}$. The argument is that $u^{\prime 2}$ is small compared to $2 U^{\prime}$ ' because $u^{\prime} / U$ is generally small, at least for strong winds $U$. Now we have:

$$
y(t)=2 U \int_{0}^{\infty} w(\tau) u^{\prime}(t-\tau) d \tau
$$

and so the response is a linear function of the fluctuating velocity $u^{\prime}(t)$. If $u^{\prime}(t)$ were a realization of a Gaussian process, then $y(t)$ would be Gaussian with spectrum (see (8.7))

$$
S_{y}(\omega)=|\hat{W}(\omega)|^{2} 4 u^{2} S_{u^{\prime}}(\omega)
$$

and by Fourier transform we would find the covariance function and thus have complete information about the statistics of $y$. In particular, for Gaussian processes it is well known that:

$$
N(y)=\frac{1}{2 \pi}\left\{\frac{\int_{0}^{\infty} \omega^{2} S_{u^{\prime}}(\omega) d \omega}{\int_{0}^{\infty} S_{u^{\prime}}(\omega) d \omega}\right\}^{1 / 2} e^{-\frac{1}{2}\left(y / \sigma_{y}\right)^{2}} .
$$

Many systems are essentially damped harmonic oscillators (or their modes behave as oscillators). Thus we restrict further analysis to systems that are described by the second-order differential equation:

$$
\ddot{Y}+2 b \dot{Y}+c Y=v(t)
$$

where $Y$ is the displacement, $2 b$ the damping coefficient, and $c$ the square of the natural frequency $(\mathrm{rad} / \mathrm{s})^{2}$ and, as before, $v(t)$ is the aerodynamic force. Upon normalization, we shall have: 


$$
\ddot{y}+2 b \dot{y}+c y=\left\{\begin{array}{ll}
u^{2}-\overline{u^{2}} & \text { nonlinear } \\
2 U u^{\prime} & \text { 1inearized }
\end{array} .\right.
$$

When the damping ratio, $R$, equals $b / \sqrt{c}<1$, the motion is underdamped, and the solution is:

$$
y(t)=\int_{0}^{\infty} e^{-b \tau} \frac{\sin \Omega \tau}{\Omega} v(t-\tau) d \tau
$$

where $\Omega=\left(c-b^{2}\right)^{1 / 2}$.

Data obtained from measurements of turbulent wind fields were used to specify the forcing $v(t)$ in the two forms (8.15) and the integral in (8.16) was valuated by summation over records with resolution of $5 / \mathrm{Hz}$. The sums were extended until $\mathrm{e}^{-\mathrm{b} \tau}<\varepsilon$ where $\varepsilon=0.001$ (two exceptions in which $\varepsilon<0.001$ were necessary to avoid excessive use of computer time). The integrations were performed for various choices of damping ratio and natural frequency typical of those found in structural design, thus producing responses that are representative of the exact and approximate solutions.

\section{CALCULATED RESULTS}

The wind fluctuation data used in this study was composed of two separate time histories--one measured at the Ris $\varnothing$ National Laboratory in Denmark, the other at the Penn State Rock Springs site. The characteristics of the data are shown in Table 8.1.

Spectral density functions for the forcing functions $u^{2}-\overline{u^{2}}$ and $2 U u^{\prime}$ were computed and are shown in Figures 8.1 and 8.2 for the two data sets.

A smoothed version of the observed spectrum was obtained for the Rock Springs data by fitting to it the Pen State model described in Dutton et al. (1979). For the second-order equation, the transfer function is:

$$
|\hat{W}(\omega)|^{2}=\left[\left(c^{2}-\omega^{2}\right)^{2}+4 b^{2} \omega^{2}\right]^{-1}
$$


and the response spectrum is then obtained from (8.7). Figure 8.3 shows the model spectrum and the resulting response spectra in the linear case $\left(v=2 U u^{\prime}\right)$ for three choices of natural frequency.

The responses were computed for the Rock Springs data for the choices of natural frequency and damping ratio shown in Table 8.2 .

For the rest of this subsection we consider exceedance statistics. The Gaussian form:

$$
N(y)=N(0) e^{-\frac{1}{2}\left(y / \sigma_{y}\right)^{2}}
$$

would evidently produce a straight line if $\ln [\mathrm{N}(\mathrm{y}) / \mathrm{N}(0)]$ were plotted against $\frac{1}{2}\left(y / \sigma_{y}\right)^{2}$. Hence deviations from the Gaussian case are readily revealed by using these coordinates. The exceedance statistics for a time history $f(t)$ are determined by counting, with a computer, the number of times $f(t)$ crosses predetermined levels. Figure 8.4 shows $N(u) / N(0)$ for the velocity component $u^{\prime}$, some deviation being evident. The exceedance curves for the forcing variables $2 U u^{\prime}$ and $u^{2}-\overline{u^{2}}$ are shown in Figure 8.5 with the exact, nonlinear version being markedly different from the linear approximation.

Figures 8.6 to 8.10 depict the calculated responses for the Gaussian linear case, the linear case, and the exact nonlinear case. It is evident that the two approximations cannot be used throughout the range of natural frequencies and damping ratios considered here. Deviations of an order of magnitude in frequency of occurrence at large $y / \sigma_{y}$ appear on some of the plots. The Gaussian and linear approximations often, but not always, give serious underestimates of the frequency of large deflections.

The same sequence of results is shown for the Ris $\phi$ data in Figures 8.11 through 8.18. The smooth model used in Figure 8.11 is the neutral limit of Kaimal et al. (1972). Figure 8.12 shows that the velocities, $u^{\prime}$, are more nearly those of a Gaussian distribution than were the Rock Springs data. Figure 8.13 demonstrates the difference in $N(v)$ for the linear and nonlinear cases. 
The calculated responses are shown in Figures 8.14 to 8.16 . For this data, there is generally fair agreement between the linear and nonlinear cases, and they are reasonably well represented by the Gaussian case. The strongest deviations occur in Figure 8.14. Here, the frequency of occurrence for the nonlinear case exceeds that of the linear case by half an order of magnitude at most.

\section{CONCLUSIONS AND IMPLICATIONS}

The responses of a second-order system to aerodynamic forcing by actual turbulence were calculated both on exact method and through a method involving two approximations often used in applications. The main result of the comparison was that the approximations can, in some cases, lead to serious error in estimating the frequency of large responses.

Of the two sets of data considered, the linearization and Gaussian approximations produced acceptable results with the Ris $\varnothing$ data, but were unacceptable when utilized with the Rock Springs data. One difference between the two cases that is immediately evident from Figures 8.3 and 8.11 is that the Rock Springs data have much more energy at low frequencies. Upon taking the transfer functions into account, we see that this is reflected in the responses having more low-frequency energy. The differences in the spectral shapes have been explained earlier in this report.

The evident result that the accuracy of the approximations depends on the shape of the spectra of the forcing leads to three conclusions. The first is that a detailed analysis of the effect of spectral shape is necessary to know in advance which cases are amenable to use of the approximations. Second, we must be able to model spectral shapes accurately. The third is that we must develop accurate and efficient methods for calculating response statistics that do not depend on the usual approximations.

The development of such techniques is not a trivial task; the difficulties are inherent in the need to estimate statistics of integrals over random functions, which necessitates taking joint probability density functions into account. 
Despite the difficulties, there is no escaping the need to be able to estimate the responses of systems to aerodynamic forcing. To do so, as manifested by this study, requires that we consider both new forms of turbulence statistics and new methods of working with them. 



\section{ACKNOWLEDGEMENTS}

The authors would like to express their appreciation to the U.S. Department of Energy, Pacific Northwest Laboratory, for sponsoring much of the analysis reported here; to the Meteorology Group at the Ris $\phi$ National Laboratory directed by Erik Petersen, who cooperated in measurements at Ris $\phi$, and to Dr. John Norman and his assistants for carrying out the complex instrumental problems there; also to the Atmospheric Science Office, U.S. Army, White Sands, particularly Dr. Henry Rachele, for making available the White Sands observations. Finally, the authors appreciate suggestions provided by Dr. Julian Hunt of Cambridge University, and Dr. Jørgen Højstrup of the Ris $\varnothing$ Laboratory. 
. 


\section{$X . \quad$ REFERENCES}

Bowen, A. J. 1979a. "Full-Scale Measurements of the Atmospheric Turbulence Over Two Escarpments." Fifth Int. Conf. Wind Engin., pp. II-6-1-II-6-12.

Bowen, A. J. 1979b. "Some Effects of Escarpments on the Atmospheric Boundary Layer." Ph.D. Thesis, Dept. of Mech. Eng., University of Canterbury, Christchurch, Canterbury, NZ.

Bradley, E. F. 1980. "An Experimental Study of Profiles of Wind Speed, Shearing Stress and Turbulence on the Crest of a Large Hill. Quart. J. Roy. Met. Soc., 106:101-123.

Britter, R. E., J.C.R. Hunt, and K. J. Richards. 1981. "Air Flow Over a TwoDimensional Hill: Studies of Velocity Speed-Up, Roughness Effects and Turbulence." Quart. J. Roy. Met. Soc., 107:91-110.

Caughey, S. J. 1977. "Boundary Layer Turbulence Spectra in Stable Conditions." Bound. Layer Meteor., $11: 3-14$.

Dutton, J. A., H. A. Panofsky, D. Larko, H. N. Shirer, G. Stone, and M. Vilardo. 1979. Statistics of Wind Fluctuations Over Complex Terrain. Final Report, Dept. of Energy, ET28-8-06-1110.

Flay, R.G.J. 1978. "Structure of a Rural Atmosphere Boundary Layer Near the Ground." Ph.D. Thesis, Dept. of Mech. Eng., University of Canterbury, Christchurch, NZ.

Højstrup, J. 1981. "A Simple Model for the Adjustment of Horizontal Velocity Spectra in Unstable Conditions Downstream of an Abrupt Change in Roughness and Heat Flux." Bound. Layer Meteor. 21:341-356.

Jackson, P. A. and J.C.R. Hunt. 1975. "Turbulent Wind Flow Over a Low Hi11." Quart. J. Roy. Met. Soc., 101:929-955.

Jensen, N. O. and E. W. Peterson. 1978. "On the Escarpment Wind Profile." Quart. J. Roy. Met. Soc., 104:719-728.

Kaima1, J. C. 1973. "Turbulence Spectra Length Scales and Structure Parameters in the Stable Boundary Layer." Bound. Layer Met., 4:289-309.

Kaima1, J. C. 1978. "Horizontal Velocity Spectra in an Unstable Surface Layer." J. Atmos. Sci., 35:18-24.

Kaima 1, J. C., J. C. Wyngaard, I. Izumi, and 0. R. Coté. 1972. "Spectral Characteristics of Surface Layer Turbulence." Quart. J. Roy. Met. Soc., 98:563-589.

Kaima 1, J. C., J. C. Wyngaard, D. A. Haugen, 0. R. Coté, Y. Izumi, S. J. Caughey, and C. J. Readings. 1976. "Turbulence Structure in the Convective Boundary Layer." J. Atmos. Sci., 33:2152-2169. 
Lumley, J. L. and H. A. Panofsky. 1964. Structure of Atmospheric Turbulence, Wiley-Interscience, New York.

Mason, P. J. and R. I. Sykes. 1979. "Flow Over an Isolated Hill of Moderate Shape." Quart. J. Roy. Met. Soc., 105:383-395.

Panofsky, H. A., C. A. Egolf, and R. Lipschutz. 1978. "On Characteristics of Wind Direction Fluctuations in the Surface Layer." Bound. Layer Meteor., $15: 439-446$.

Panofsky, H. A. and V. E. Mares. 1968. "Recent Measurements of Cospectra of Heat Flux and Stress." Quart. J. Roy. Met. Soc. 94:581-585.

Perry, S. G., J. M. Norman, H. A. Panofsky, and J. D. Martsolf. 1978. "Horizontal Coherence Decay Near Large Mesoscale Variations of Topography." J. Atmos. Sci. 35:1884-1889.

Peterson, E. W. 1969. "Modification of Mean Flow and Turbulent Energy by a Change in Surface Roughness Under Conditions of Neutral Stability." Quart. J. Roy. Met. Soc., 95:561-575.

Peterson, E. W., P. A. Taylor, J. Højstrup, N. O. Jensen, L. Kristensen, and E. L. Peterson. 1980. "Further Investigations into the Effects of Local Terrain Irregularities on Tower-Measured Wind Profiles." Bound. Layer Meteor. 19:303-313.

Schotz, S. and H. A. Panofsky. 1980. "Wind Characteristics at the Boulder Atmospheric Observatory." Bound. Layer Meteor., 19:155-164.

Taylor, P. A. and P. R. Gent. 1974. "A Model of Atmospheric Boundary Layer Flow Above an Isolated Two-Dimensional 'Hill'; An Example of Flow Above Gentle Topography." Bound. Layer Meteor., 7:349-362. 


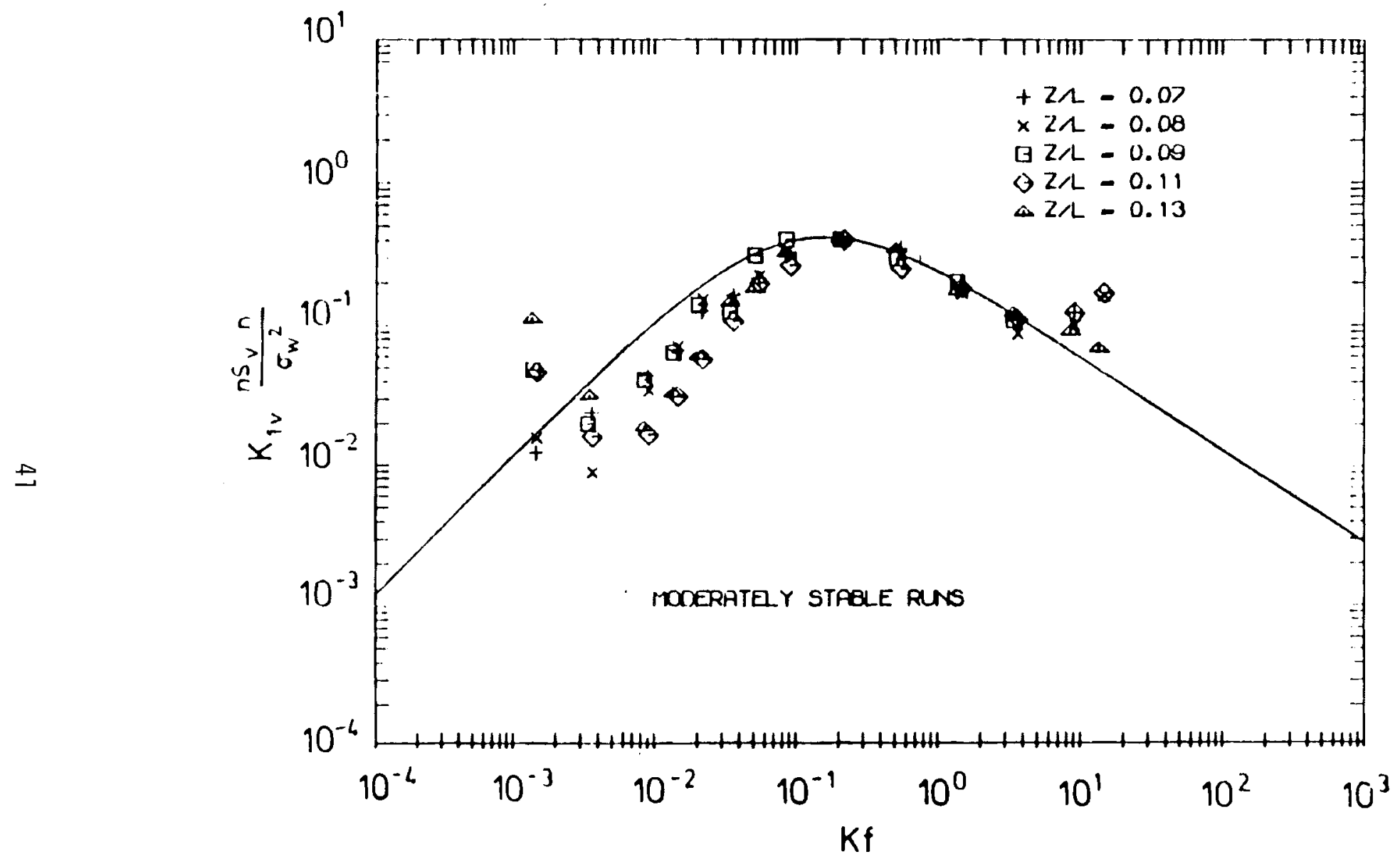

FIGURE 2.1. Spectra of the Lateral Velocity Component in Stable Air in Kansas (Computed by Søren Larsen) 


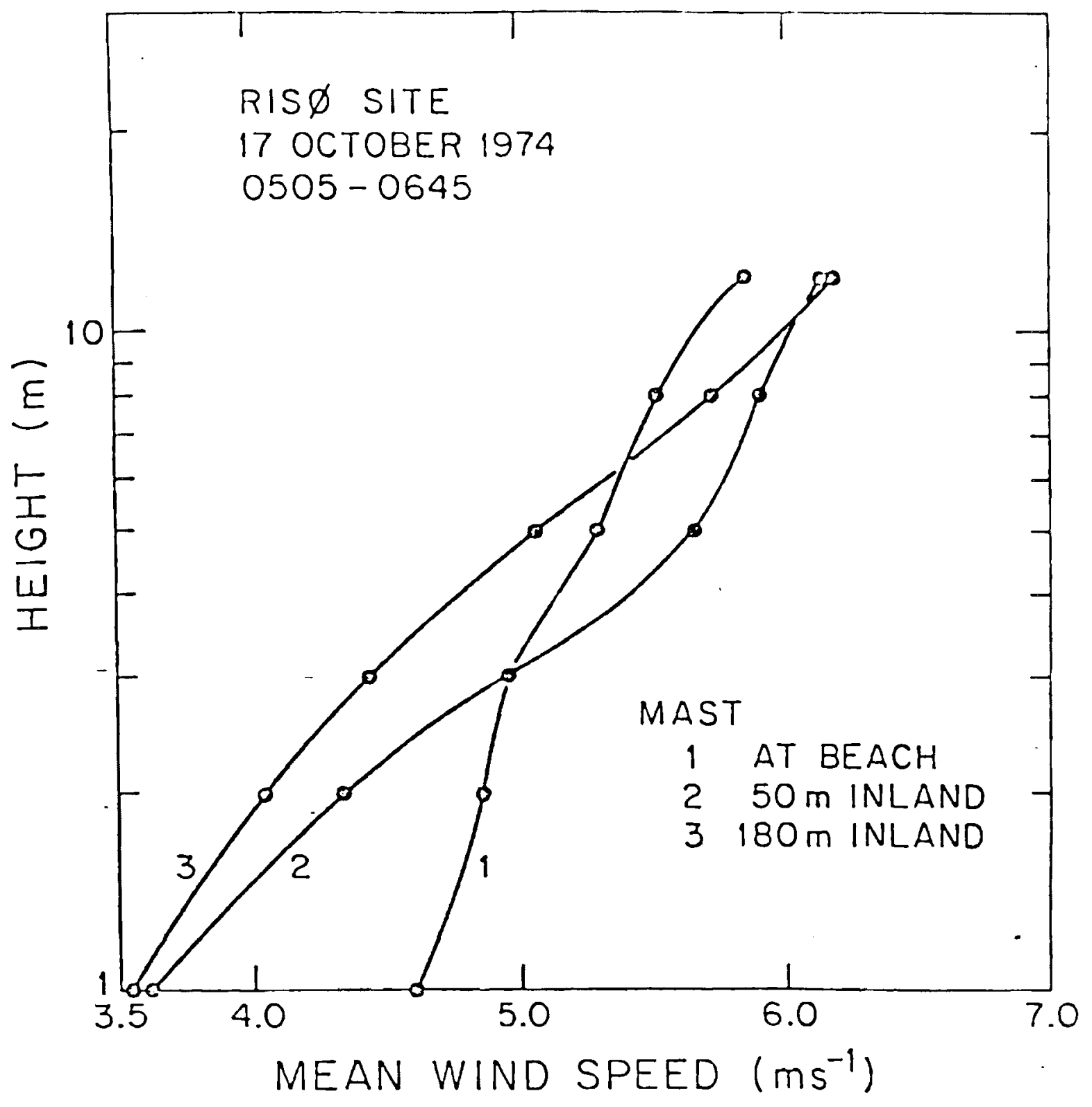

FIGURE 3.1. Wind Profiles Downstream of a Roughness Change in Slightly Sloping Terrain 


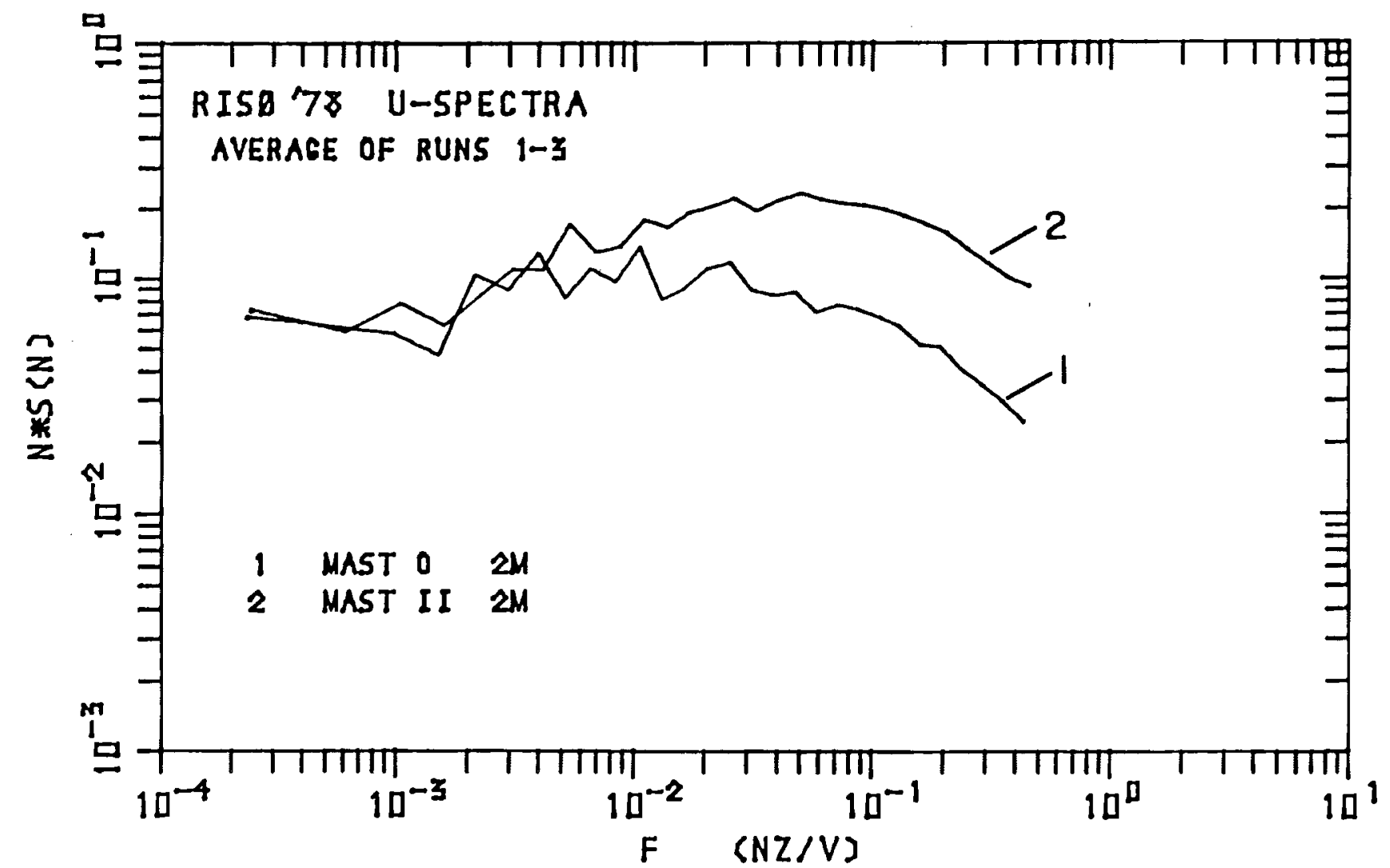

FIGURE 4.1. Spectra of the Longitudinal Component at $2 \mathrm{~m}$ at Ris $\varnothing$, Off-Shore and On Inland Mast 


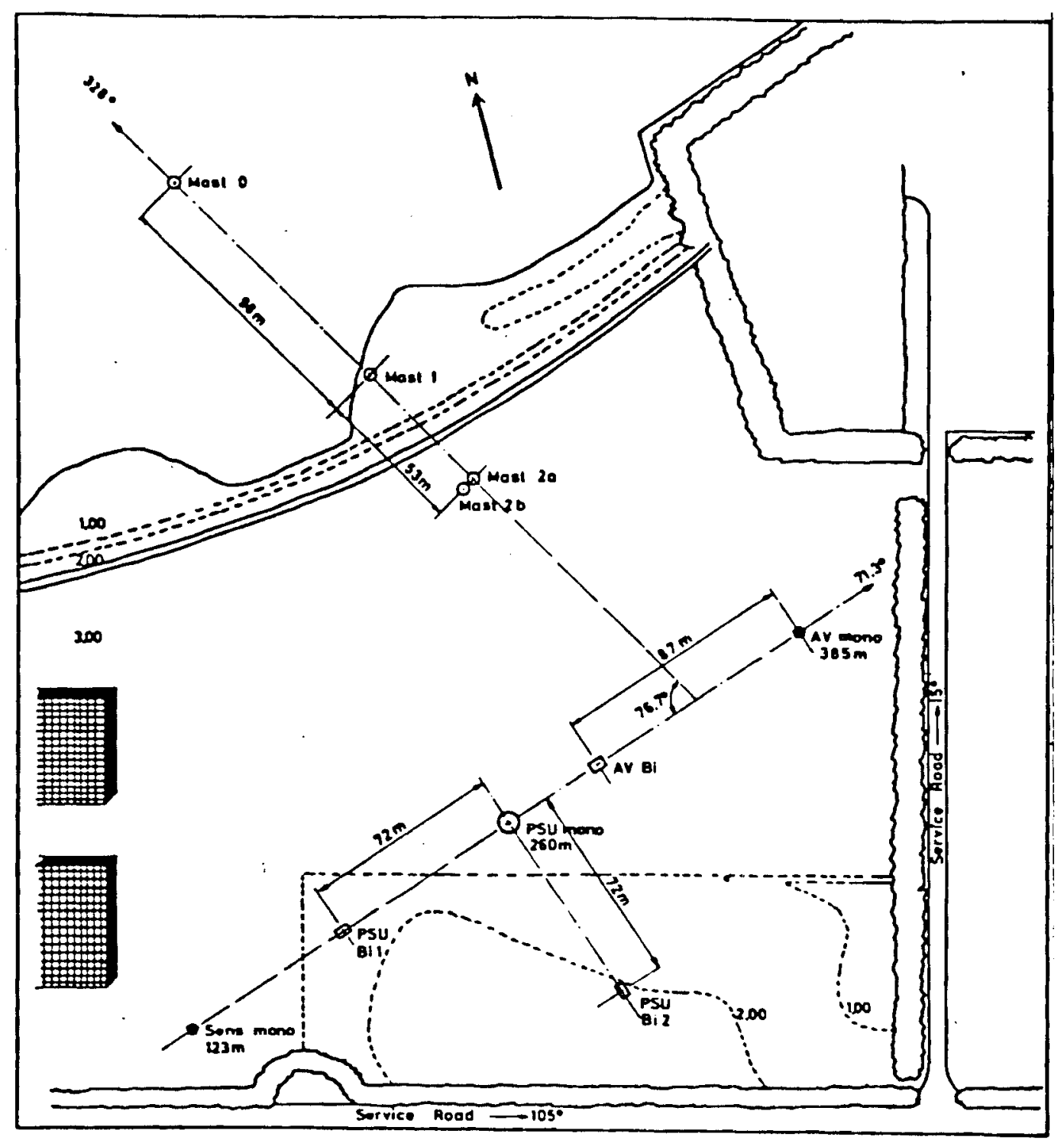

FIGURE 5.1. Plan of Ris $\phi$ Experiments 


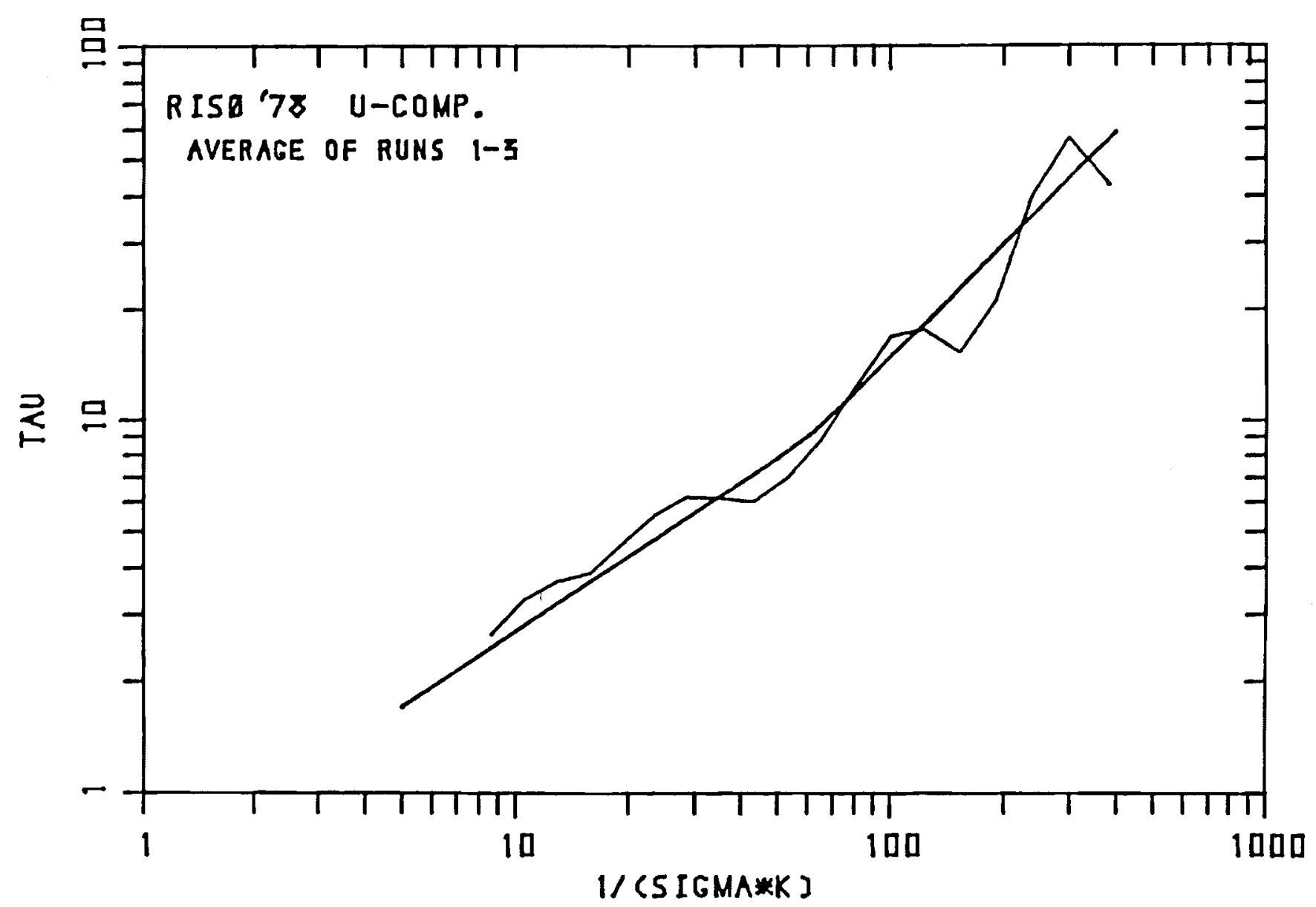

FIGURE 5.2. Relation Between Response Time and Wave Number 


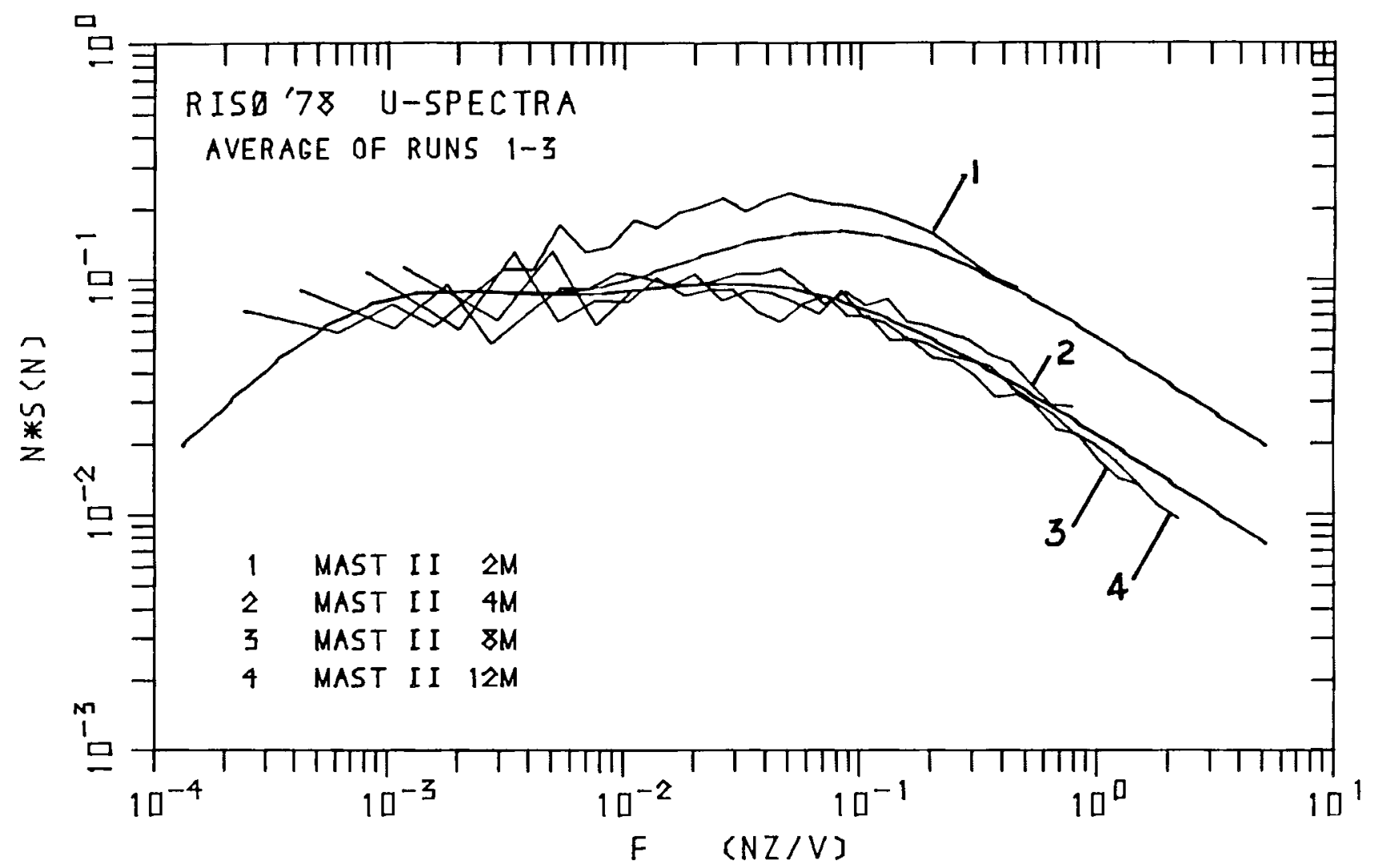

FIGURE 5.3. Spectra of the u-Component at Ris $\varnothing$, Near-Neutral Conditions. Højstrup (1981) model shown for comparison. 


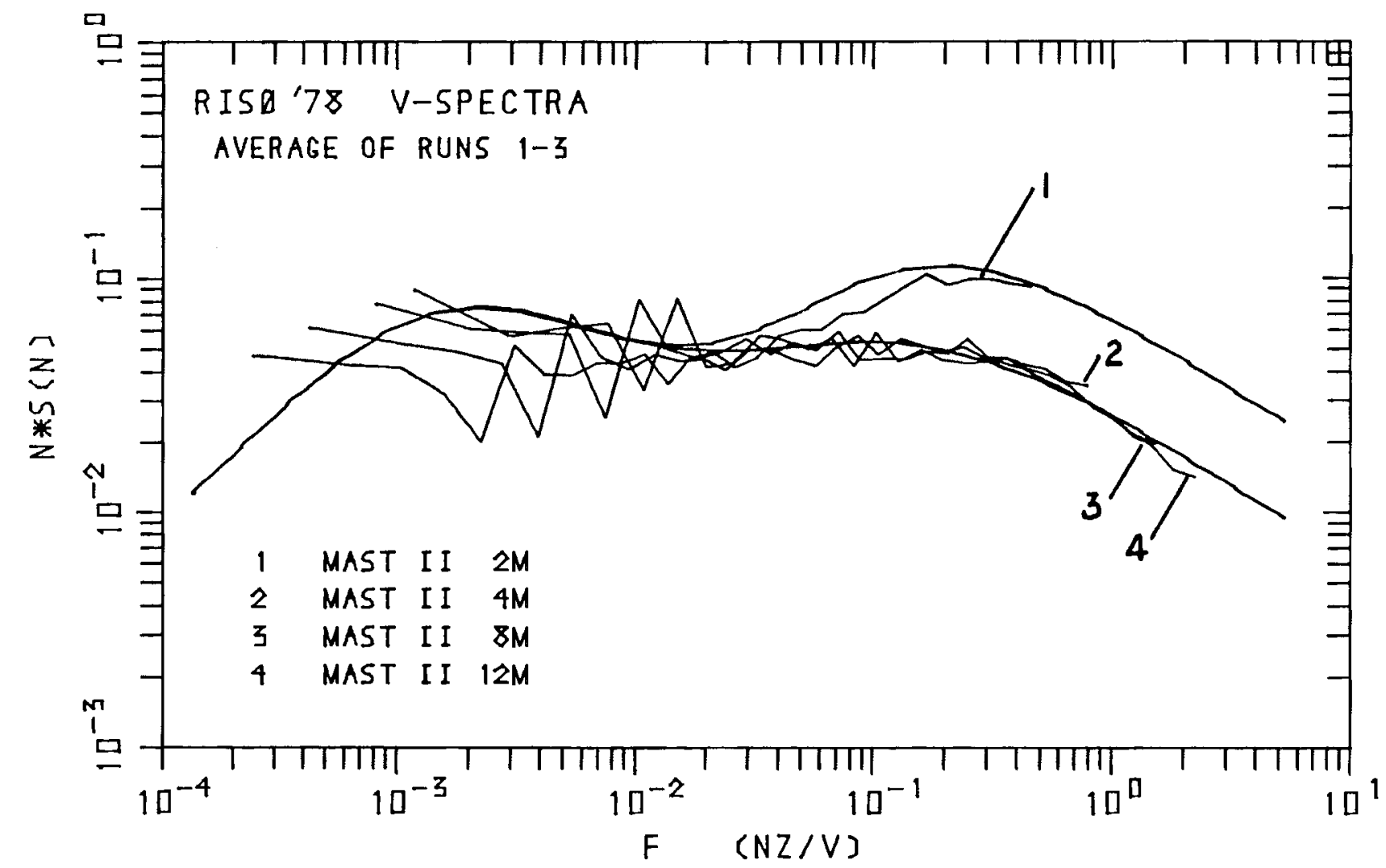

FIGURE 5.4. Spectra of the $v$-Component at Ris $\phi$, Near-Neutral Conditions 


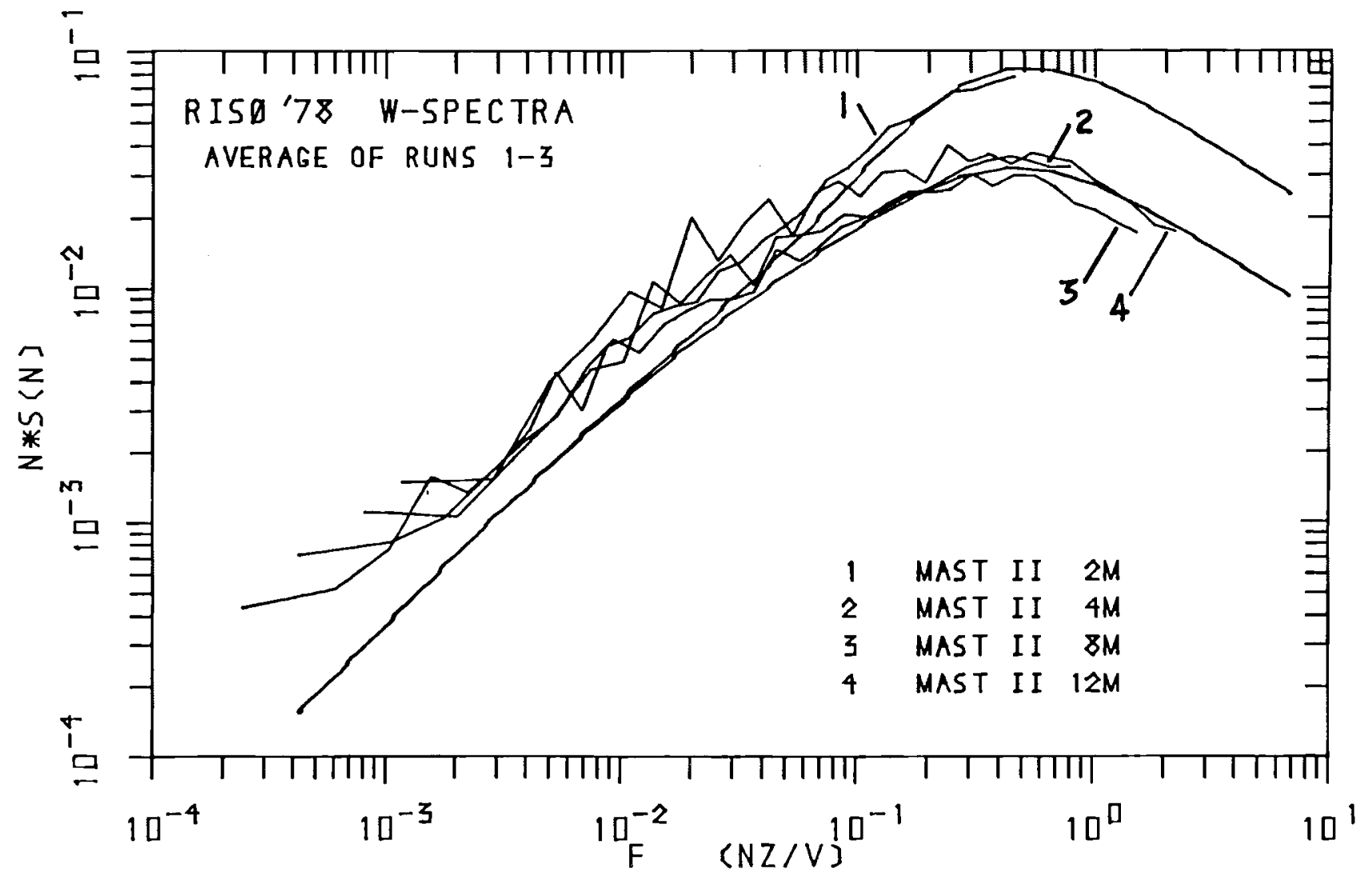

FIGURE 5.5. Spectra of the w-Component at Ris $\varnothing$, Near-Neutral Conditions 


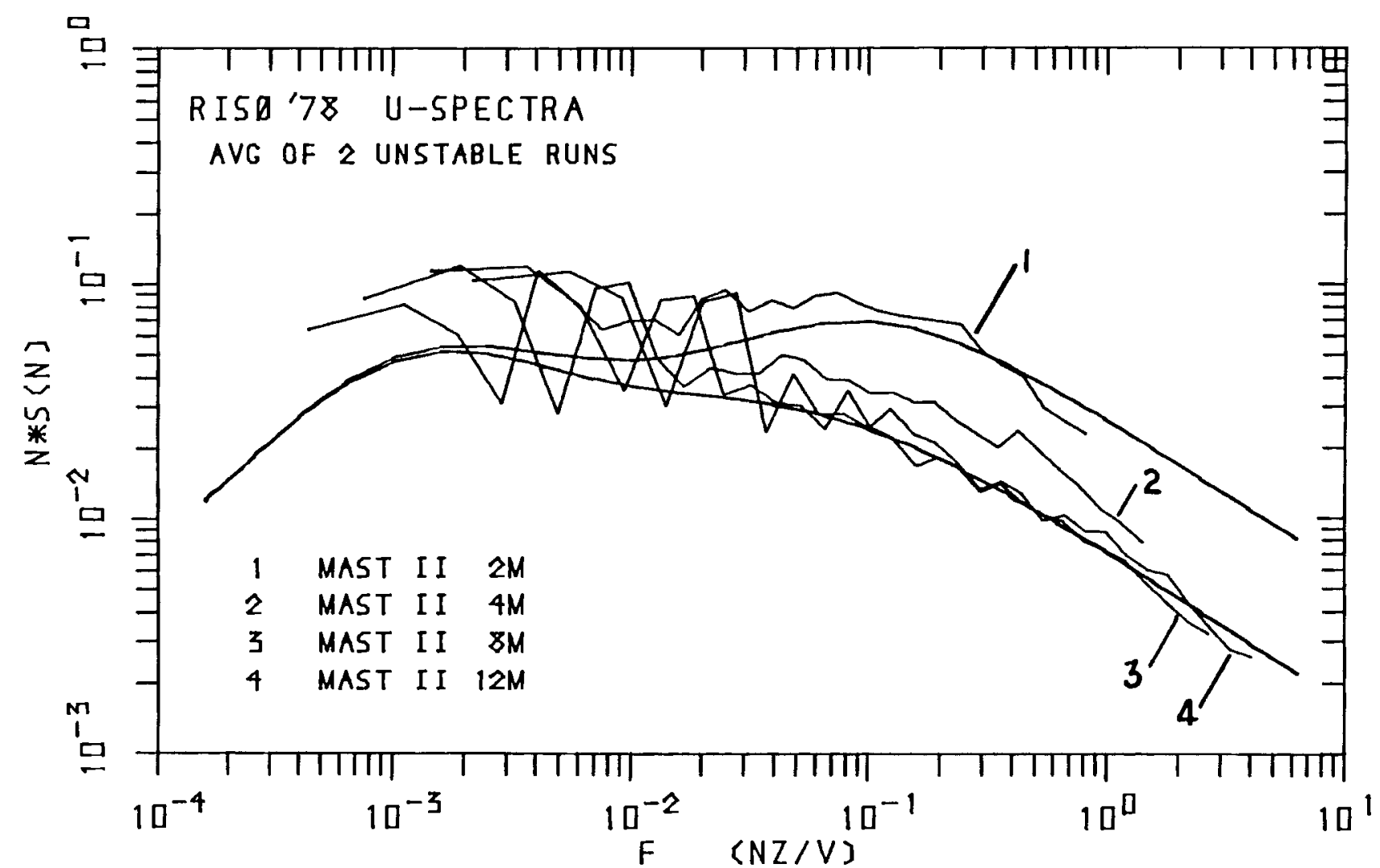

FIGURE 5.6. Spectra of the u-Component at Ris $\varnothing$, Unstable Air 


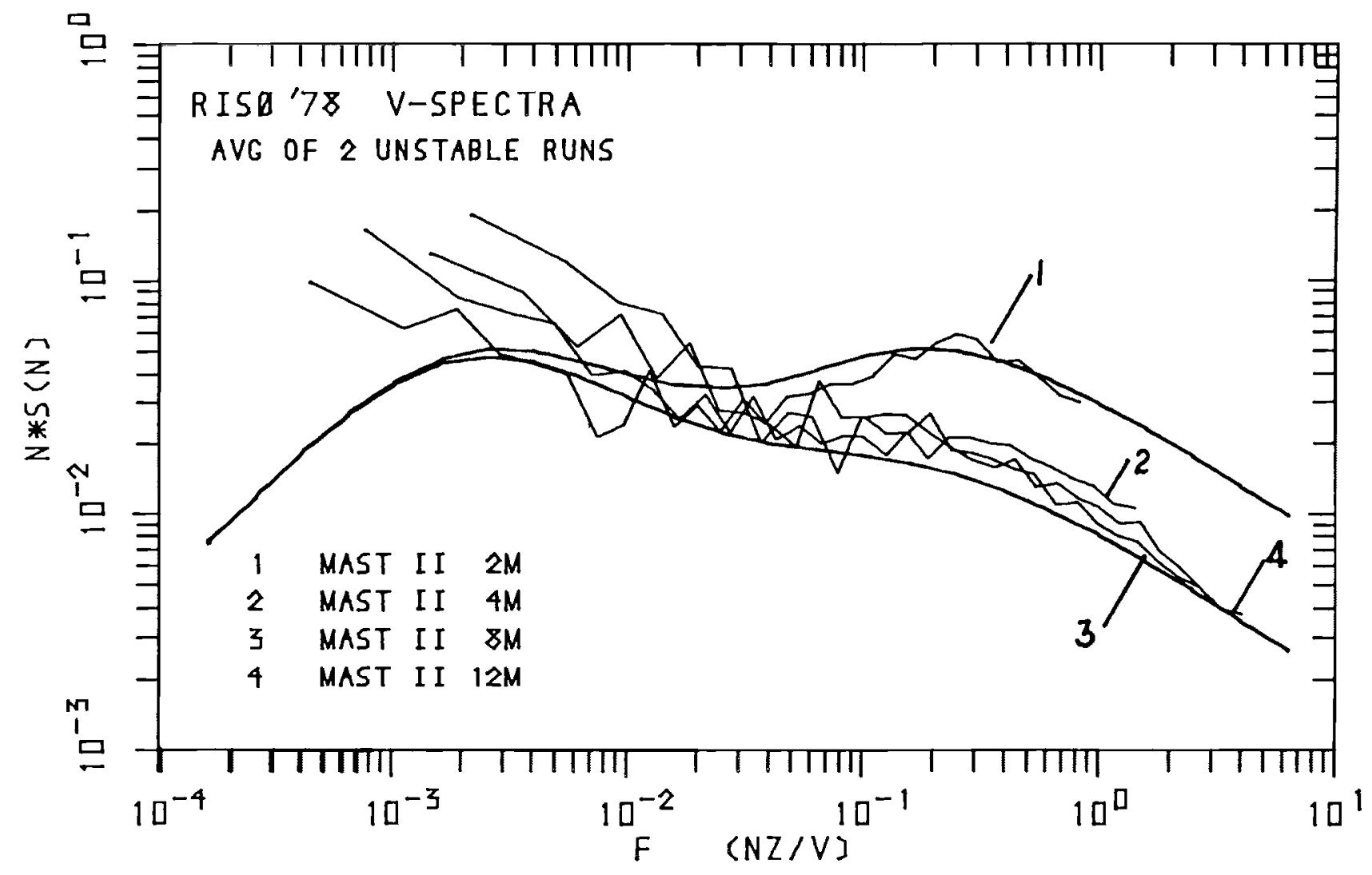

FIGURE 5.7. Spectra of the $v$-Component at Ris $\phi$, Unstable Air 


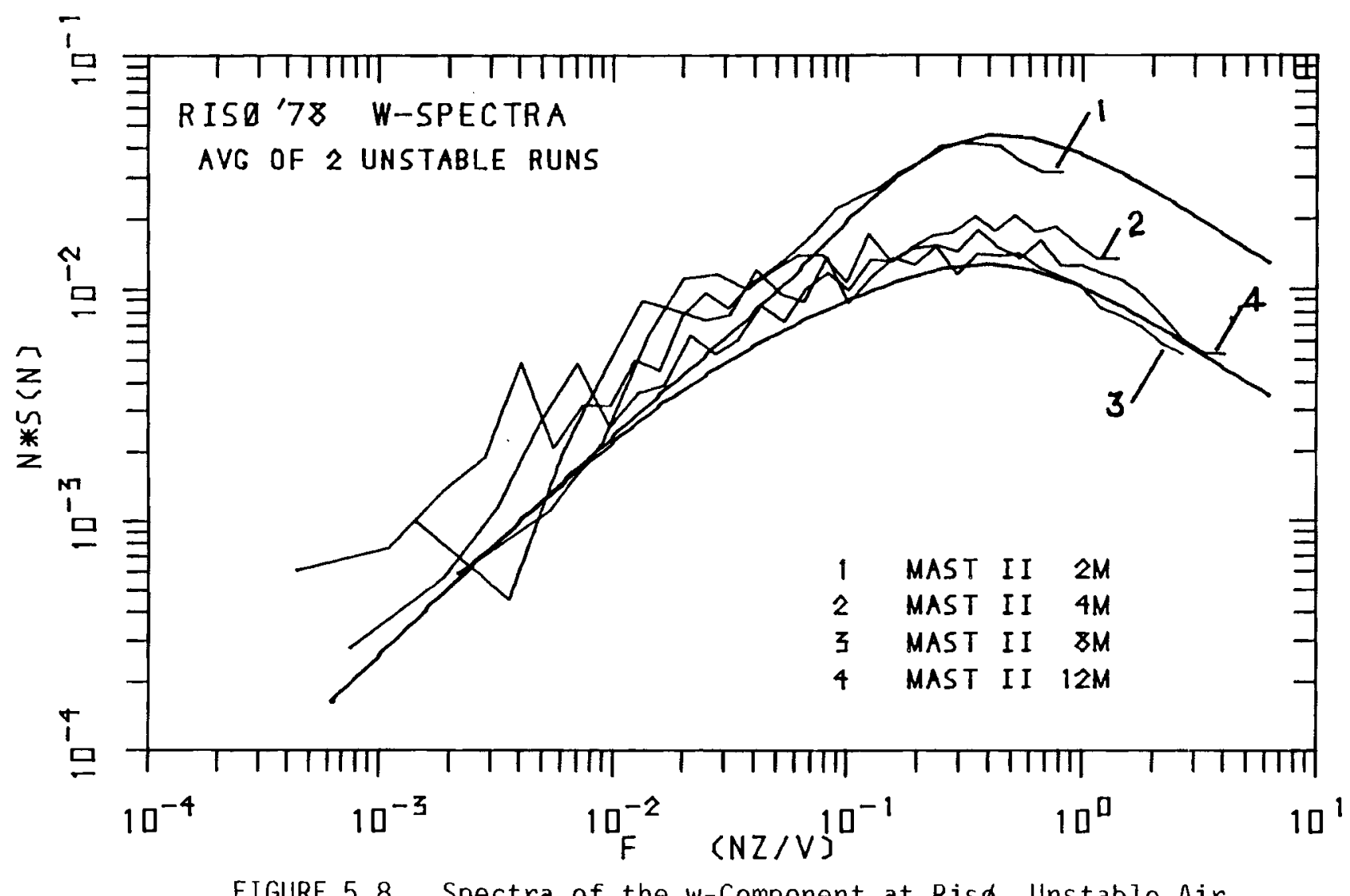

FIGURE 5.8. Spectra of the w-Component at Ris $\phi$, Unstable Air 


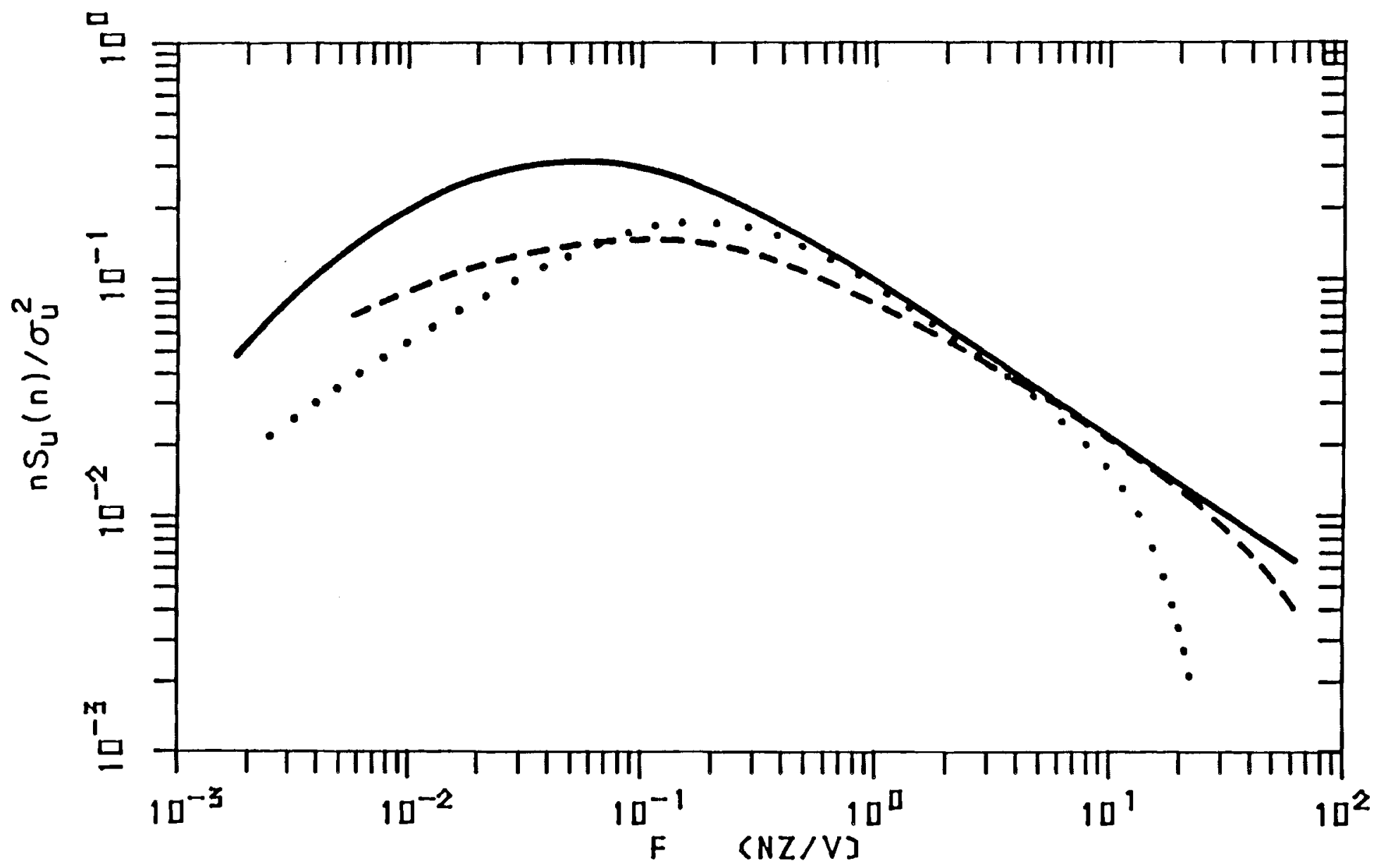

FIGURE 6.1. Normalized Spectra of the u-Component, Black Mountain, Canberra (Computed by Bradley). Dotted, $9 \mathrm{~m}$; dashed, $86 \mathrm{~m}$; solid, Kaimal (1972) model fitted at high frequencies. 


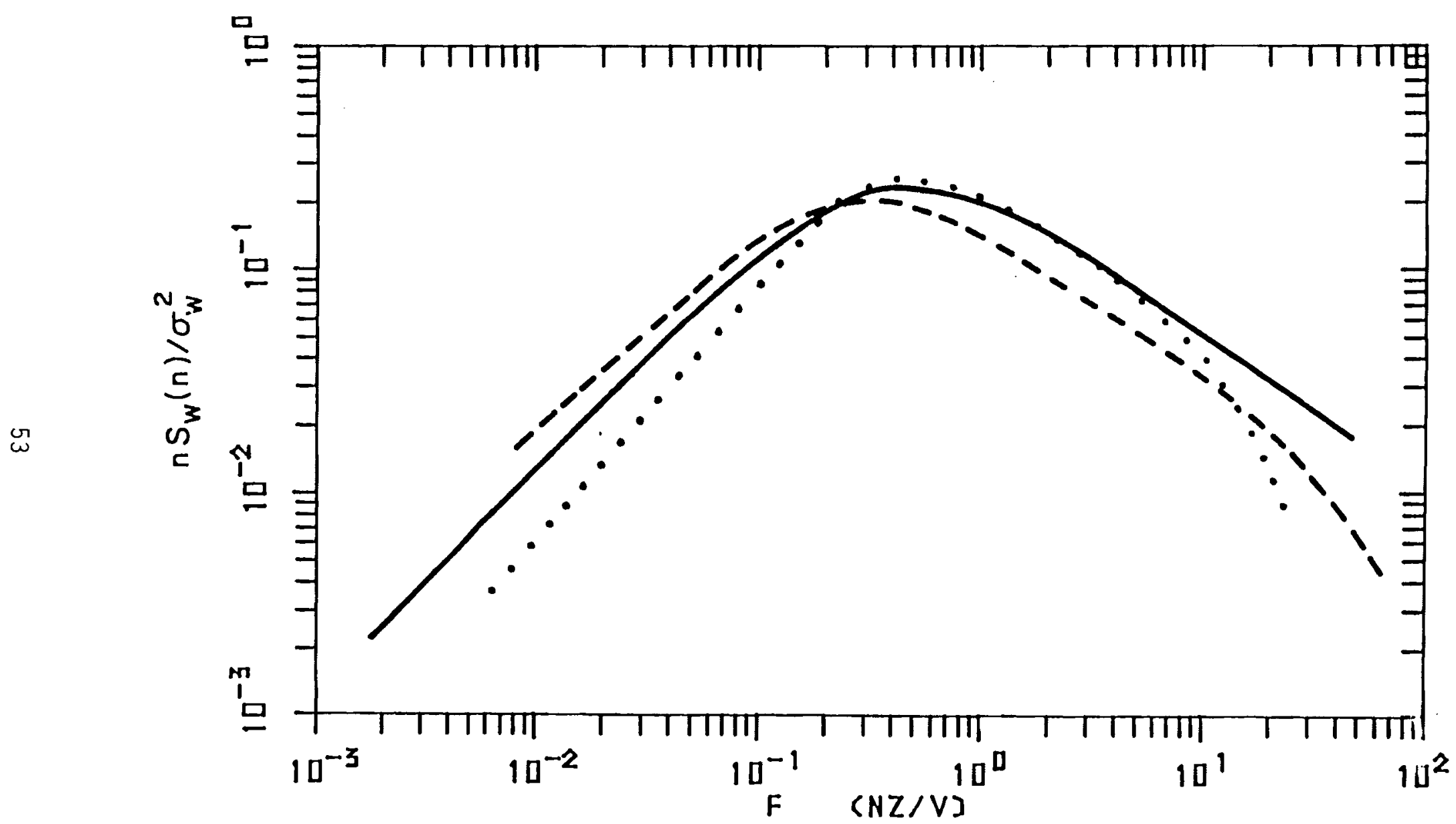

FIGURE 6.2. Normalized Spectra of the w-Component, Black Mountain, Canberra (Computed by Bradley) 


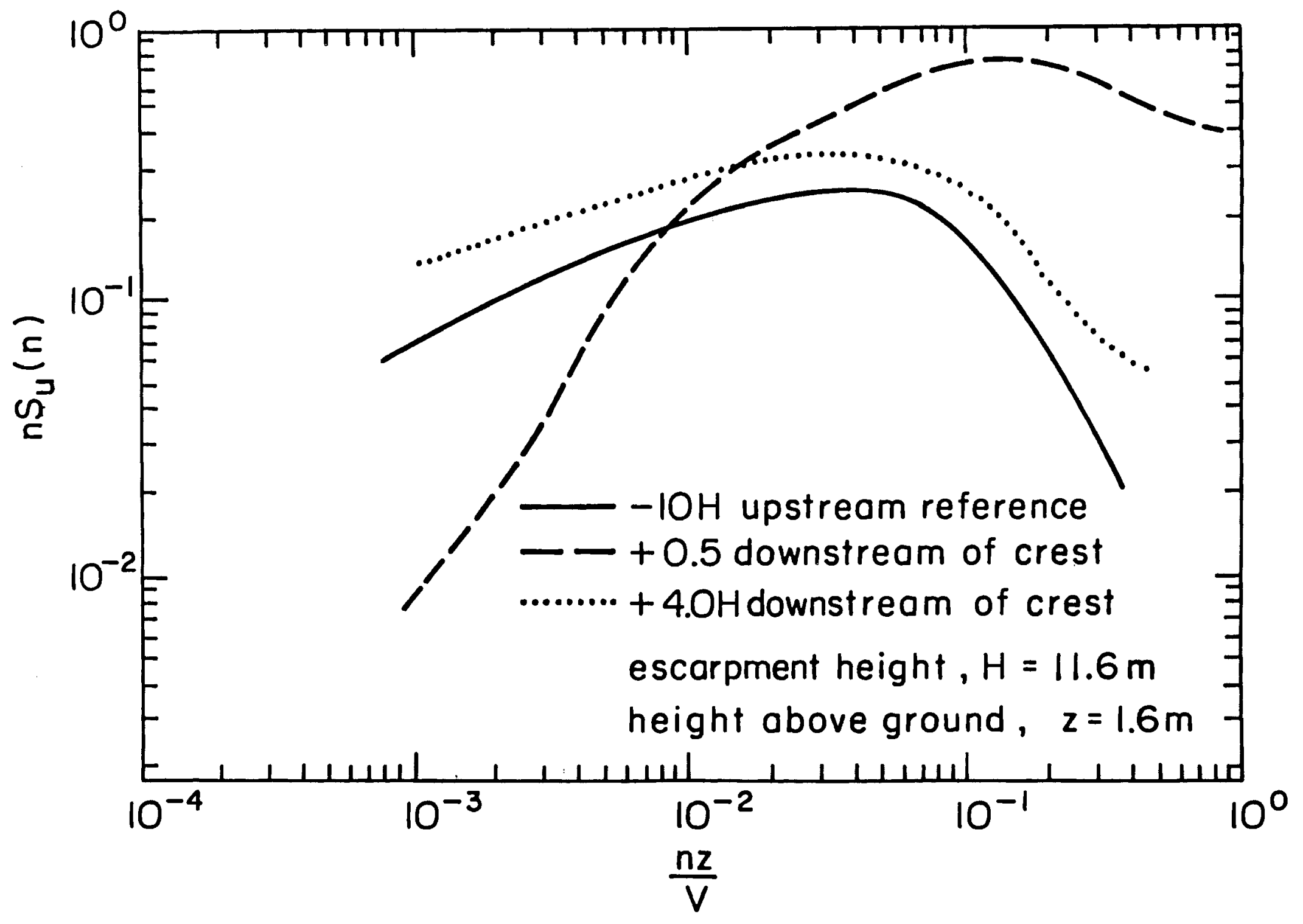

FIGURE 6.4. Spectra of u-Components Influenced by Steep Cliff 


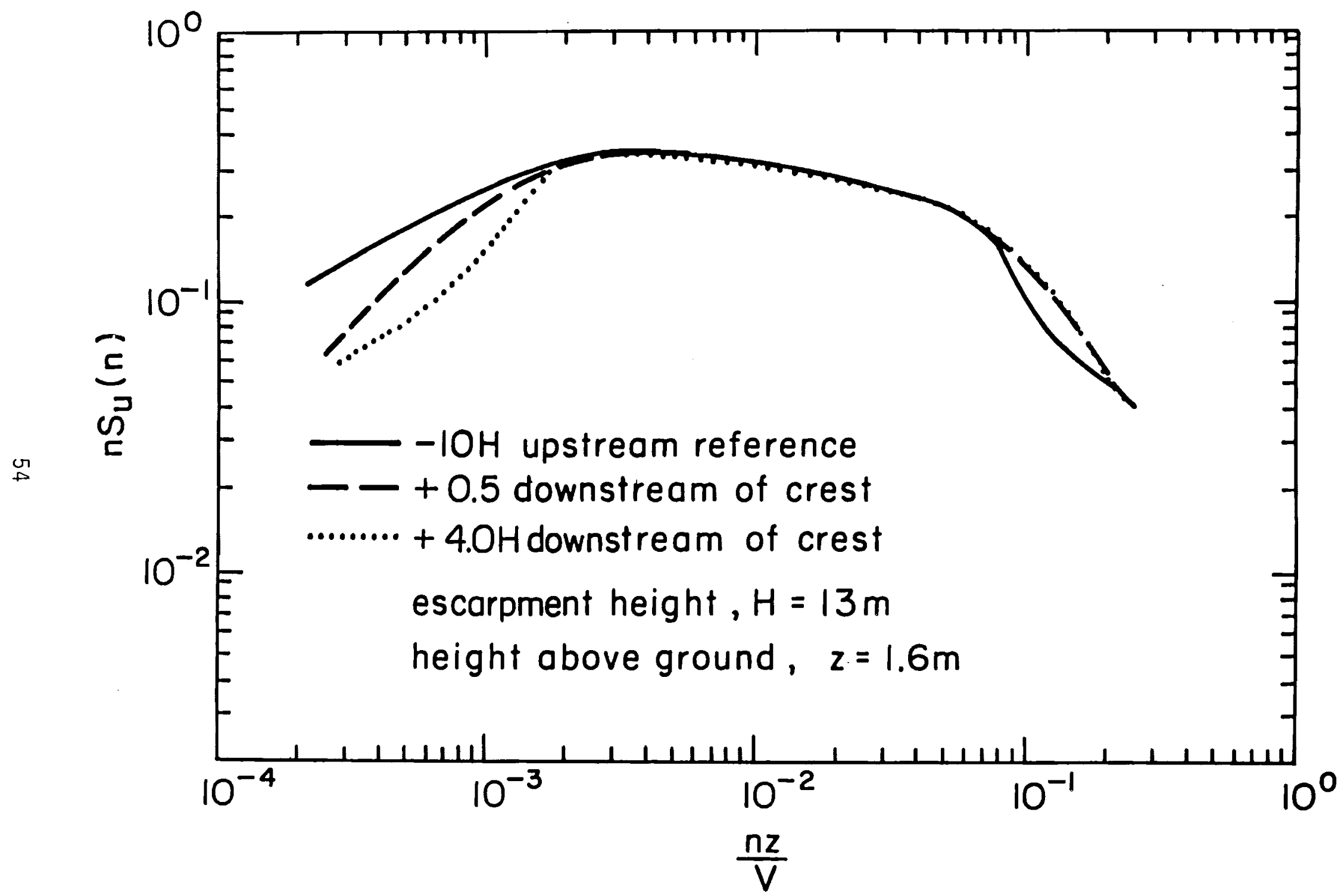

FIGURE 6.3. Spectra of the u-Component Influenced by Sloping Escarpment (After Bowen) 


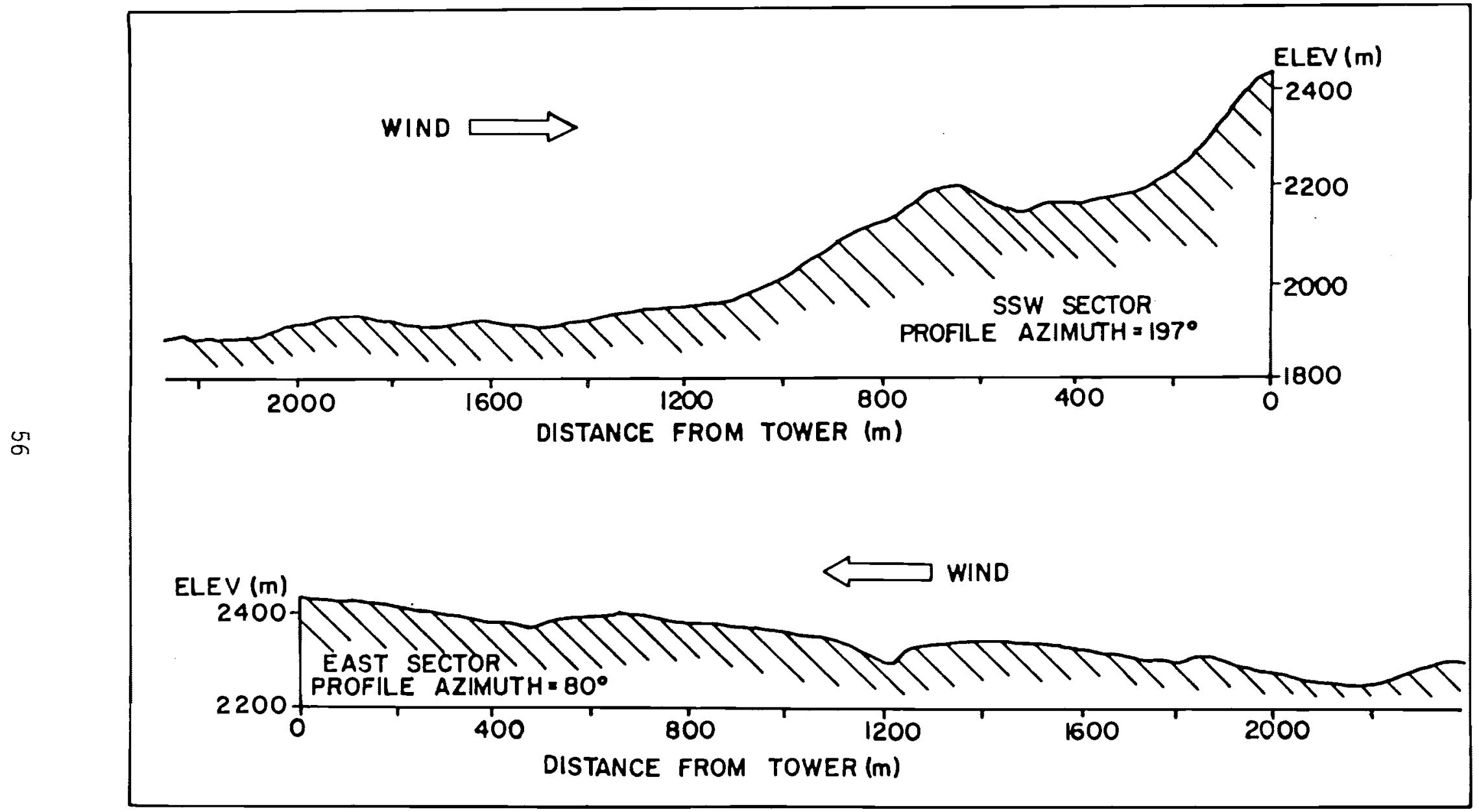

FIGURE 6.5. Terrain Cross Sections at White Sands 

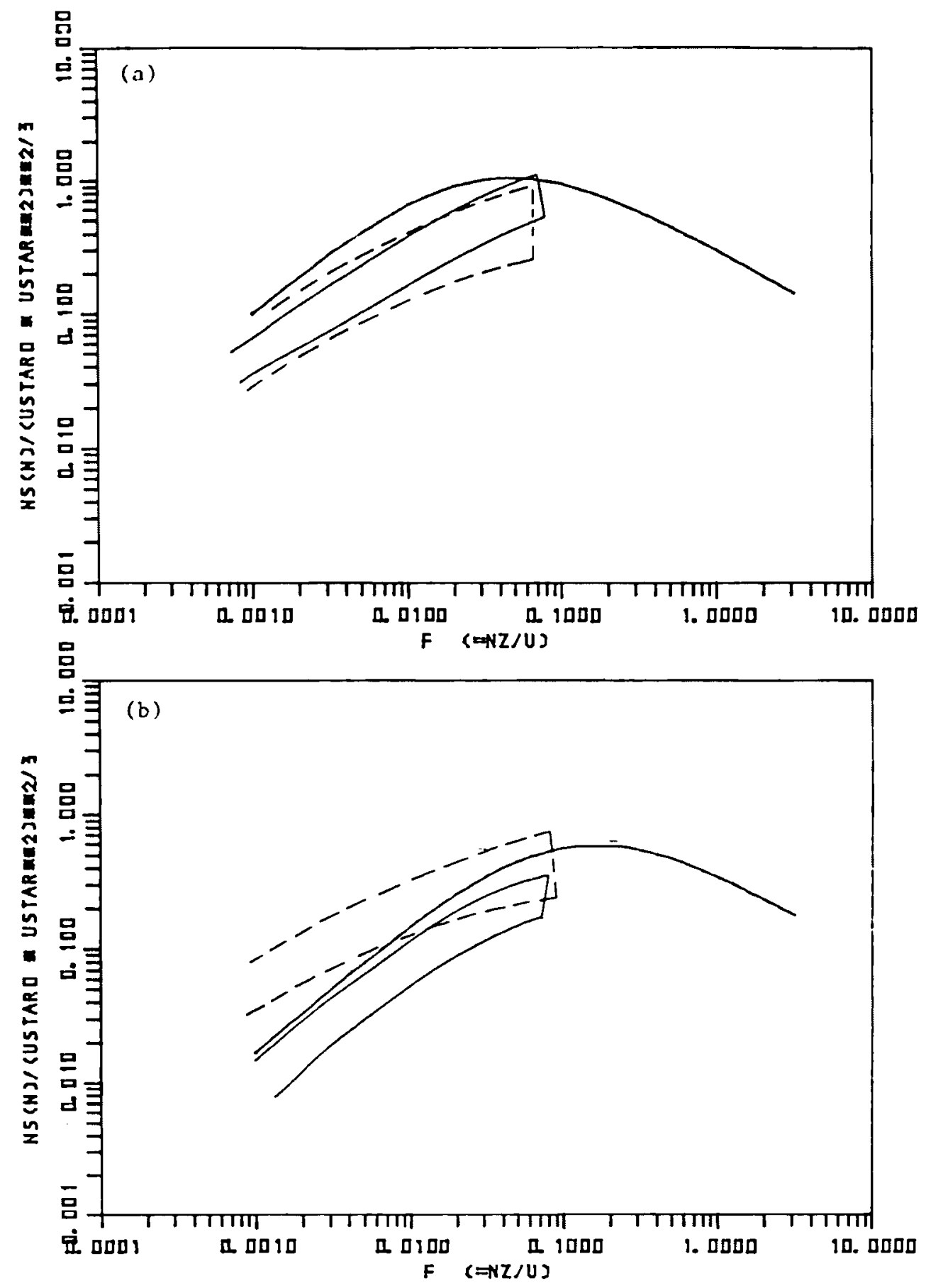

FIGURE 6.6. Envelopes for Normalized u-Spectra (a) and v-Spectra (b) for SSW Winds at White Sands. Solid, $8 \mathrm{~m}$; dashed, $16 \mathrm{~m}$; smooth curve, Kaimal (1972) model. 

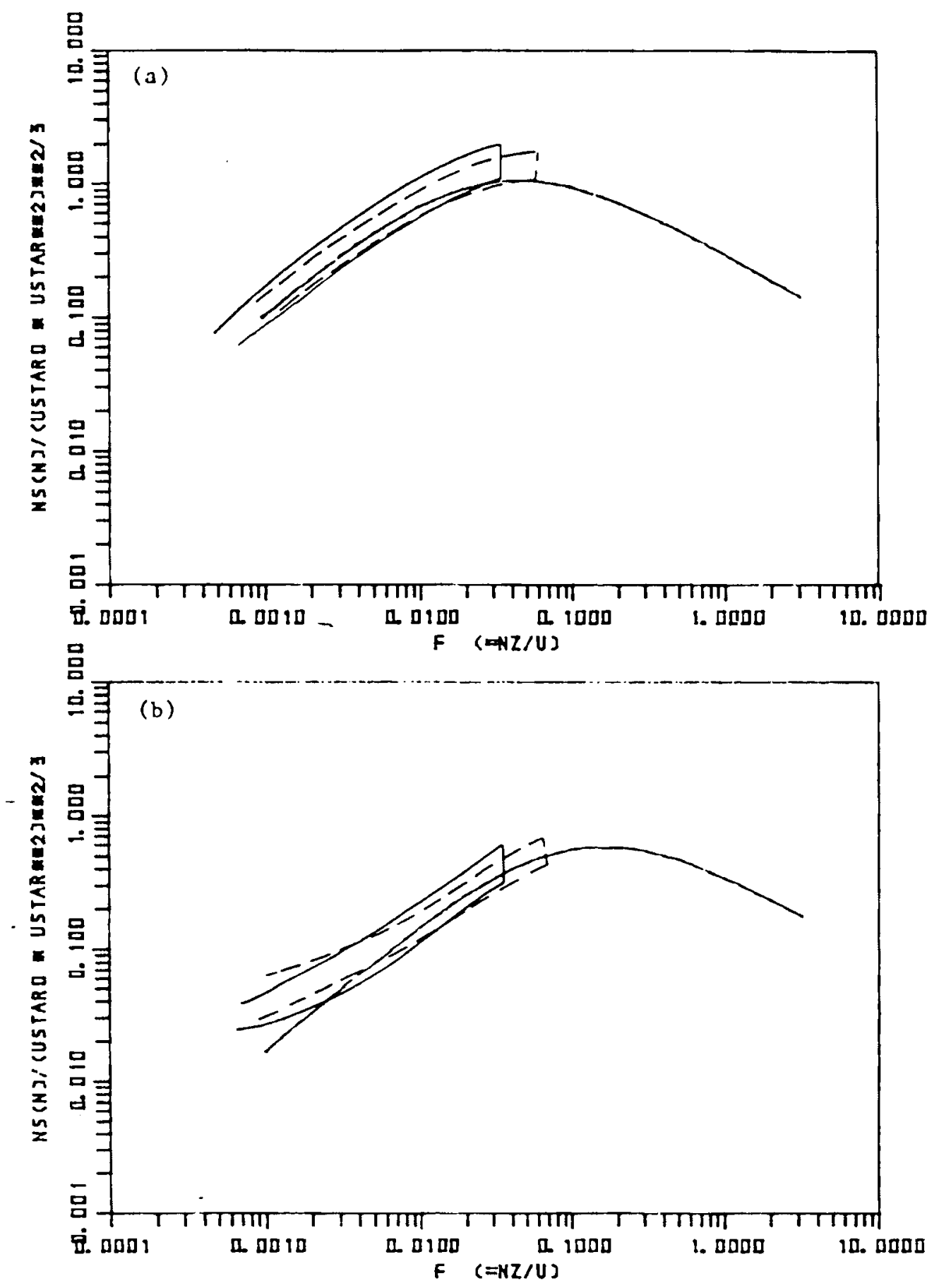

FIGURE 6.7. Terrain Cross Sections at White Sands, East Winds 


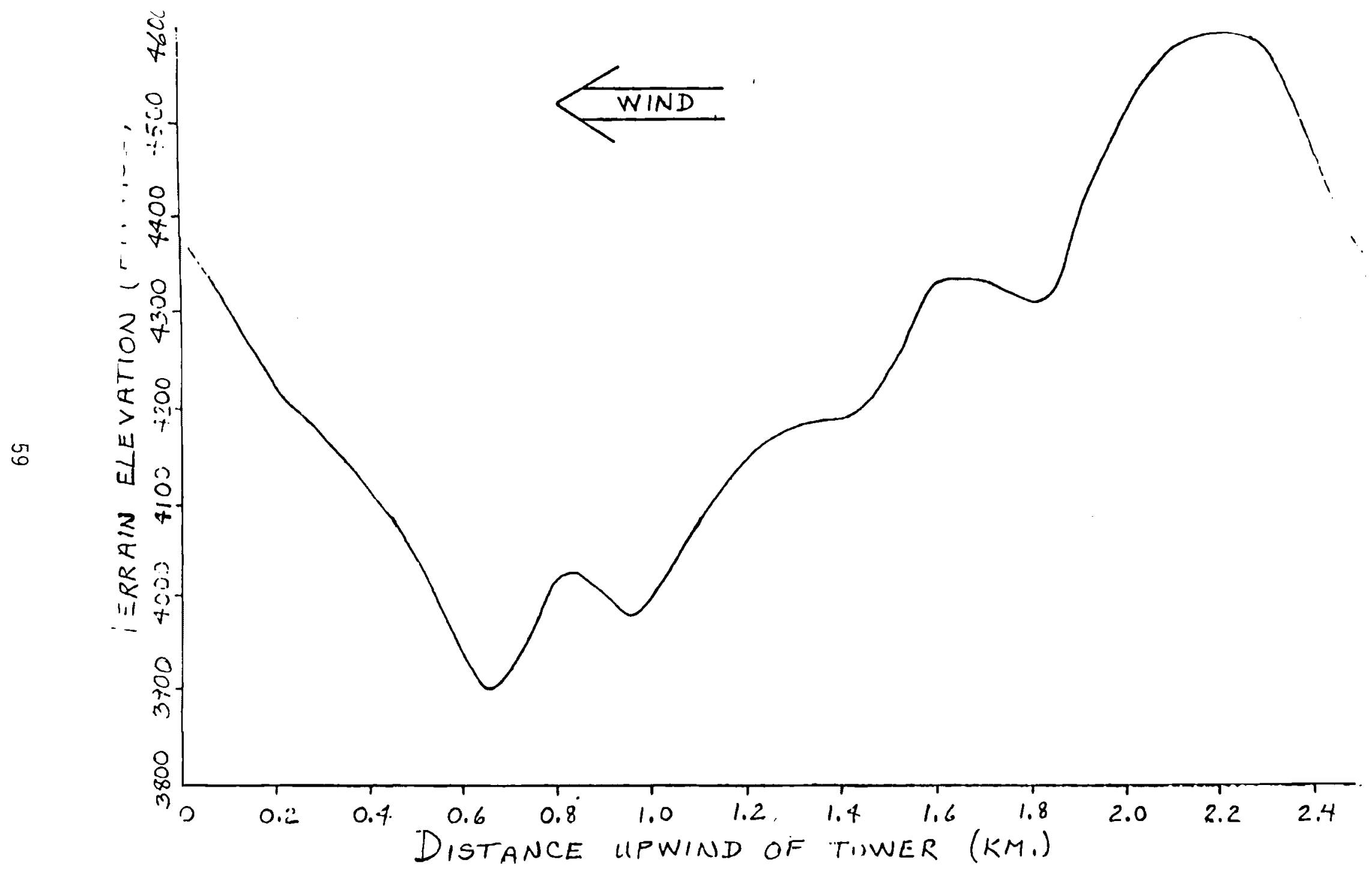

FIGURE 6.8. Terrain Cross Section at Boone, NC, West Winds 


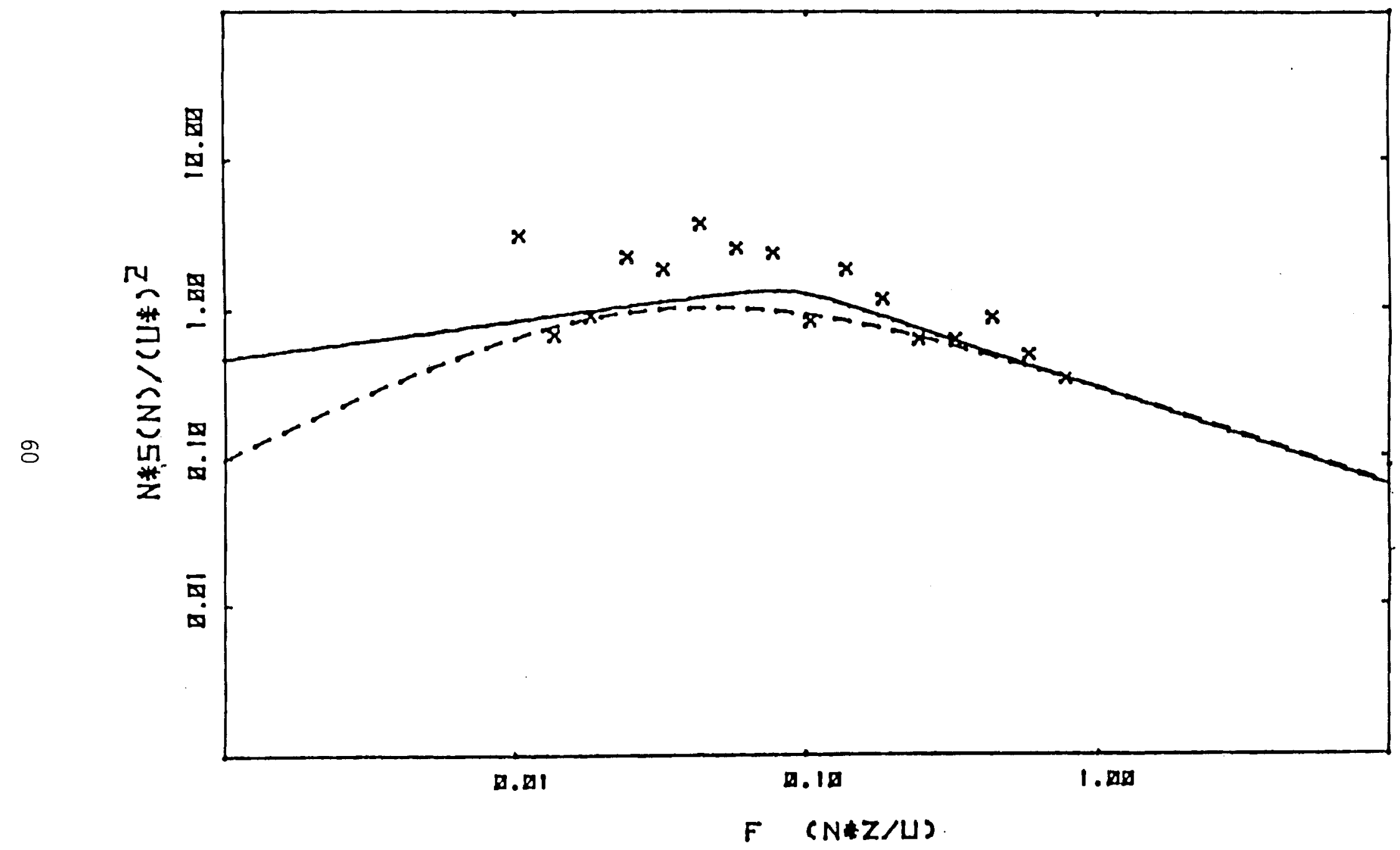

FIGURE 6.9. Spectrum of u-Component at Boone, West Winds, at $18 \mathrm{~m}$. Smooth curve, model by Dutton et a1. (1979); dashed, Kaimal (1972). 


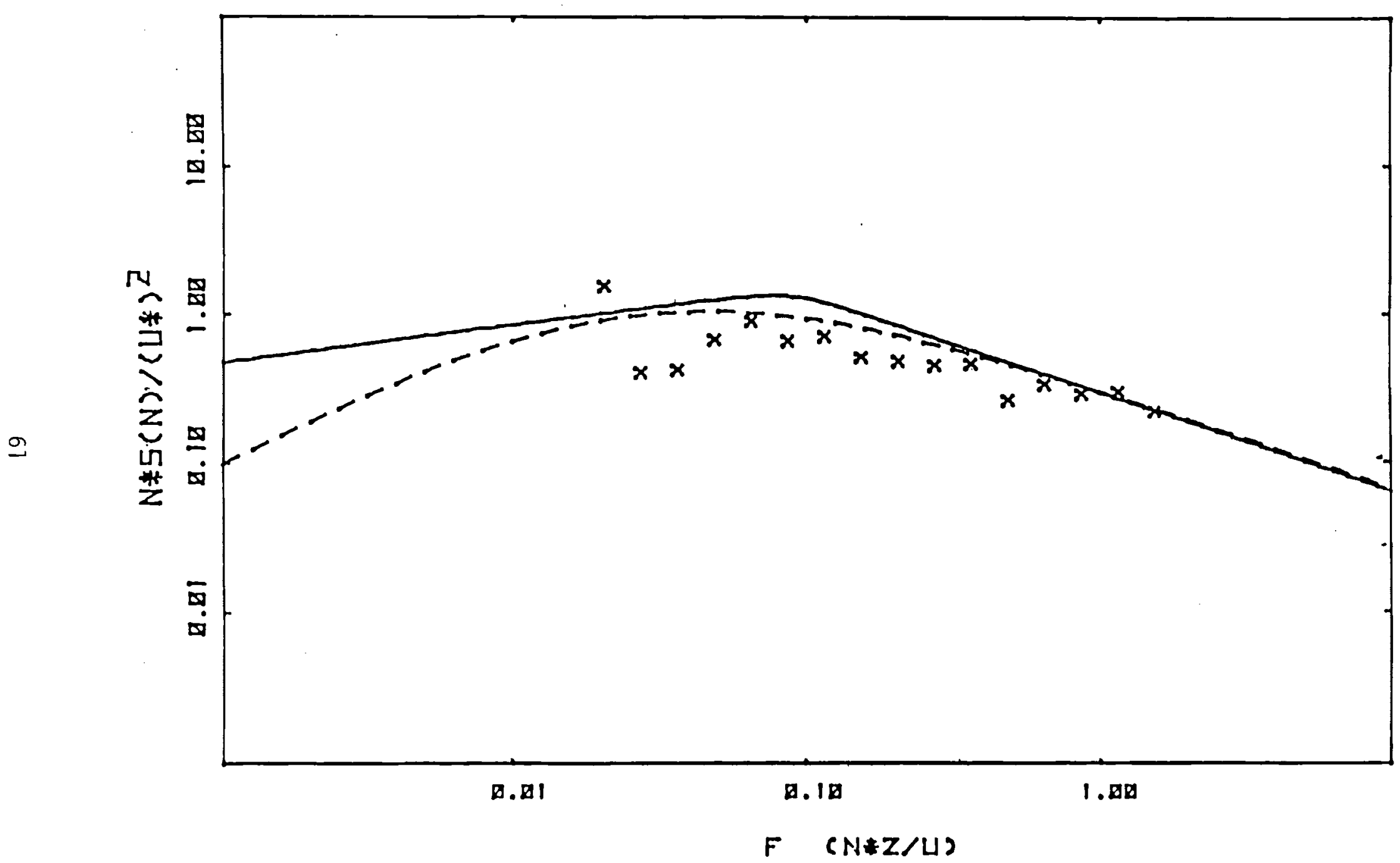

FIGURE 6.10. Spectrum of u-Component at Boone, West Winds, at $46 \mathrm{~m}$ 


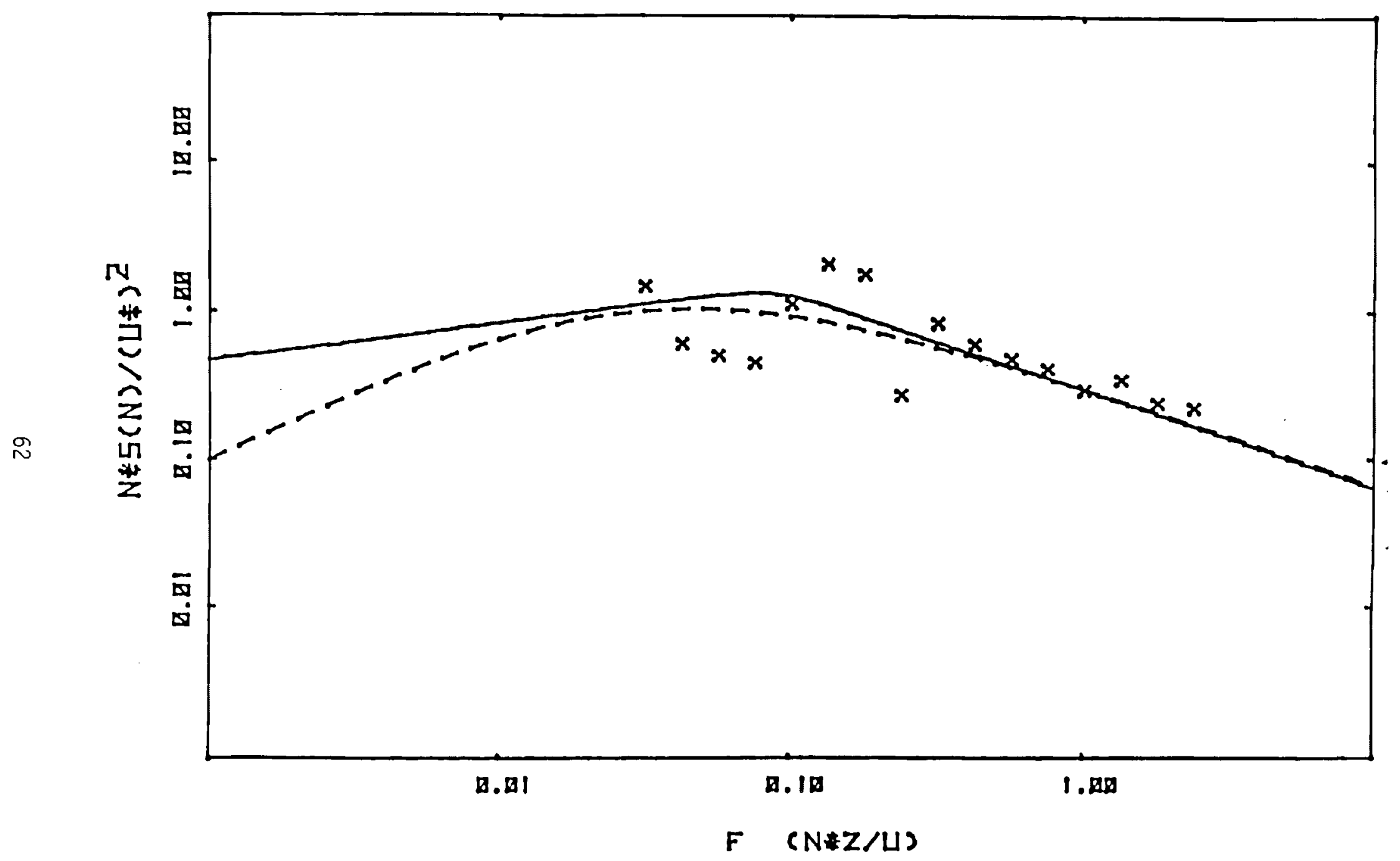

FIGURE 6.11. Spectrum of u-Component at Boone, West Winds, at $76 \mathrm{~m}$ 


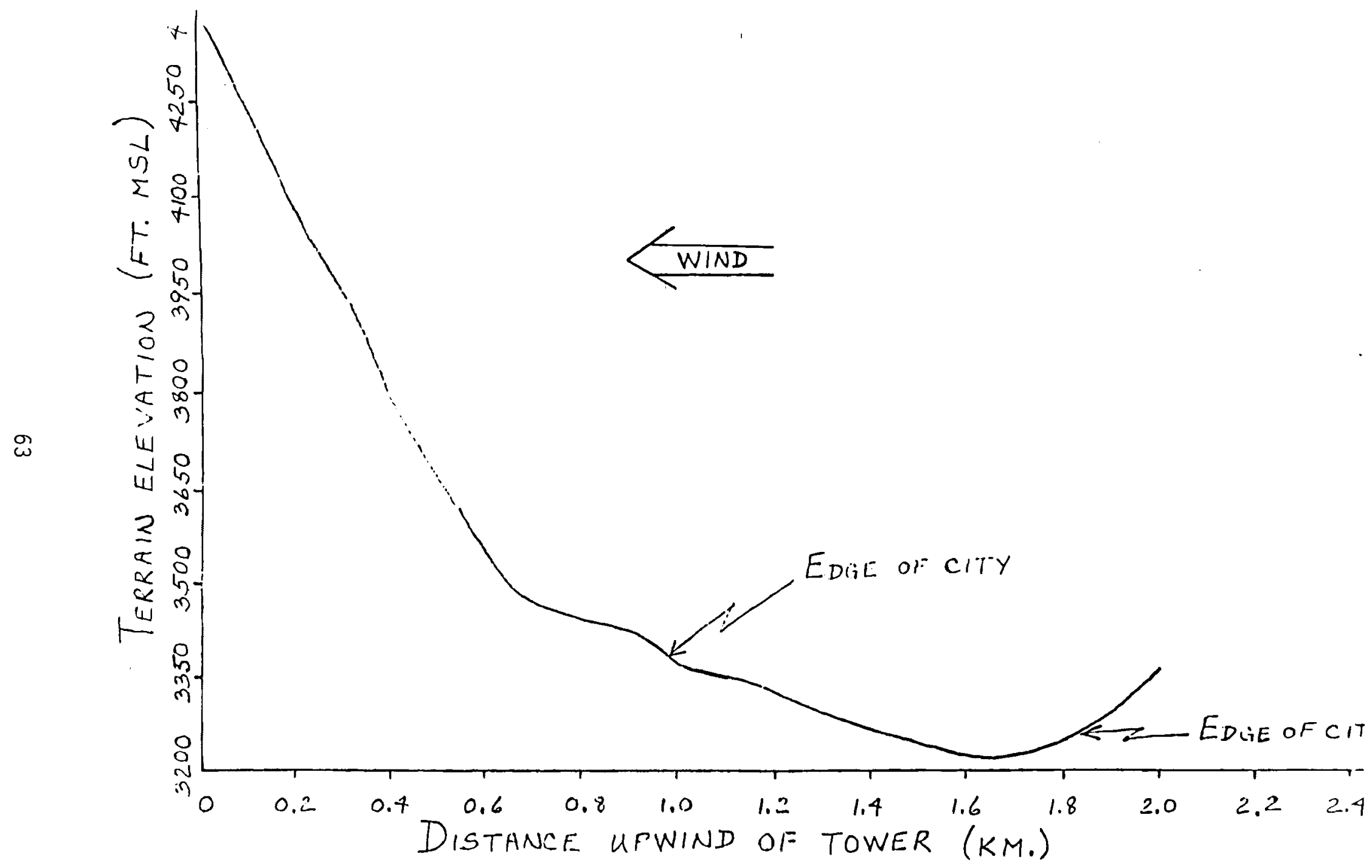

FIGURE 6.12. Terrain Cross Section at Boone, NC, SSW Winds 


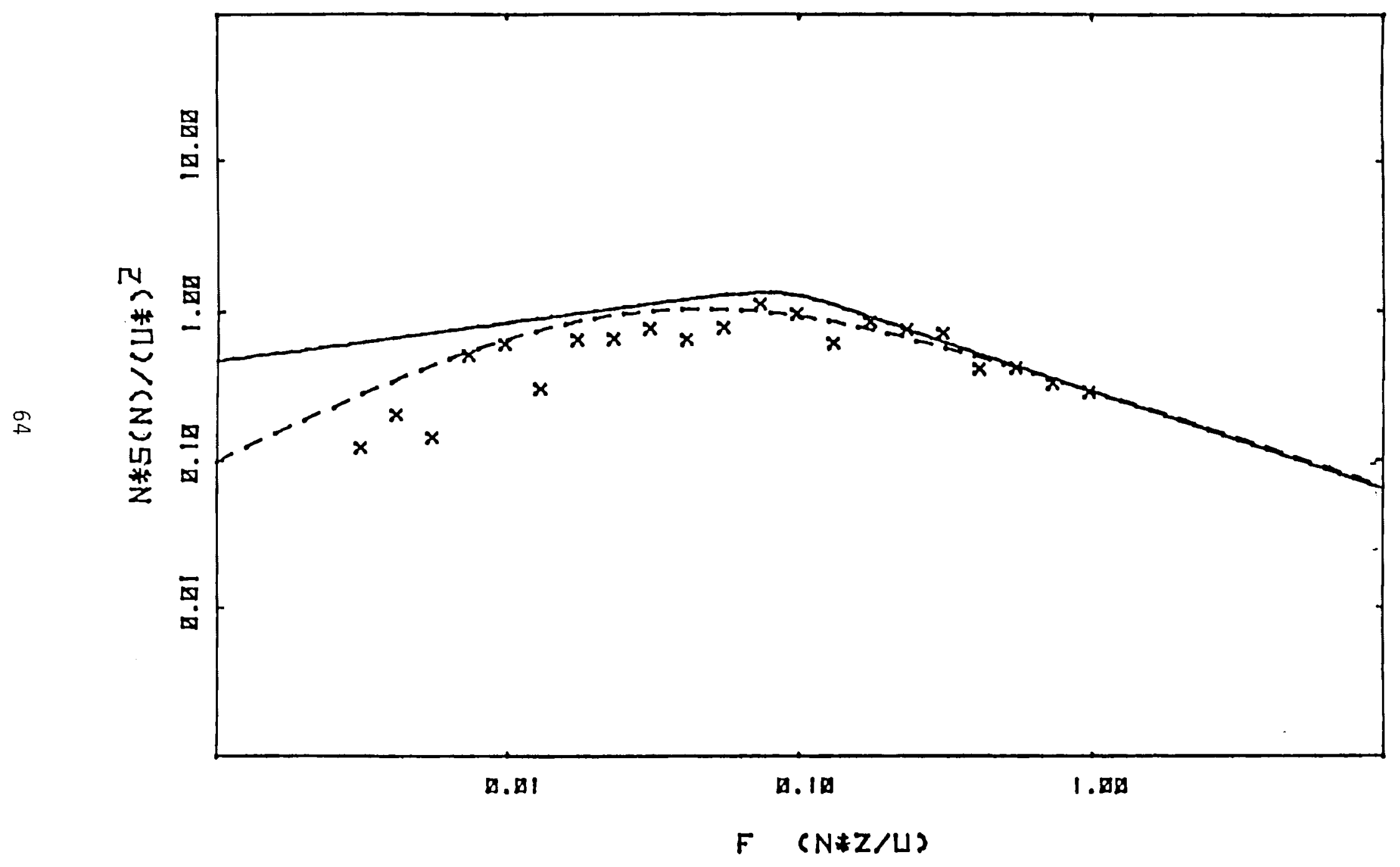

FIGURE 6.13. Spectrum of u-Component at Boone, SSW Winds, at $18 \mathrm{~m}$ 


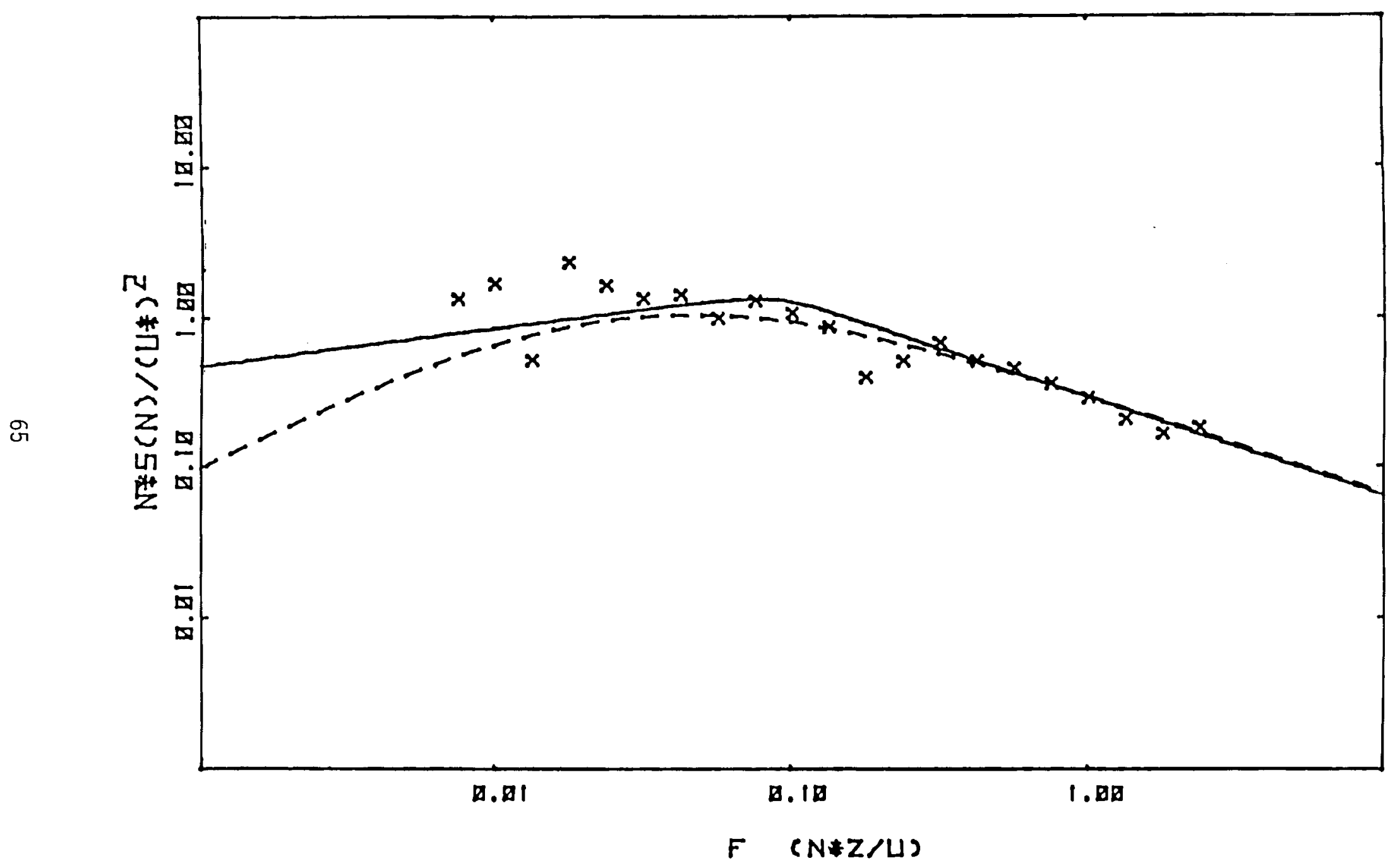

FIGURE 6.14. Spectrum of u-Component at Boone, SSW Winds, at $76 \mathrm{~m}$ 


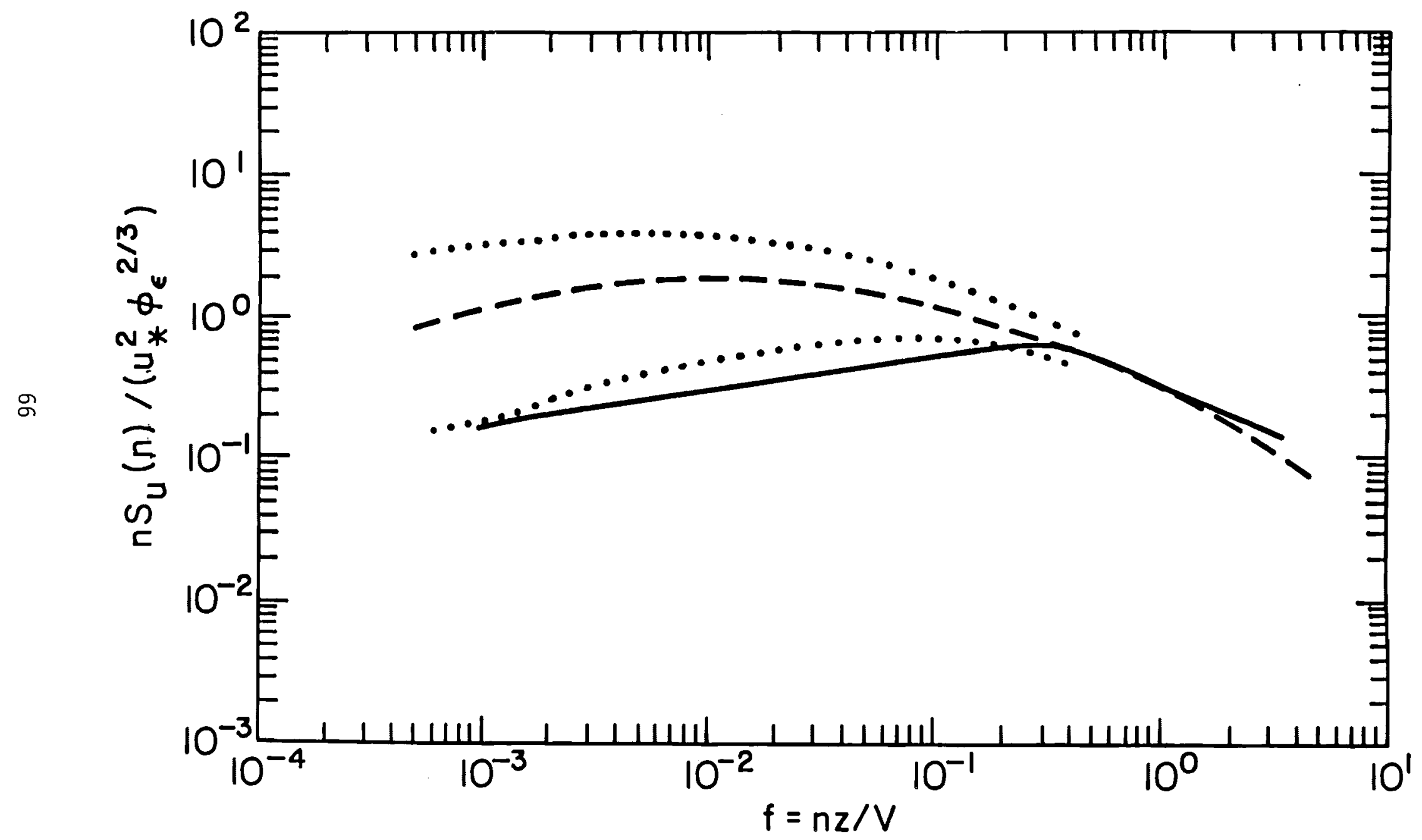

FIGURE 7.1. Average u-Spectrum at Rock Springs, Stable Air. Dashed, mean; dotted, extremes; solid, Shirer and Rossi (1981). 


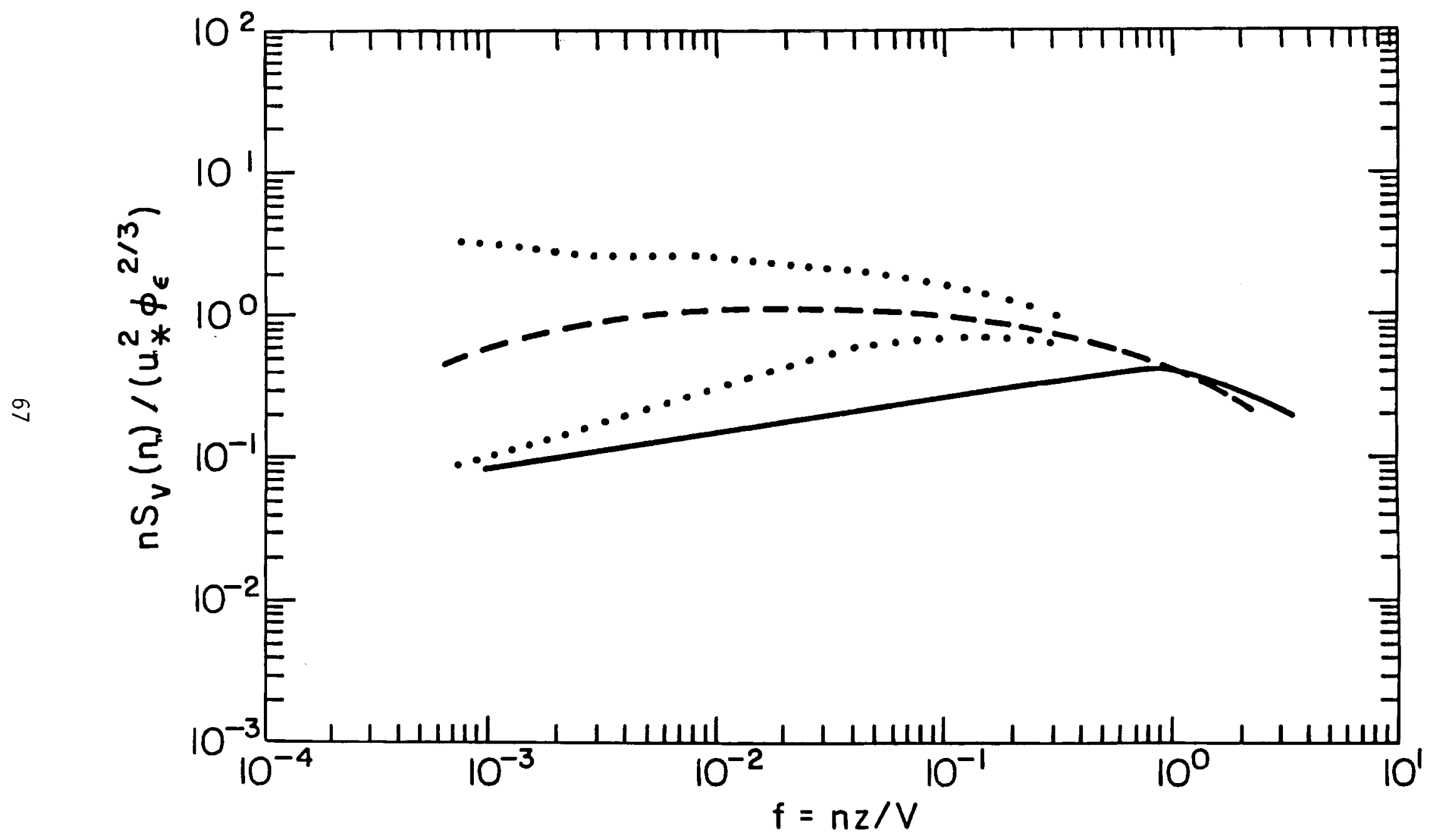

FIGURE 7.2. Average v-Spectrum at Rock Springs, Stable Air 


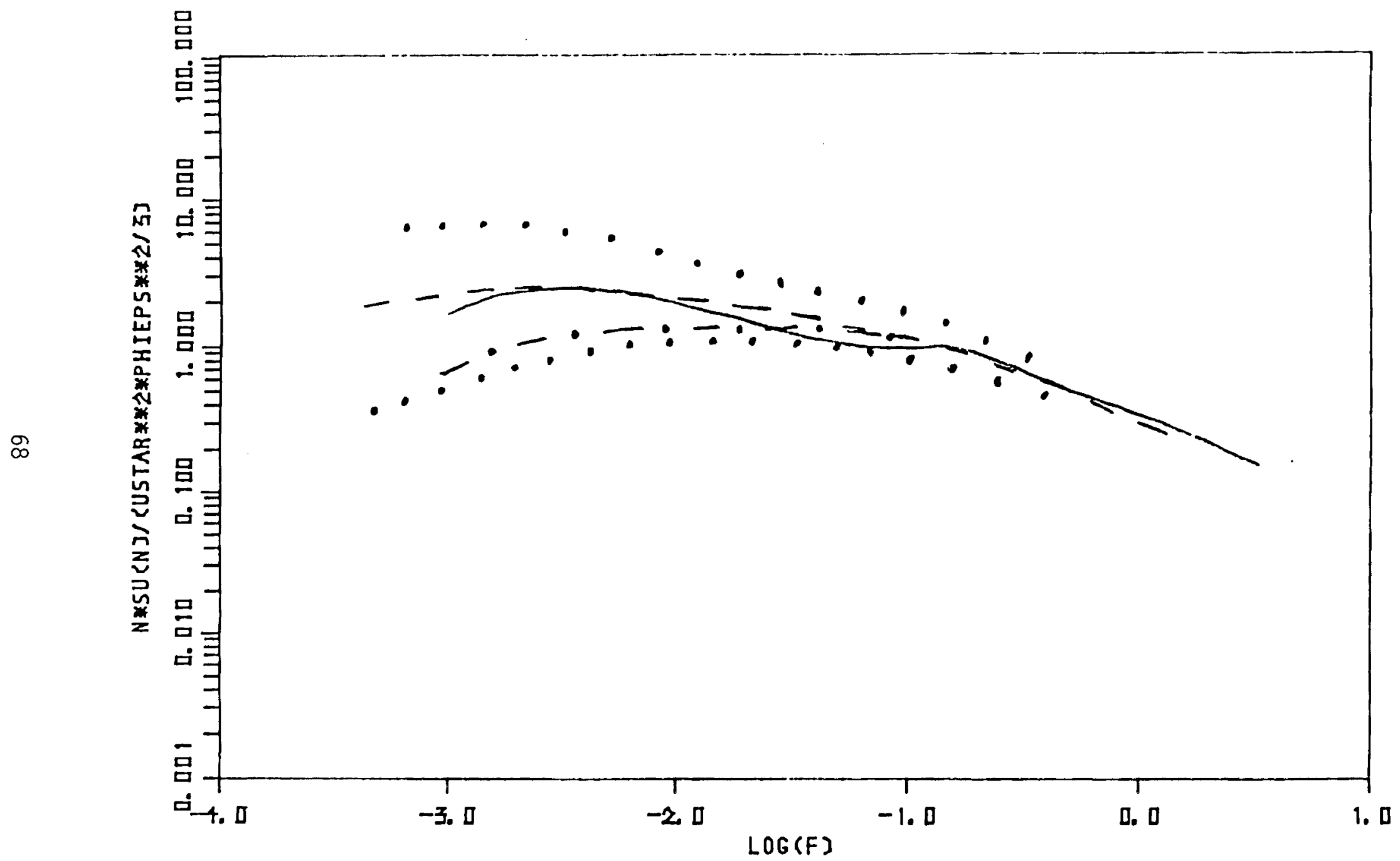

FIGURE 7.3. Average U-Spectrum at Rock Springs, $-0.1<z, L<0$. Dashed, mean; dotted, extremes; solid, Shiver and Ross (1981). Also Højstrup (1981). 


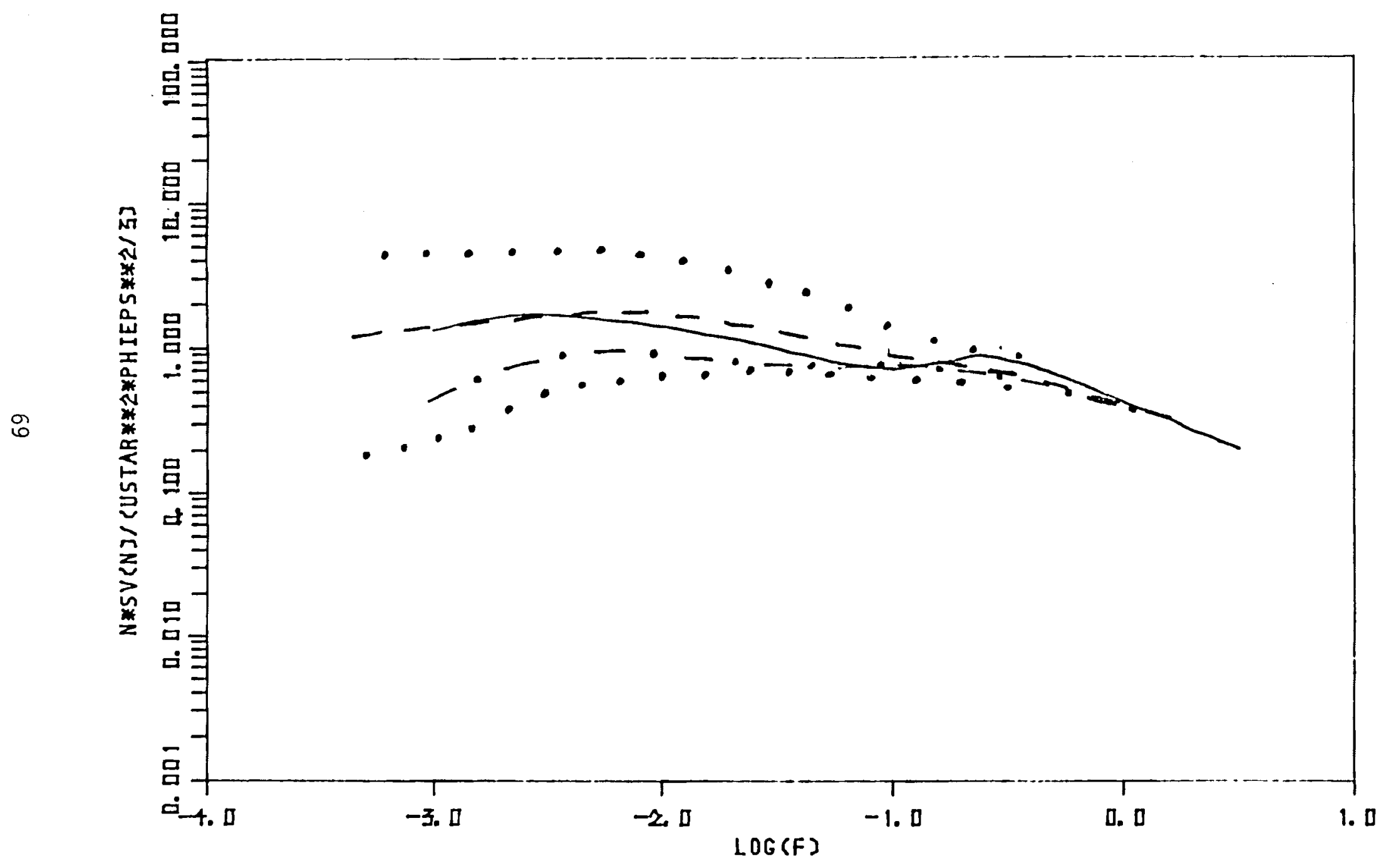

FIGURE 7.4. Average $v$-Spectrum at Rock Springs, $-0.1<z / L<0$ 


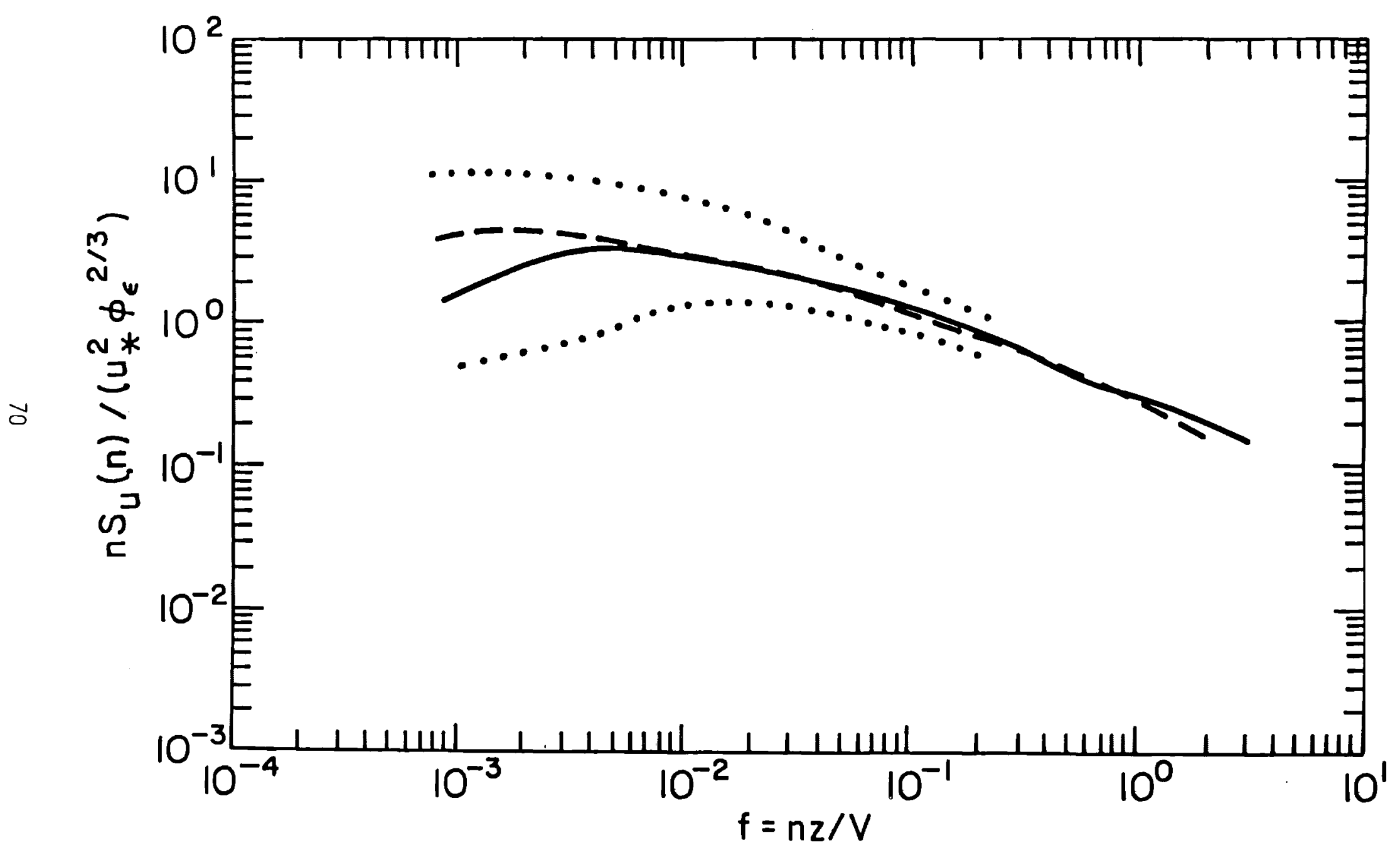

FIGURE 7.5. Average u-Spectrum at Rock Springs, $z / L<-0.1$ 


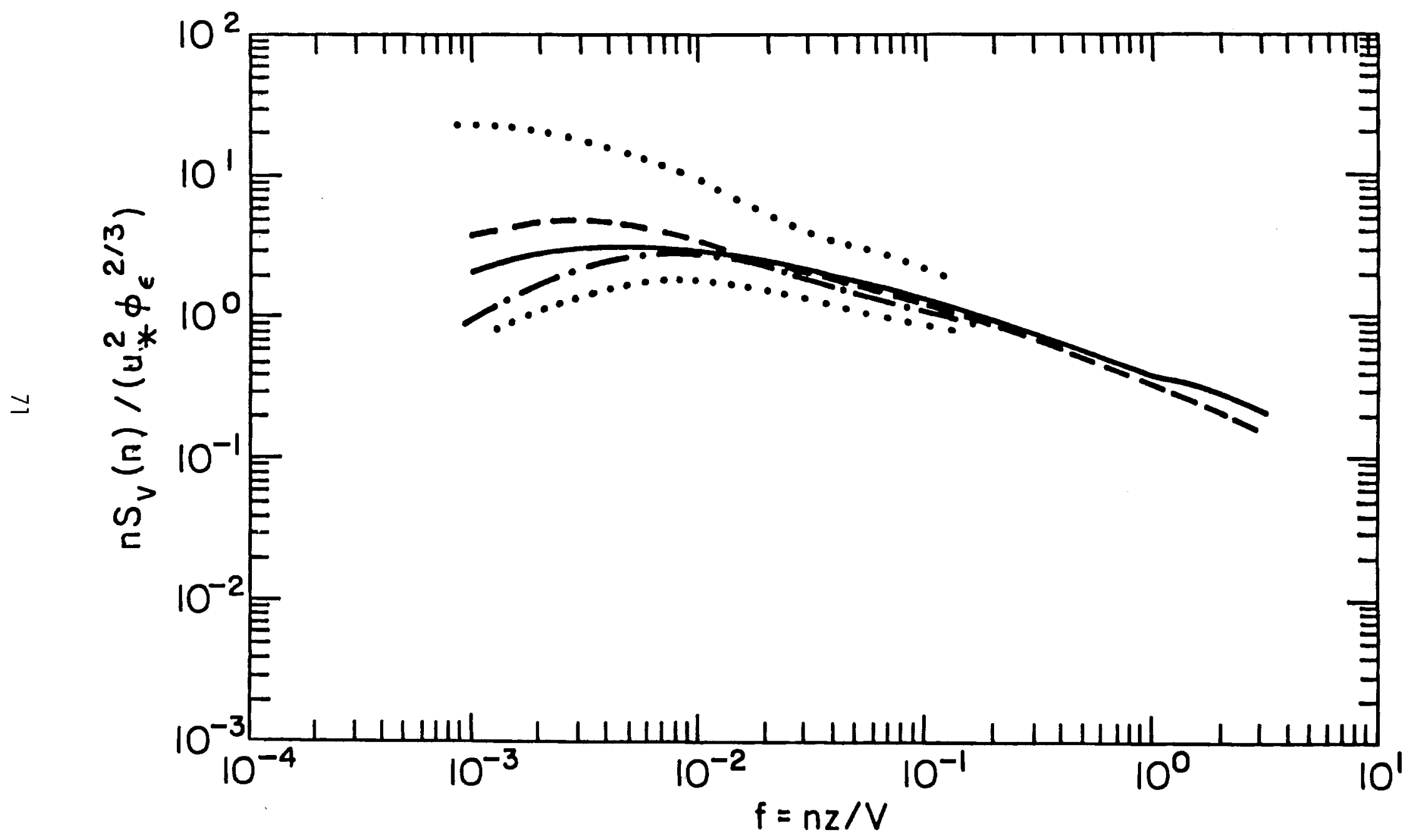

FIGURE 7.6. Average $v$-Spectrum at Rock Springs, $z / L<-0.1$ 


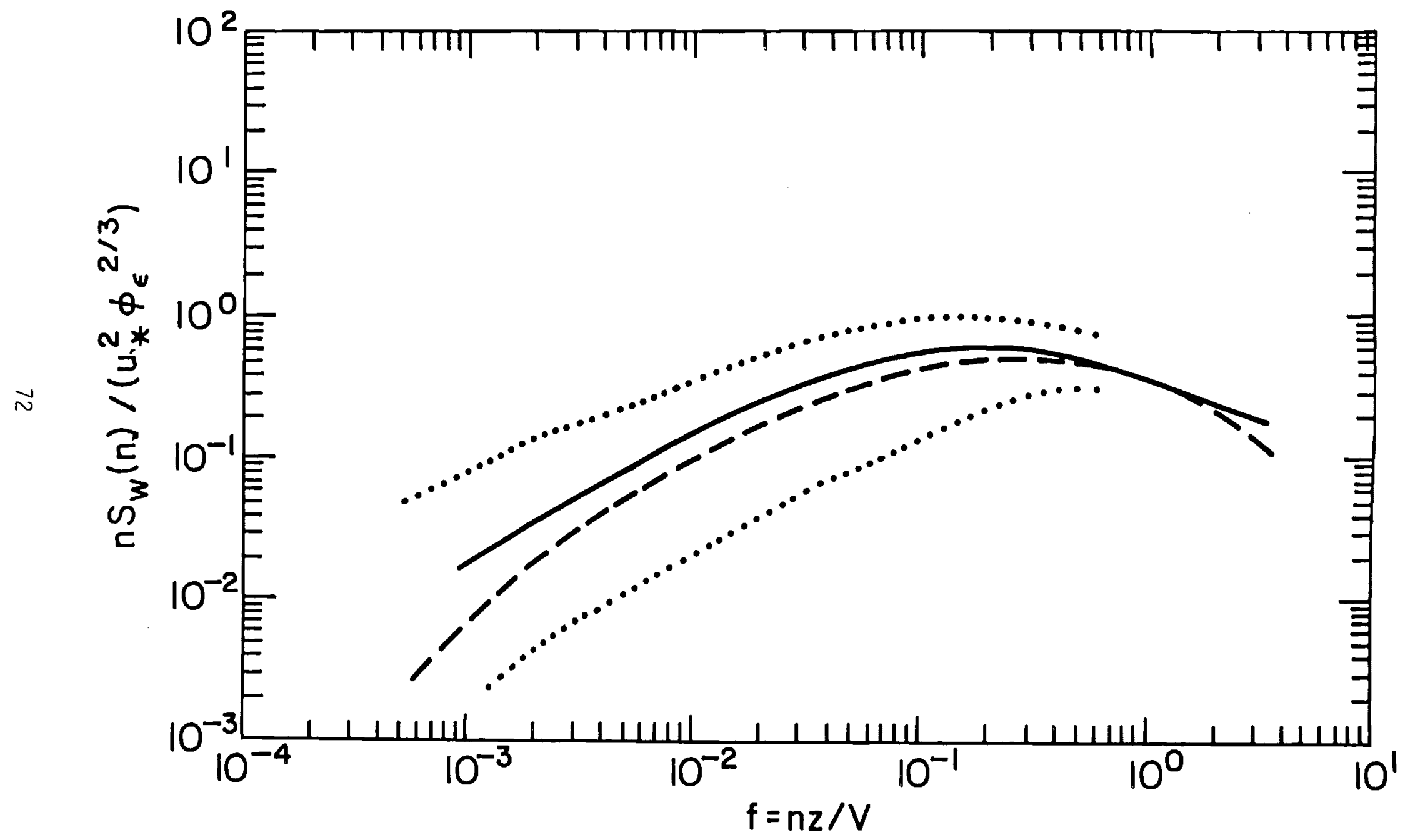

FIGURE 7.7. Average w-Spectrum at Rock Springs, Stable Air 


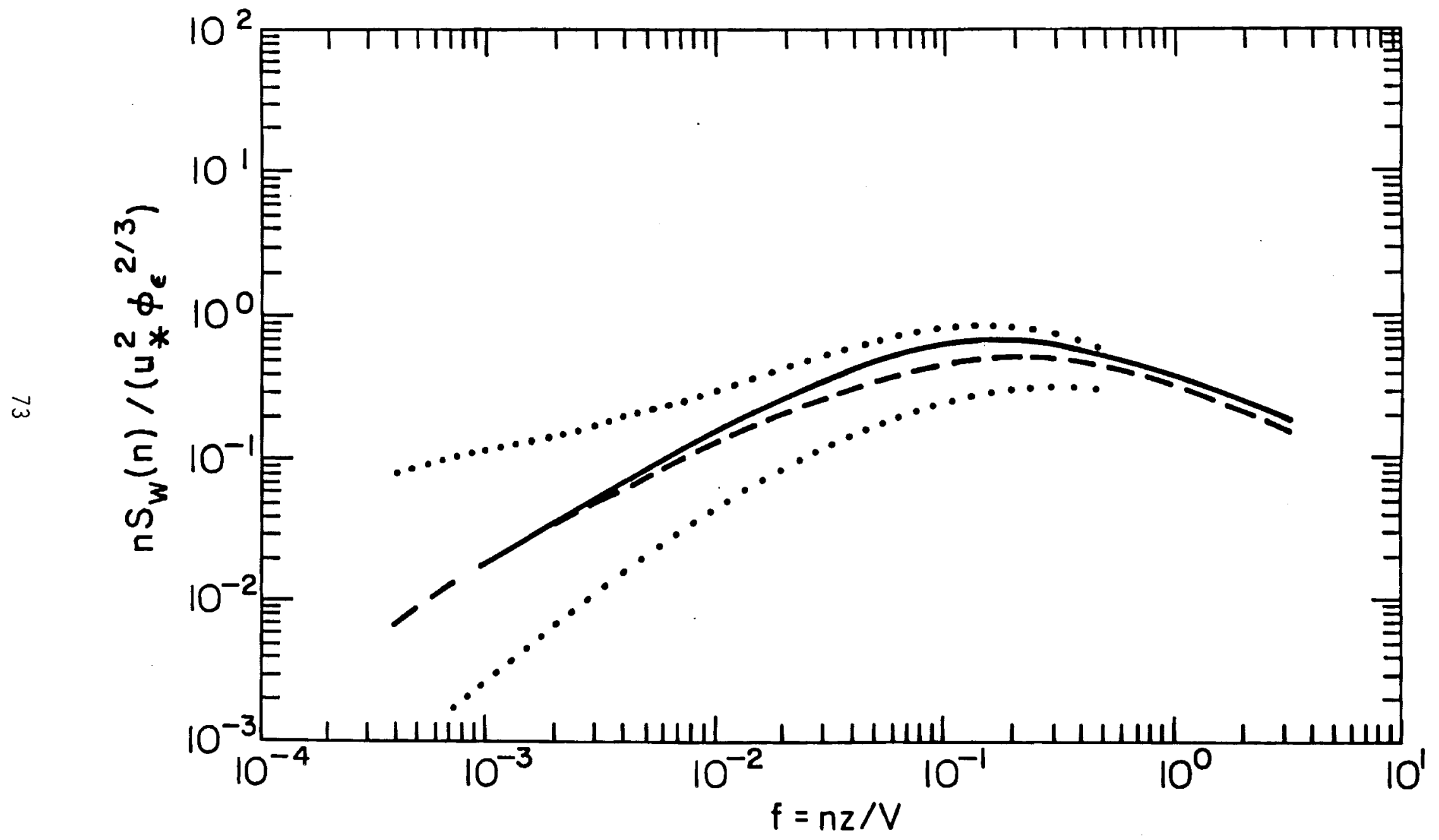

FIGURE 7.8. Average w-Spectrum at Rock Springs, Unstable Air 


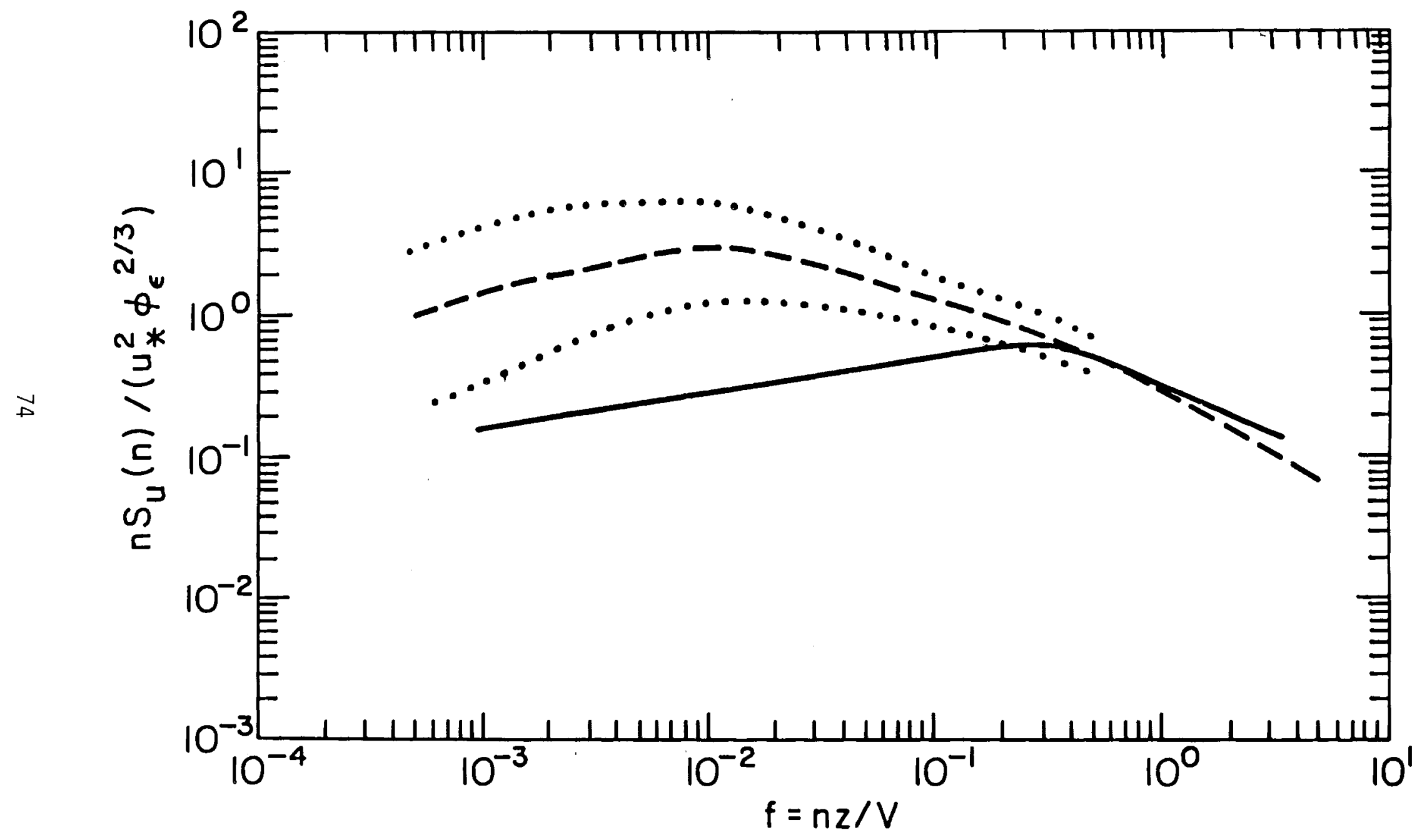

FIGURE 7.9. Average u-Spectrum at Rock Springs, Stable Air, Mountain Trajectories 


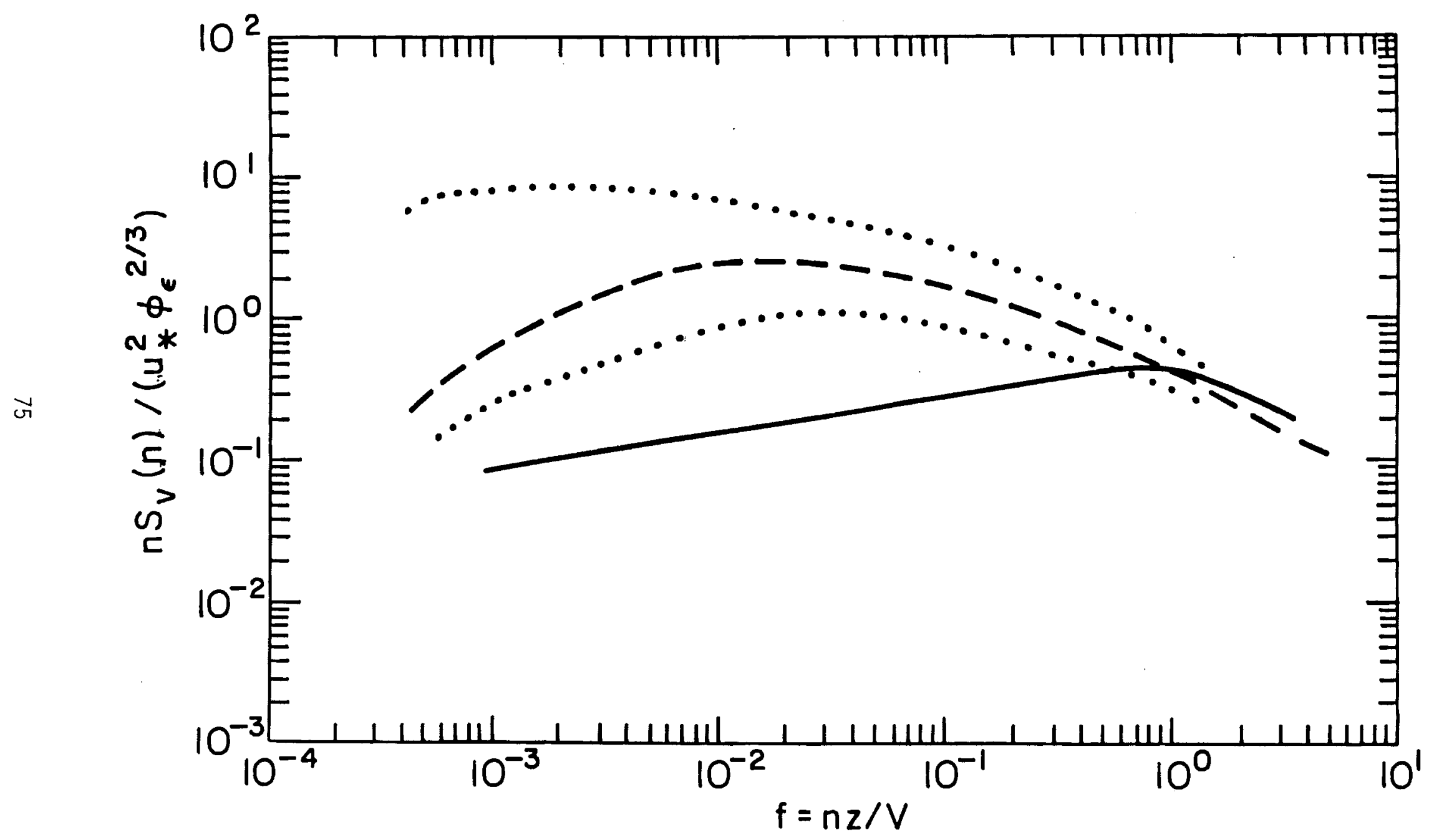

FIGURE 7.10. Average v-Spectrum at Rock Springs, Stable Air, Mountain Trajectories 


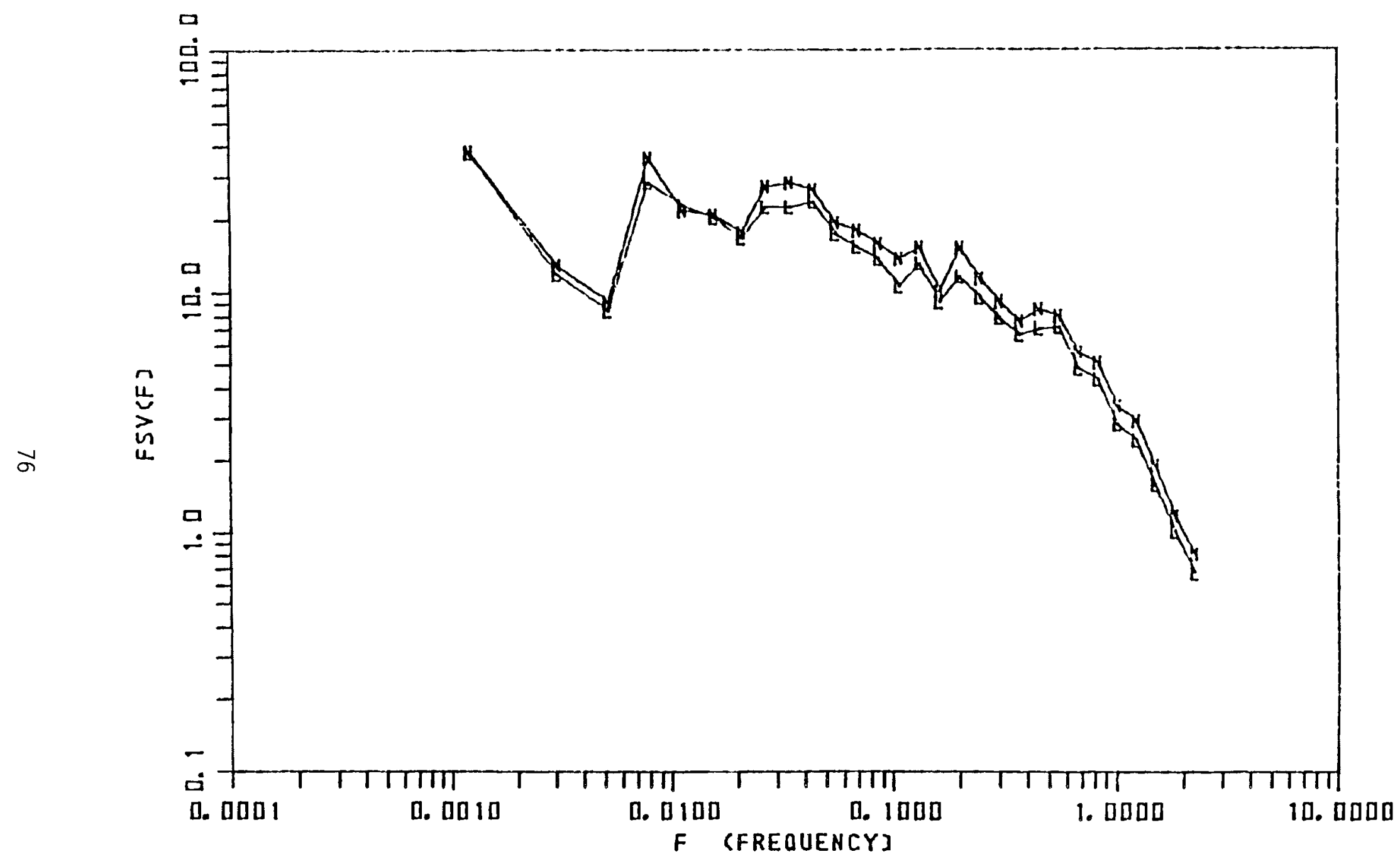

FIGURE 8.1. Spectral Density Functions for the Longitudinal Component of the and $L$ denotes the linear approximation $v(t)=2 U u^{\prime}$. 


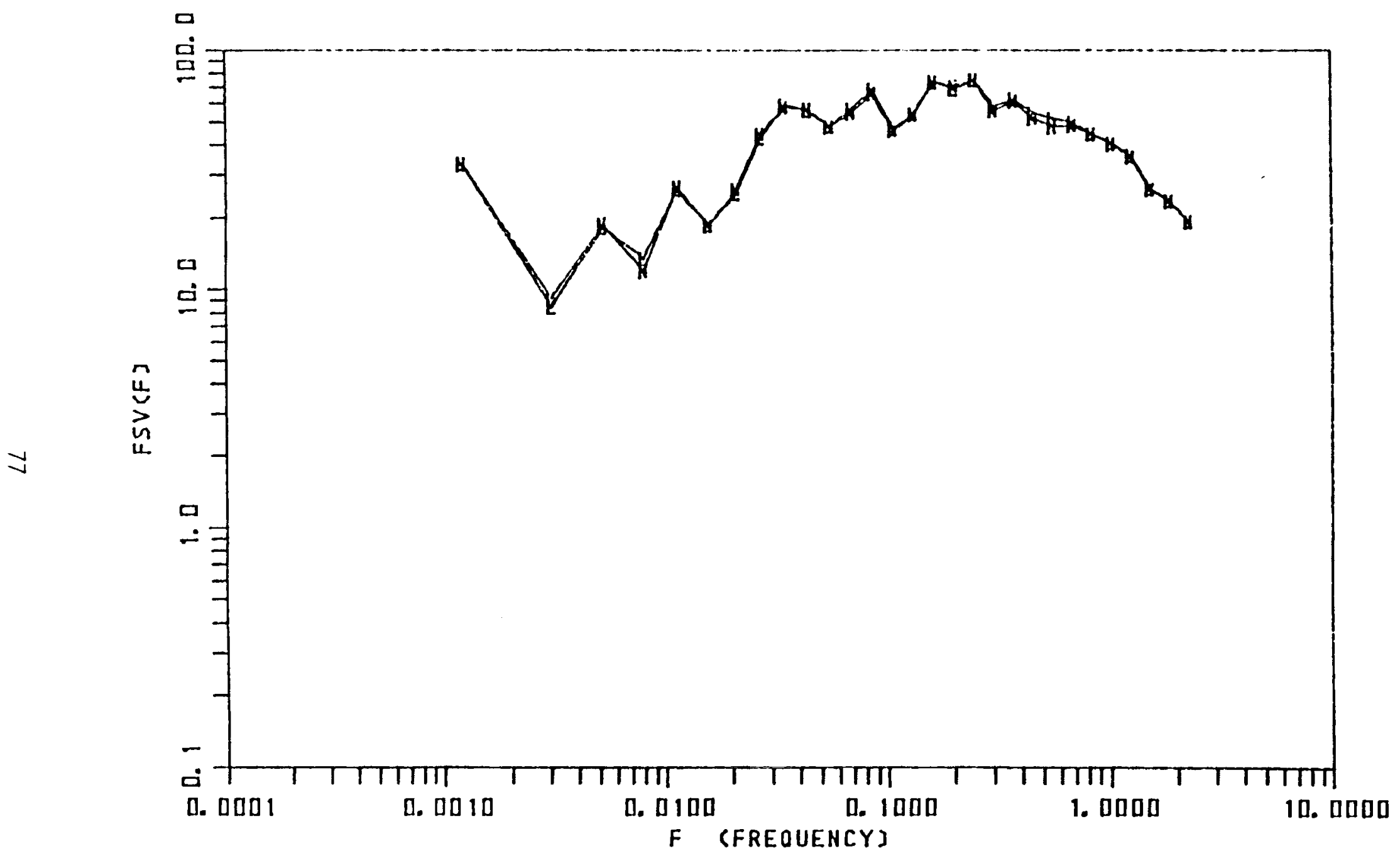

FIGURE 8.2. Spectral Density Functions for the Longitudinal Component of the Ris $\varnothing$ Data 

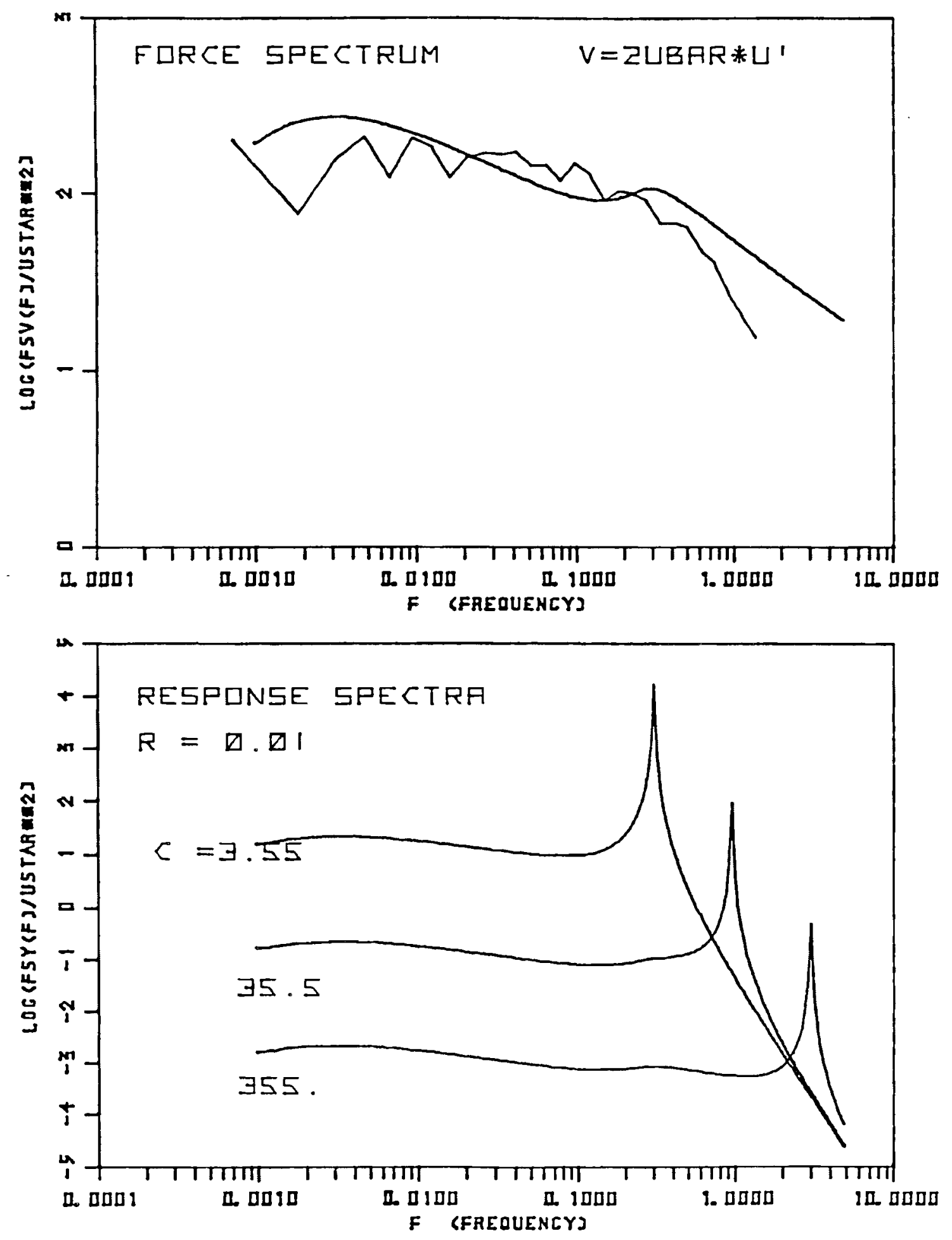

FIGURE 8.3. Spectra of the Linearized Aerodynamic Forcing and the Responses for Three Natural Frequencies for the Rock Springs Data 


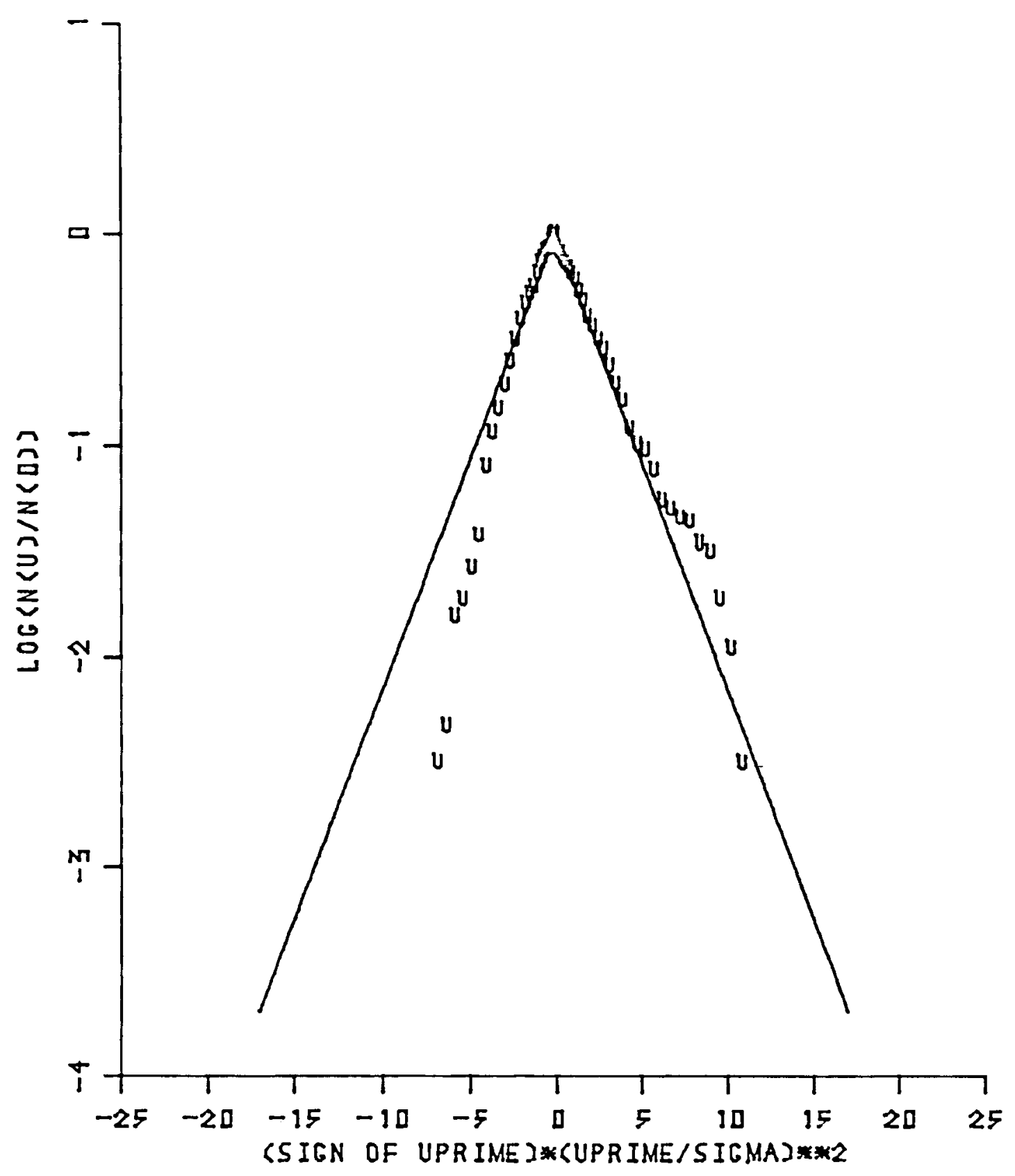

RUCK SPRINES - VELDCITY

FIGURE 8.4. Exceedance Statistics for the Longitudinal Compnnent $u^{\prime}$ of the Rock Springs Data 


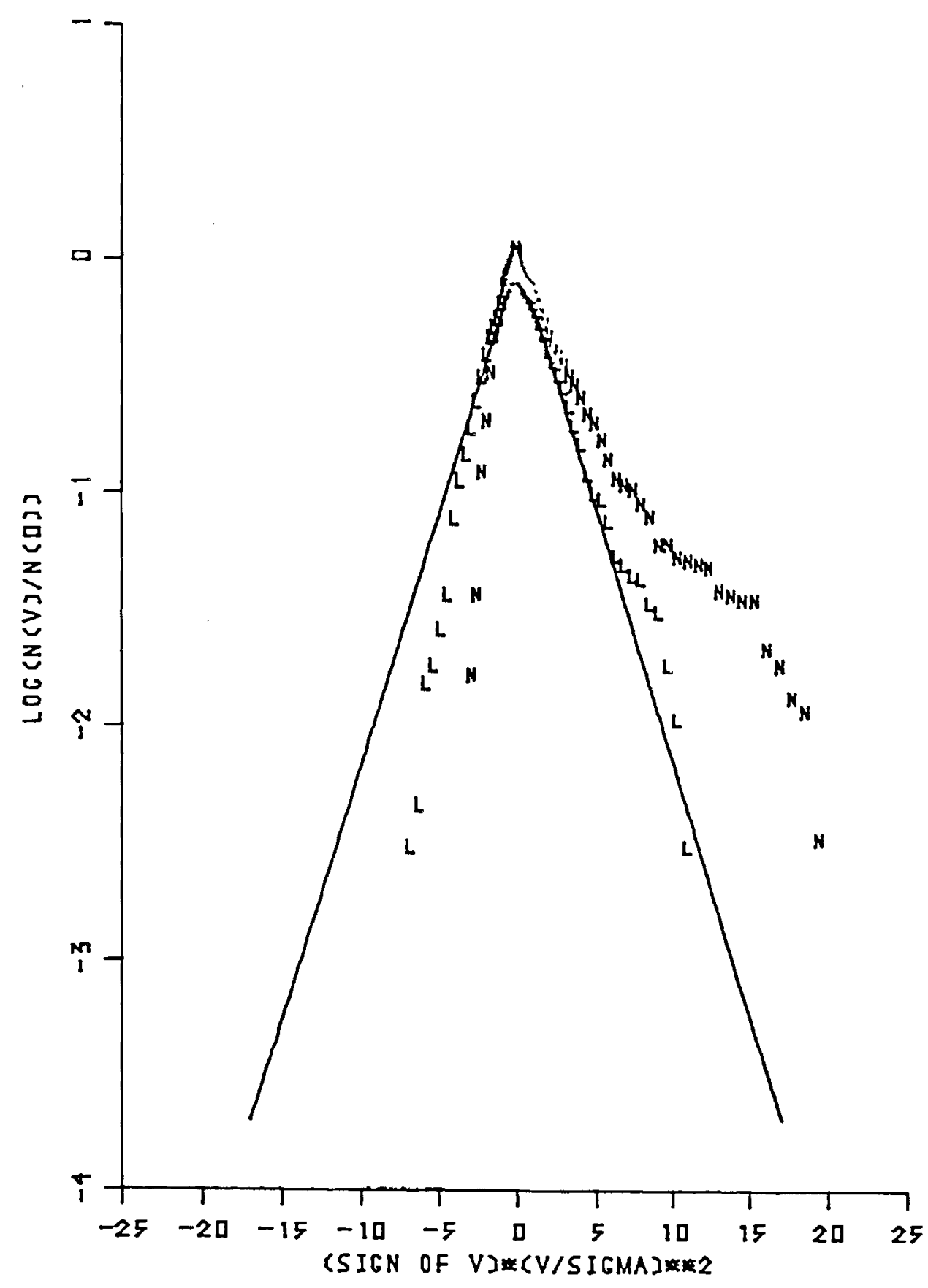

RDCK SPRINGS - FDRCING

FIGURE 8.5. Exceedance Statistics for the Linear (L) and Nonlinear (N) Forms of the Aerodynamic Forcing for the Rock Springs Data. Here $v(t)=u^{2}-u^{2}$ in the nonlinear case and $v(t)=2 U u^{\prime}$ in the linear case. 


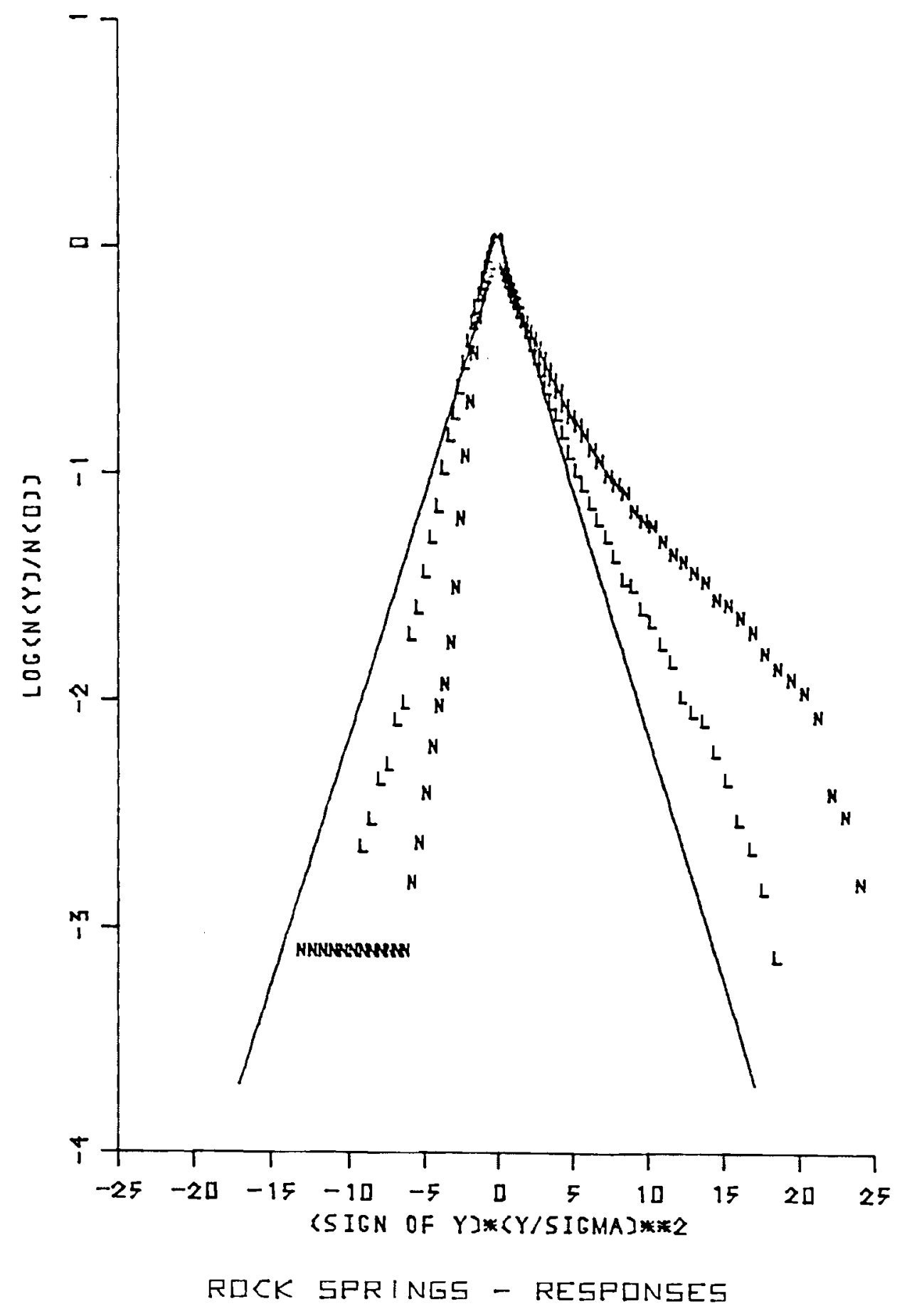

FIGURE 8.6. Responses to Linear (L) and Nonlinear (N) Aerodynamic Forcing for $R=0.1$ and $c=35.5$ 


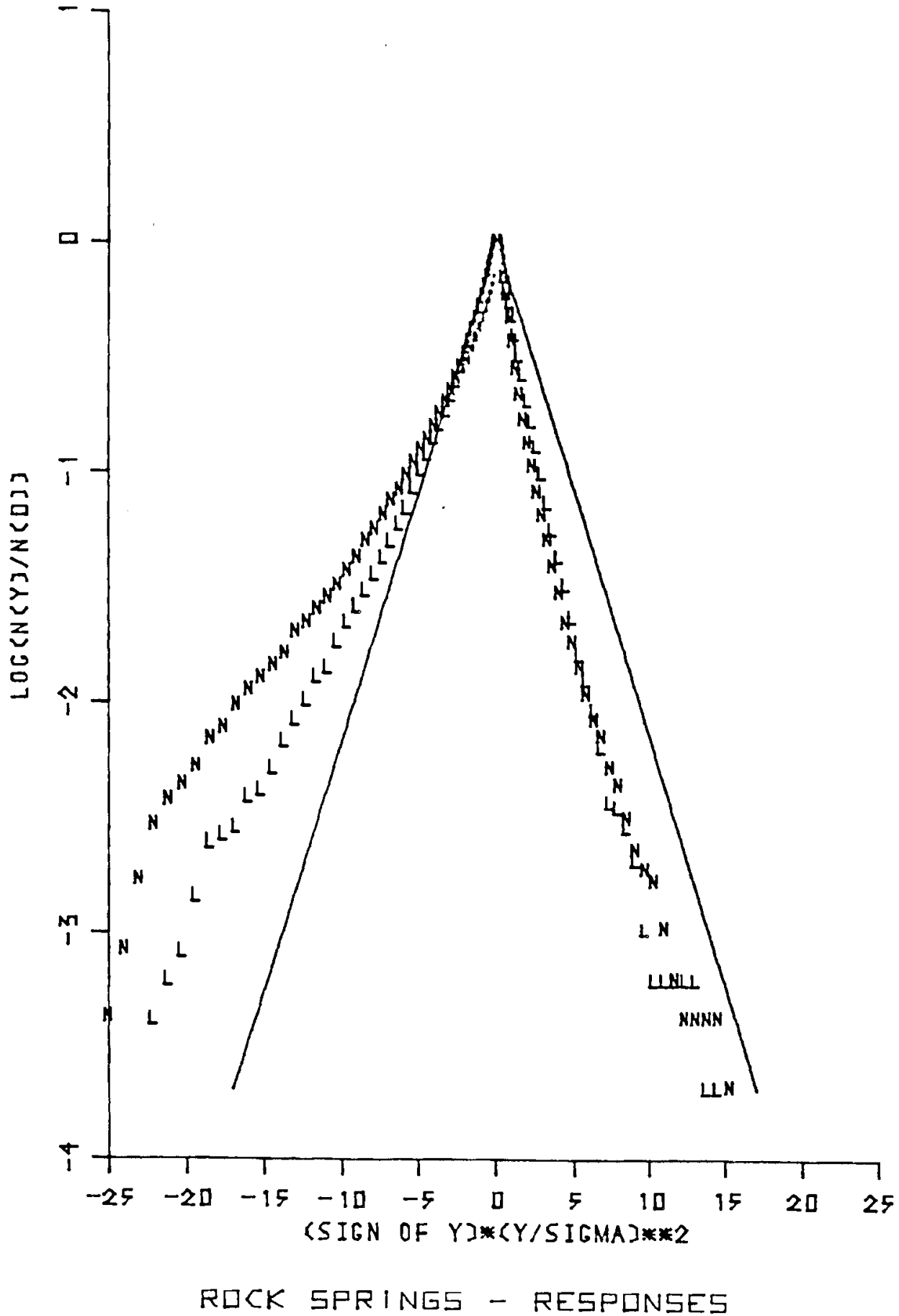

FIGURE 8.7. Responses to Linear $(L)$ and Nonlinear $(N)$

Aerodynamic Forcing for $R=0.01$ and $c=355$

82 


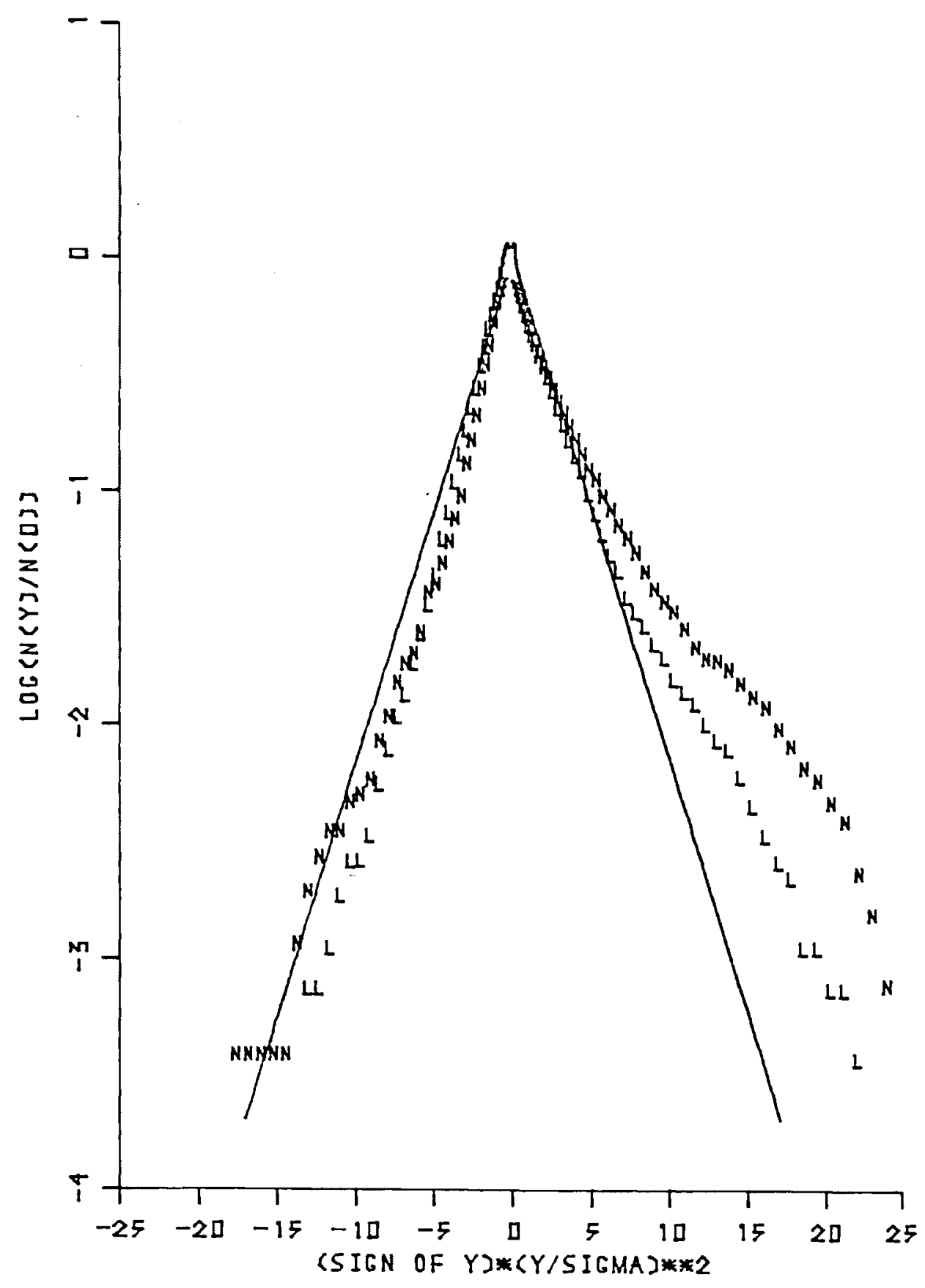

RDCK SPRINGS - RESPUNSES

FIGURE 8.8. Responses to Linear (L) and Nonlinear (N) Aerodynamic Forcing for $R=0.01$ and $c=35.5$ 


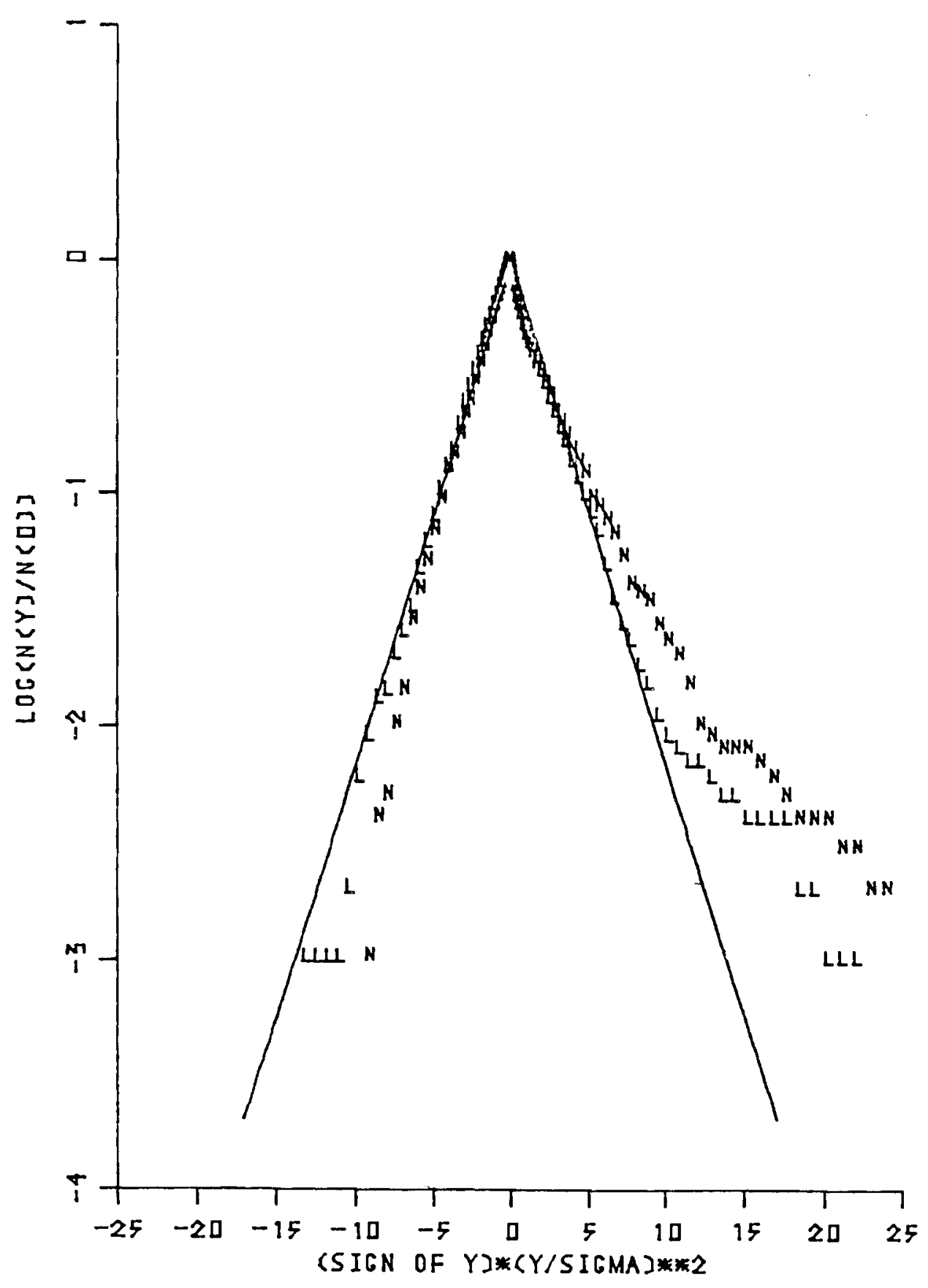

RUCK SPRINES - RESPINSES

FIGURE 8.9. Responses to Linear $(L)$ and Nonlinear (N)

Aerodynamic Forcing for $R=0.01$ and $c=3.55$ 


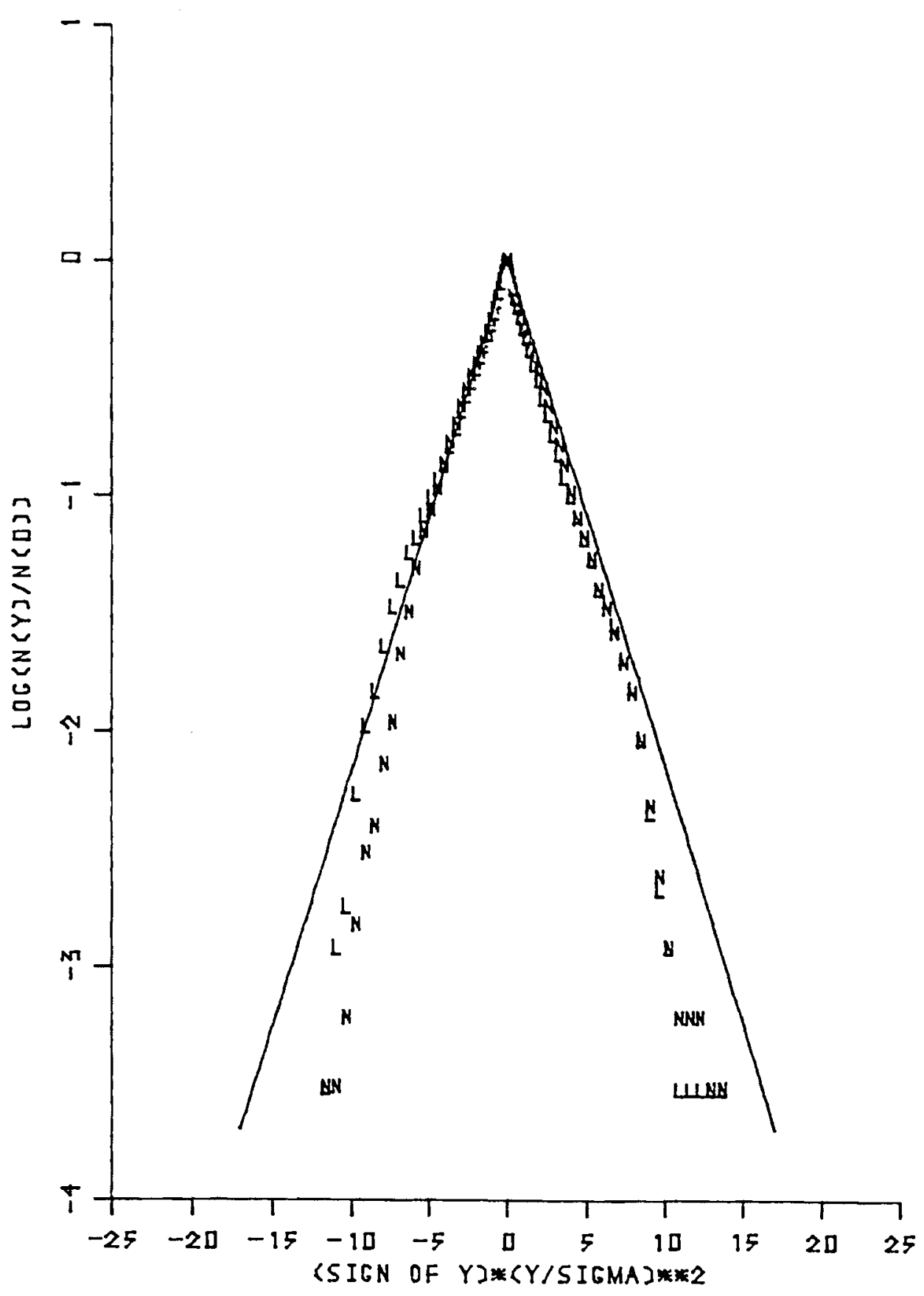

RUCK SPRINES - RESPUNSES

FIGURE 8.10. Responses to Linear $(L)$ and Nonlinear (N) Aerodynamic Forcing for $R=0.001$ and $c=35.5$ 

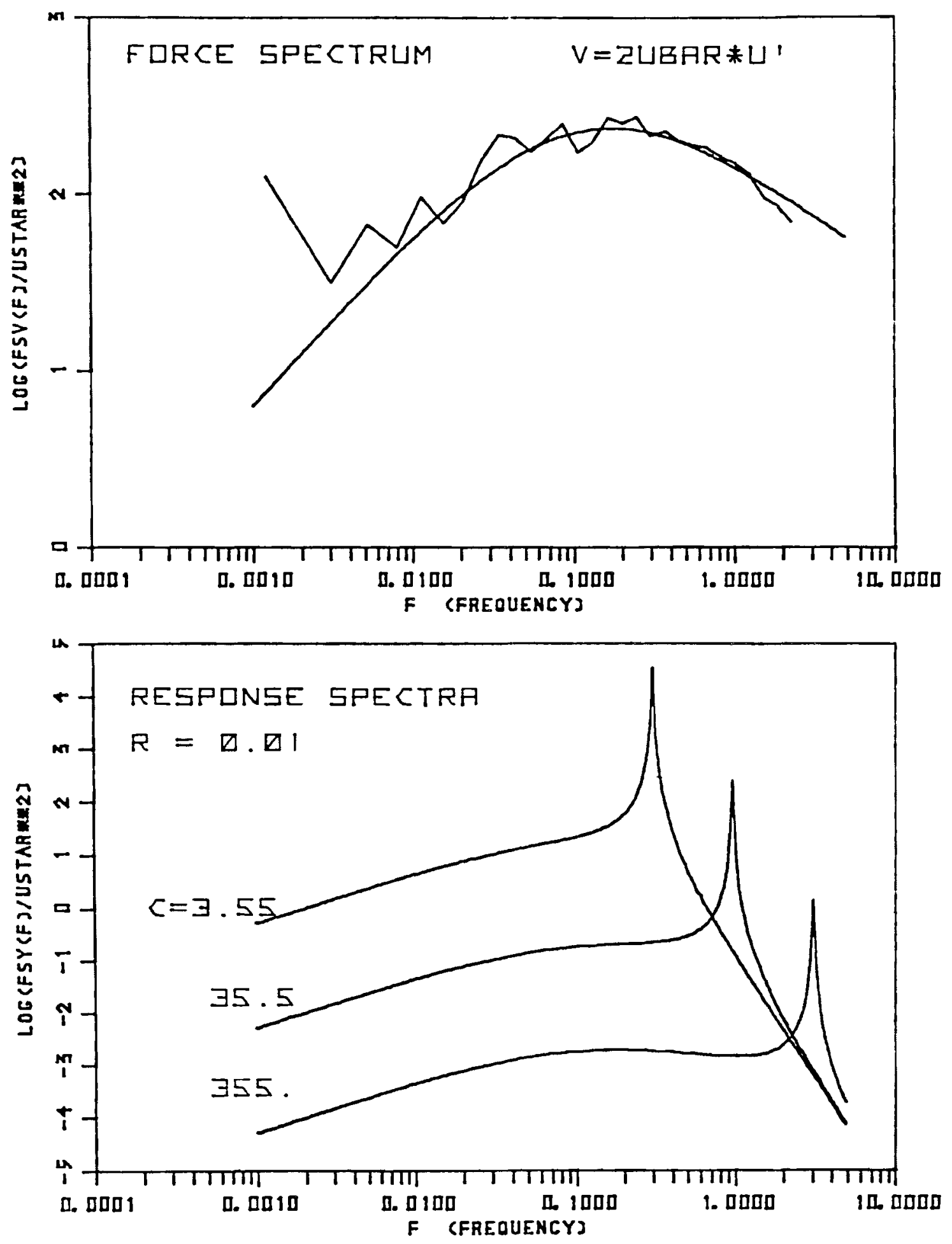

FIGURE 8.11. Spectra of the Linearized Aerodynamic Forcing and the Responses for Three Neutral Frequencies for the Ris $\varnothing$ Data 


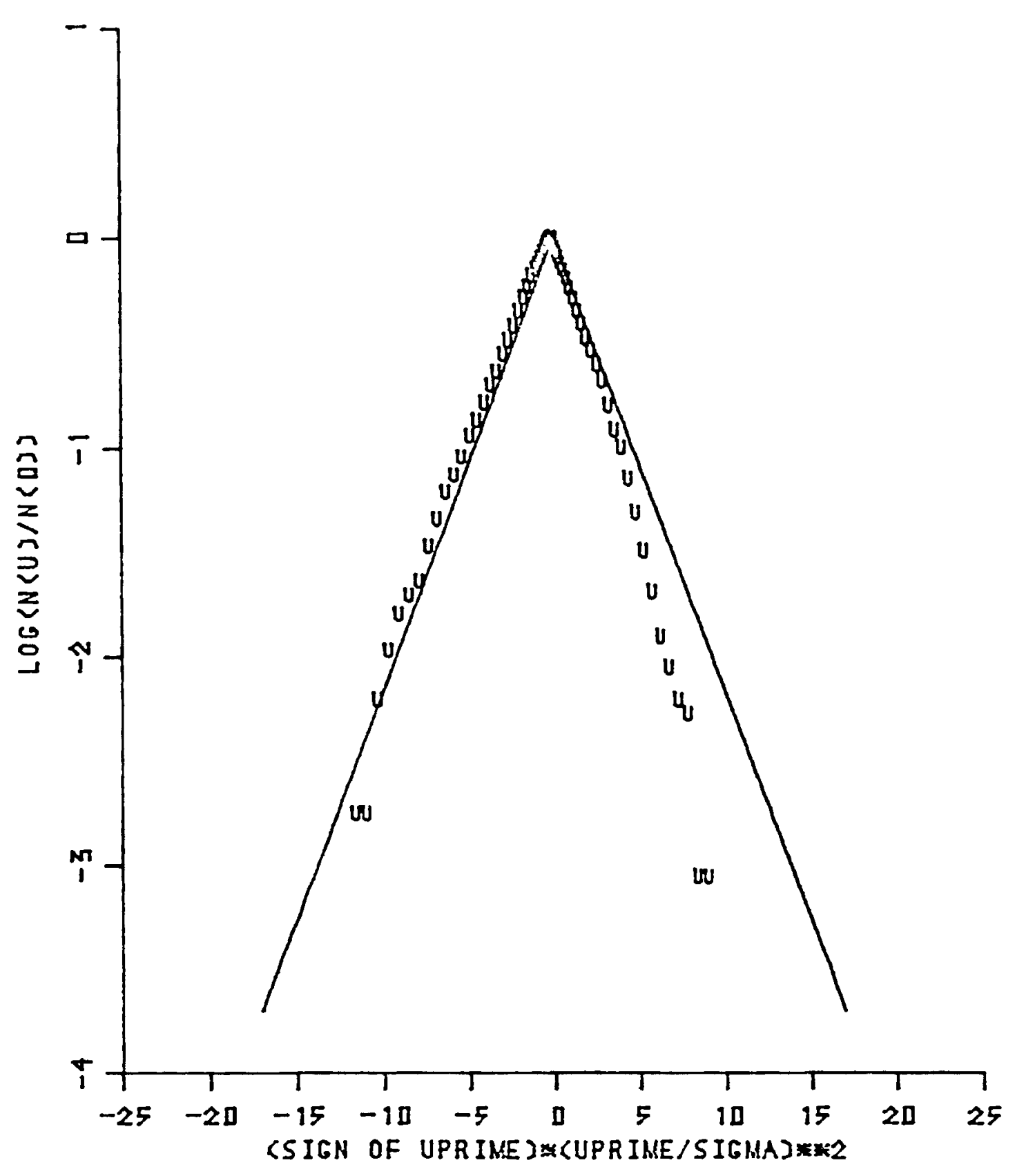

RISD - VELDCITY

FIGURE 8.12. Exceedance Statistics for the Longitudinal

Component $u^{\prime}$ of the Ris $\phi$ Data 


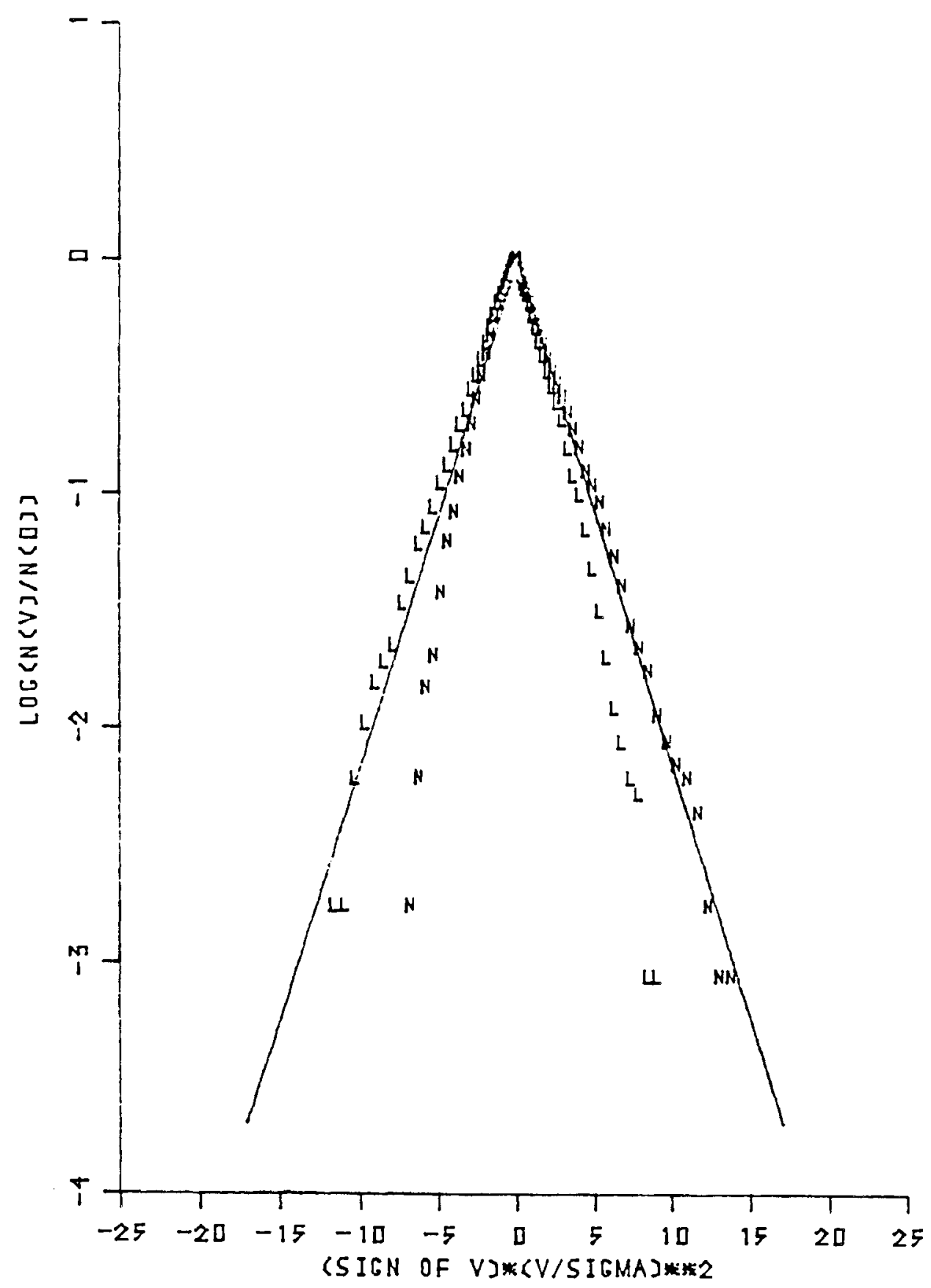

RISD - FDRCINE

FIGURE 8.13. Exceedance Statistics for the Linear (L) and Nonlinear (N) Forms of the Aerodynamic Forcing for the Ris $\varnothing$ Data. Here $v(t)=u^{2}-u^{2}$ in the nonlinear case and $v(t)=2 U u^{\prime}$ in the linear case. 


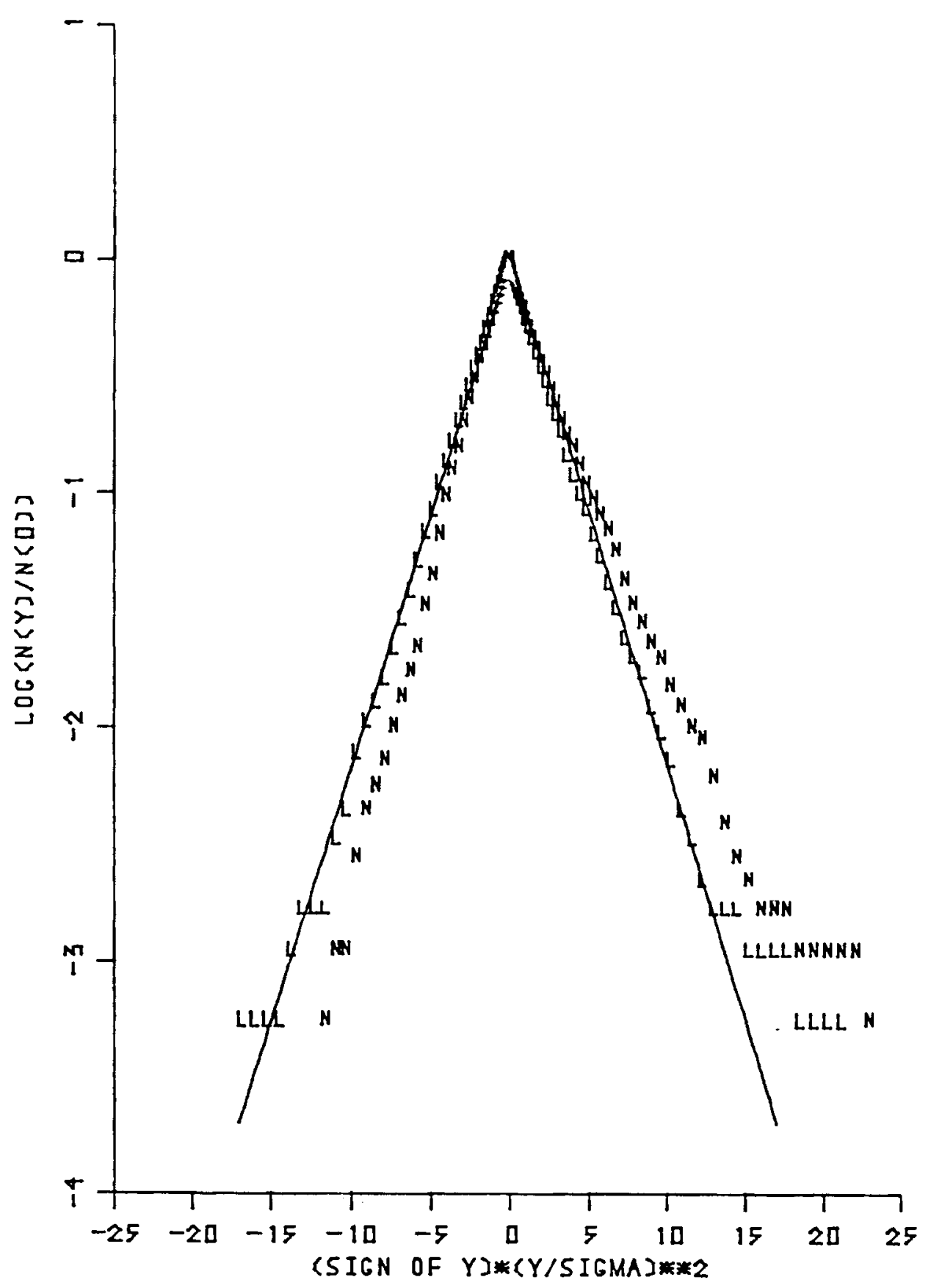

RI5V - RESPDNSES

FIGURE 8.14. Responses to Linear ( $L$ ) and Noniinear (N) Aerodynamic Forcing for $R=0.1$ and $c=35.5$ 


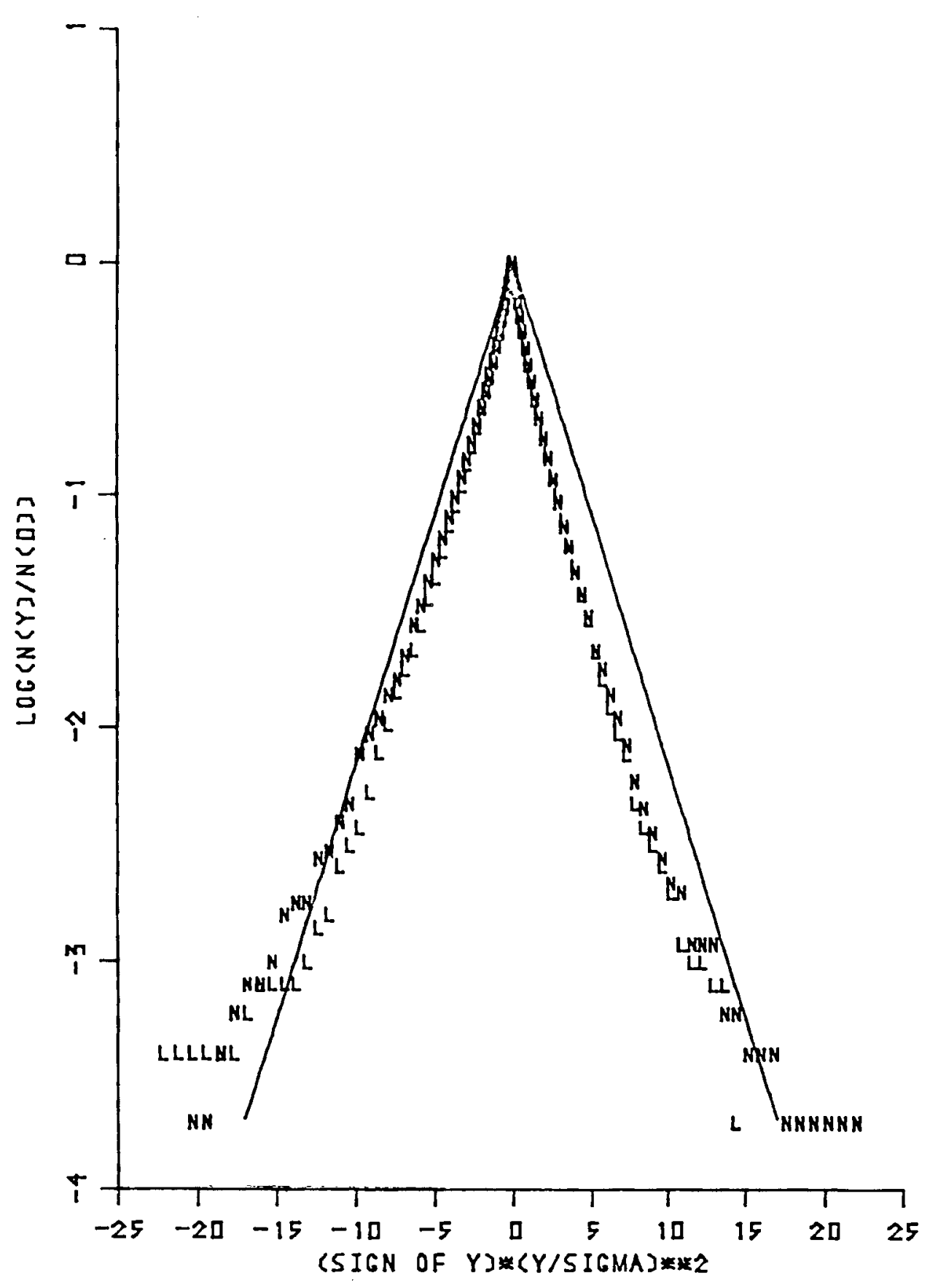

\section{RISU - RESPRNSES}

FIGURE 8.15. Responses to Linear (L) and Nonlinear (N) Aerodynamic Forcing for $R=0.01$ and $c=355$ 


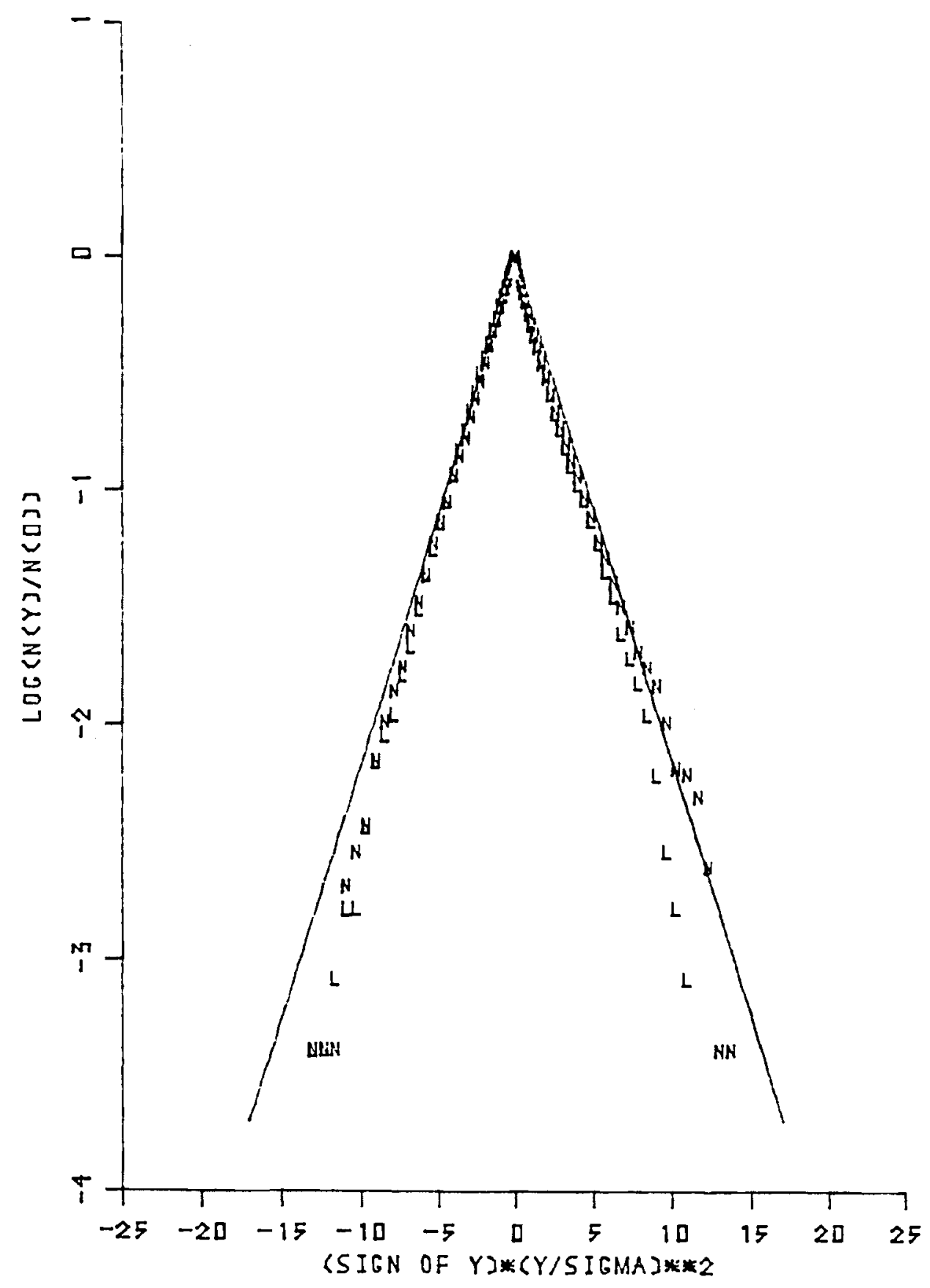

RISD - RESPLNSES

FIGURE 8.16. Responses to Linear ( $L$ ) and Nonlinear (N) Aerodynamic Forcing for $R=0.01$ and $c=35.5$ 


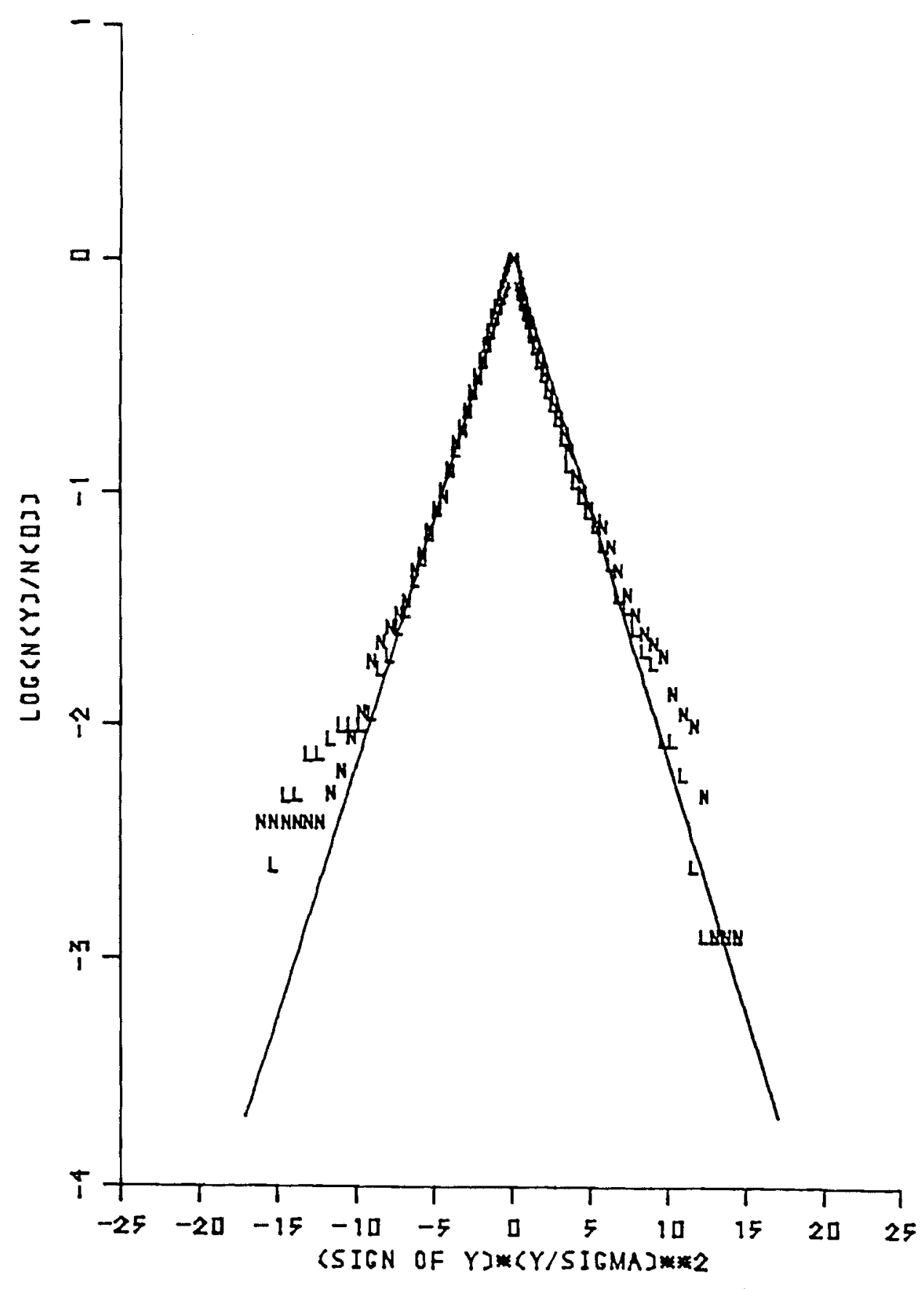

RISR - RESPRNSES

FIGURE 8.17. Responses to Linear (L) and Nonlinear (N) Aerodynamic Forcing for $R=0.01$ and $c=3.55$ 


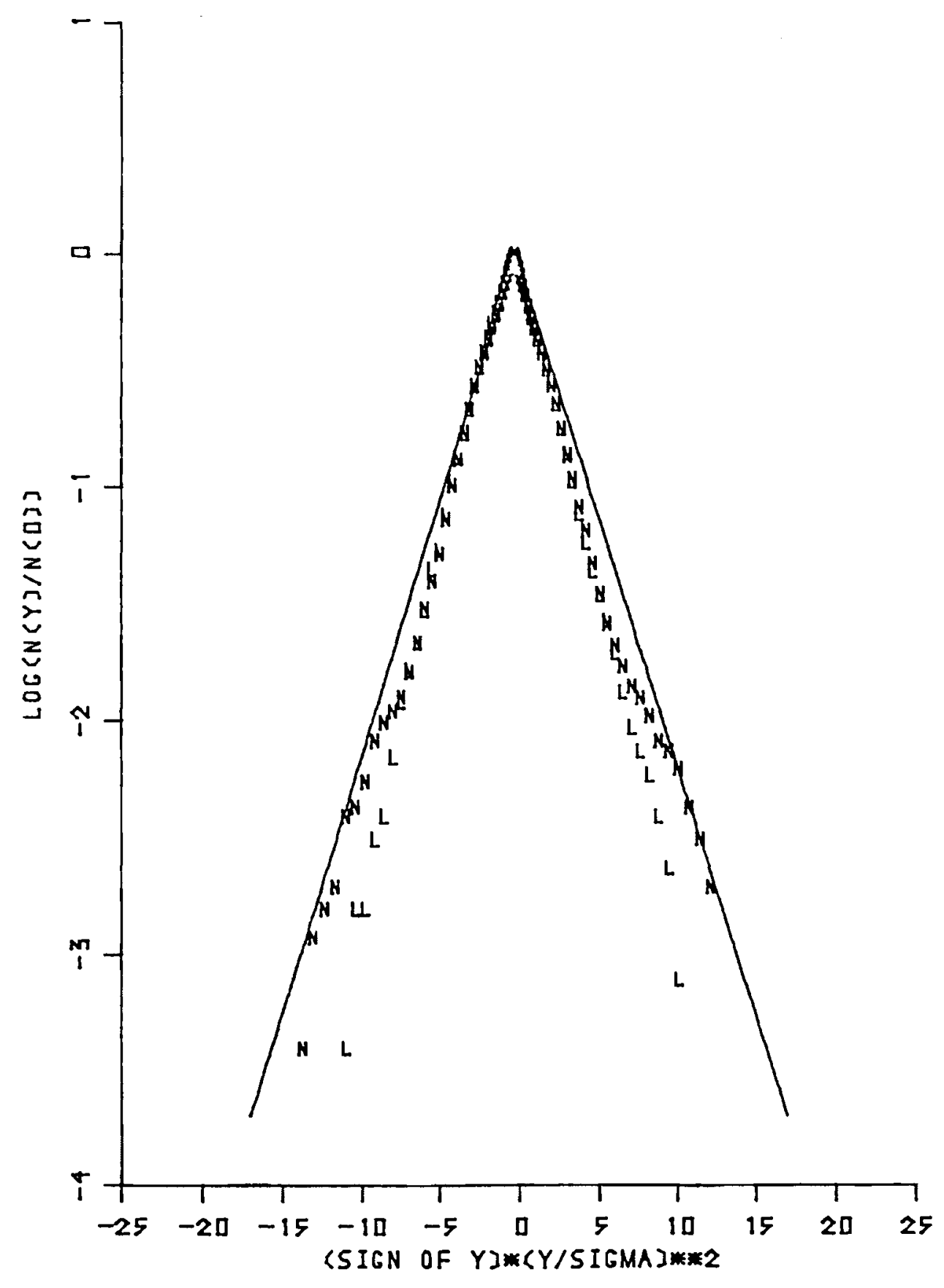

R15日 - RESPDNSES

FIGURE 8.18. Responses to Linear (L) and Nonlinear (N)

Aerodynamic Forcing for $R=0.001$ and $c=35.5$ 
TABLE 8.1. Characteristics of the Turbulence Data Records

Ris $\emptyset$ Data (PSU Tape RIS01, File 1)

Sample Period

Number of Points

Frequency

Wind Direction

Height, $z$

Wind Speed, $\bar{u}$

Standard Deviation

After Linear Trend

Removal

Friction Velocity

$z_{i} / L$

$\mathrm{z} / \mathrm{L}$
44.9 minutes

13472

$5 \mathrm{~Hz}$

obtained from $30 \mathrm{~Hz}$ raw data by 2-pt. block averaging

$344^{\circ}$

2 meters

$7.57 \mathrm{~m} / \mathrm{s}$

$1.21 \mathrm{~m} / \mathrm{s}$

$0.46 \mathrm{~m} / \mathrm{s}$
Rock Springs Data (PSU Tape VMIXI2, File MDIOR1)

60 minutes

18000

$5 \mathrm{~Hz}$ obtained from $30 \mathrm{~Hz}$ raw data by 6-pt. block averaging

$277^{\circ}$

(non-mountain trajectory)

2 meters

$4.76 \mathrm{~m} / \mathrm{s}$

$1.25 \mathrm{~m} / \mathrm{s}$

$0.36 \mathrm{~m} / \mathrm{s}$

$-27.65$

$-0.042$

Note: Instrumental filtering resulted in a half-power cut-off frequency at about $3 \mathrm{~Hz}$, explaining the rapid drop-off of the velocity and forcing spectra. 
TABLE 8.2. Responses Calculated for the Rock Springs Data Squared Natural Frequency $c\left(\operatorname{rad}^{2} / \mathrm{s}^{2}\right)$

\begin{tabular}{|c|c|c|c|c|}
\hline & & 3.55 & 35.5 & 355.0 \\
\hline $\begin{array}{c}\text { Damping } \\
\text { Ratio }\end{array}$ & 0.001 & & $\begin{array}{c}\star \theta \\
\varepsilon=0.01\end{array}$ & * \\
\hline $\mathrm{R}$ & 0.01 & $\star 0$ & $\star 0$ & * 0 \\
\hline & 0.1 & * & $\star 0$ & * \\
\hline
\end{tabular}

ऋ Responses and exceedance statistics computed for nonlinear forcing

o Responses and exceedance statistics computed for linear forcing 
TABLE 8.3. Responses Calculated for the Risø Data

Squared Natural Frequency $c\left(\operatorname{rad}^{2} / \mathrm{s}^{2}\right)$

\begin{tabular}{|c|c|c|c|c|}
\hline & & 3.55 & 35.5 & 355.0 \\
\hline $\begin{array}{c}\text { Damping } \\
\text { Ratio }\end{array}$ & 0.001 & $\begin{array}{c}\star \\
\varepsilon=0.005\end{array}$ & * 0 & * \\
\hline$R$ & 0.01 & $* 0$ & * 0 & $* 0$ \\
\hline & 0.1 & * & $\star 0$ & * \\
\hline
\end{tabular}

ऋ Responses and exceedance statistics computed for nonlinear forcing

a Responses and exceedance statistics computed for linear forcing 


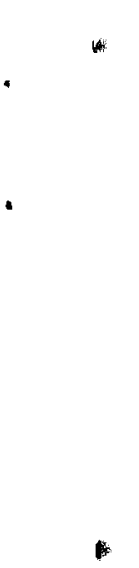

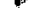




\section{DISTRIBUTION}

No. of

Copies

OFFSITE

S. D. Berwager

Department of Energy

Wind Energy Technology Division

1000 Independence Avenue

Forrestal Building, Room 5F059

Washington, DC 20585

C. I. Aspliden

Battelle Memorial Institute

Washington Operations Office

2030 M Street, N.W.

Washington, DC 20036

L. V. Divone

Department of Energy

Wind Energy Technology Division

1000 Independence Avenue

Forrestal Building, Room 5F059

Washington, DC 20585

W. C. Reddick

Department of Energy

Wind Energy Technology Division

1000 Independence Avenue

Forrestal Building

Washington, DC 20585

G. P. Tennyson

Department of Energy

Albuquerque Operations office

P.0. Box 5400

A1buquerque, NM 87115

27 DOE Technical Information Center

D. K. Ai

Alcoa Laboratories

Alcoa Technical Center

Alcoa Center, PA 15069
No. of

Copies
Don Nielson

Boeing Engineering and Construction Co.

P.0. Box 3707, MS-9A-65

Seattle, WA 98124

Nick Butler

Bonneville Power Administration

P.0. Box 3621

Portland, OR 97208

Tom Hoffer

Desert Research Institute

Atmospheric Sciences Center

University of Nevada System

P.0. Box 60220

Reno, NV 89506

Walter Frost

FWG Associates, Inc.

271A Lakewood Drive

Tullahoma, TN 37388

George Ficht1

7703 Oakridge Drive

Huntsville, AL 35802

Stanley Macklis

General Electric Company

Advanced Energy Systems

P.0. Box 8661

Philadelphia, PA 19101

J. M. Kos

Hamilton Standard

Bradley Field Road

Windsor Locks, CT 06096

Jean Mayhew

Hami 1 ton Standard, MS-IM3

Bradley Field Road

Windsor Locks, CT 06095 
M. A. Bowes

Kaman Aerospace Corporation

01d Windsor Road

Bloomfield, CT 06095

Tim R. Richards

NASA/Lewis Research Center

21000 Brookpark Road

Cleveland, OH 44135

Dave Spera

NASA/Lewis Research Center

21000 Brookpark Road

Cleveland, $\mathrm{OH} \quad 44135$

J. C. Kaimal

National Oceanic \& Atmospheric Administration/Wave Propagation Laboratory

3000 Marine Street

Boulder, CO 80302

W. Holley

Department of Mechanical Engineering Oregon State University

Corvallis, OR 97331

R. Thresher

Department of Mechanical Engr.

Oregon State University

Corvallis, OR 97331

J. Dutton

Department of Meteorology

Pennsylvania State University

University Park, PA 16902

H. A. Panofsky

Department of Meteorology

Pennsylvania State University

University Park, PA 16902

A. C. Hansen

Rockwel1 International

P.0. Box 464

Golden, CO 80401
E. G. Kadlec

Sandia Labs 4715

Box 5800

A1buquerque, NM 87165

Rick Mitche11

Solar Energy Research Institute

1617 Cole Boulevard

Golden, CO 80401

T. Anderson Westinghouse Electric Co.

P. 0. Box 10824

Pittsburgh, PA 15236

R. H. Kirchhoff

Department of Mechanical Engineering University of Massachusetts

Amherst, MA 01003

A. B. Van Rennes

The Bendix Corporation

Bendix Center

Southfield, MI 48037

F. S. Stoddard

U.S. Windpower Association

25 Adams Street

Burlington, MA 01803

R. Akins

Department of Engineering Sciences \& Mechanics

Virginia Polytechnic and State University

B1acksburg, VA 24061

H. Tielman

Department of Engineering Sciences \& Mechanics

Virginia Polytechnic and State University

Blacksburg, VA 24061 
No. of

Copies

ONSITE

1 DOE Richland Operations Office

H. E. Ransom

35 Pacific Northwest Laboratory

W. C. Cliff

J. R. Connel1

J. C. Doran

C. E. Elderkin

R. L. George

A. H. Miller

E. L. Owczarski

D. C. Powe11

J. V. Ramsde11

D. S. Renné

H. L. Wegley

L. L. Wende 11

R. K. Woodruff

Technical Information Files (5)

Publishing Coordination (2)

WCPE Program Office (15)

Distr-3 


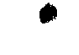

